\title{
The Role of Friction
}

in Tow Mechanics

Bo Cornelissen 


\section{THE ROLE OF FRICTION IN TOW MECHANICS}

Bo Cornelissen 
De promotiecommissie is als volgt samengesteld:

Voorzitter en secretaris:

prof.dr. F. Eising

Universiteit Twente

Promotor:

prof.dr.ir. R. Akkerman

Universiteit Twente

Leden (in alfabetische volgorde):

prof.dr.ir. R. Benedictus

Technische Universiteit Delft

prof.dr.ir. H.J.M. ter Brake

Universiteit Twente

dr. P. Potluri

prof.dr.ir. D.J. Schipper

The University of Manchester

Universiteit Twente

prof.dr.ir. M.M.C.G. Warmoeskerken

Universiteit Twente

This research project was financially supported by Stichting Technologie en Wetenschap (STW), Van der Leeuw grant STW-06182.

The role of friction in tow mechanics

Cornelissen, Bo

PhD Thesis, University of Twente, Enschede, The Netherlands

December 2012

ISBN 978-90-365-3472-7

DOI $10.3990 / 1.9789036534727$

(C) 2012 by B. Cornelissen, Enschede, The Netherlands

Printed by Ipskamp Drukkers B.V., Enschede, The Netherlands

Cover: close-up photograph of a spool with aramid tow material. The tow consists of 2000 filaments with a typical diameter about five times smaller than a human hair. Photo by Gijs van Ouwerkerk, used with permission. 


\title{
THE ROLE OF FRICTION IN TOW MECHANICS
}

\section{PROEFSCHRIFT}

\author{
ter verkrijging van \\ de graad van doctor aan de Universiteit Twente, \\ op gezag van de rector magnificus, \\ prof.dr. H. Brinksma, \\ volgens besluit van het College voor Promoties \\ in het openbaar te verdedigen \\ op vrijdag 25 januari 2013 om 14.45 uur
}

door

Bo Cornelissen

geboren op 1 maart 1983

te Eindhoven 
Dit proefschrift is goedgekeurd door de promotor: prof.dr.ir. R. Akkerman 


\section{Summary}

Friction plays an important role in the processing of fibrous materials: during production of tow materials, during textile manufacturing and during preforming operations for composite moulding processes. One of the poorly understood phenomena in these processes is the frictional behaviour of the fibrous tows. This thesis addresses the characterisation of this behaviour during the production of Continuous Fibre Reinforced Polymers (CFRPs). The aim is to provide a physically based understanding of the dynamic friction of dry tow arrangements during processing by means of experimental and predictive modelling work.

The multi-scale nature of textile reinforcements is represented using a hierarchical approach. Macroscopic deformations of, for example, a fabric can be translated to deformation mechanisms on the mesoscopic tow scale and finally to the microscopic filament scale. The frictional behaviour of filaments sliding with respect to each other in a longitudinal and transverse direction determines the macroscopic behaviour to a large extent. The friction of fibrous tows is investigated with a capstan type friction experiment, involving mainly longitudinal sliding friction of filaments. The sliding friction of tows in contact with different metal counterfaces and in contact with each other is addressed. Additional experimental work on other setups provides a validation of the capstan experiment.

A contact mechanics modelling approach is developed to provide a means to understand and predict the observed frictional behaviour of fibrous tows. The model is based on the assumption that frictional forces are determined by the product of the real contact area between the contacting bodies and an interfacial shear strength. The friction of individual filaments is modelled for filamentmetal and filament-filament contact. The surface topography of the metal counterface, which is investigated on the sub-microscopic level, has a significant influence on the developed friction. For filament-filament contact friction the relative orientation of filaments is an important parameter, as well as the surface topography of the filaments. The contribution of adhesion to the real contact area is assessed by means of a Maugis-Dugdale contact analysis. The model predictions for the frictional behaviour of individual filaments are translated to 
the mesoscopic scale of fibrous tows by estimating the amount of filaments in the contact interface. A qualitative and quantitative agreement is obtained between the friction model and the capstan tow friction measurements.

Furthermore, the frictional behaviour of carbon fabric is investigated experimentally to link the mesoscopic frictional behaviour of tows to the macroscopic behaviour of a fabric. Based on the physical background of the contact model, the frictional behaviour of tows and fabric should be comparable for equal mesoscopic contact pressures. This hypothesis is confirmed by the capstan experiment on carbon tow and fabric specimens.

In short, the sub-microscopic friction at the level of contacting asperities and filament ridges has a significant influence on the final macroscopic behaviour of dry arrangements of fibrous tows, thereby providing a coupling between the multiple length scales. The developed friction model gives a clear indication which parameters should be addressed to improve industrial processing of fibrous materials. 


\section{Samenvatting}

Wrijving speelt een belangrijke rol bij het verwerken van vezelbundels tijdens het vervaardigen, het maken van textiel en het draperen van textiel bij de productie van composieten. Eén van de minder goed begrepen aspecten van deze processen is het wrijvingsgedrag van de vezelbundels. Dit proefschrift behandelt het wrijvingsgedrag van vezelbundels in de context van de productie van vezelversterkte kunststoffen. Deze studie heeft tot doel een fysisch onderbouwd begrip te verkrijgen van het dynamische wrijvingsgedrag van droge bundels tijdens de verwerking. Dit gebeurt door middel van experimenten en voorspellende modellen.

De geometrische structuur van textiel versterkingsmateriaal wordt op meerdere lengteschalen gekarakteriseerd volgens een hiërarchische benadering. Deformaties op macroscopisch niveau, bijvoorbeeld van een weefsel, kunnen worden vertaald naar mechanismen op de mesoscopische bundelschaal en uiteindelijk naar de microscopische filamentschaal. Het wrijvingsgedrag van onderlinge filamenten in langs- en dwarsrichting bepaalt voor een groot deel het macroscopisch gedrag van het weefsel. In dit onderzoek wordt het wrijvingsgedrag van bundels onderzocht met behulp van een op het kaapstaanderprincipe gebaseerde opstelling. Hierin vindt voornamelijk wrijving tussen filamenten in de langsrichting plaats. Het kaapstaanderexperiment is gevalideerd met aanvullende experimenten op andere opstellingen.

Een op contactmechanica gebaseerd model is ontwikkeld om het geobserveerde wrijvingsgedrag van vezelbundels te begrijpen en te voorspellen. Het model heeft als uitgangspunt dat wrijvingskrachten op sub-microscopisch niveau bestaan uit het product van het werkelijke contactoppervlak en een afschuifsterkte op het raakvlak. Het wrijvingsgedrag van individuele filamenten is gemodelleerd voor filament-metaal en filament-filament contact. De textuur van het metaaloppervlak, dat tot op sub-microscopische schaal is bestudeerd, heeft een significante invloed op de ontstane wrijving. De onderlinge oriëntatie van de filamenten speelt een belangrijke rol in de wrijvingsopbouw bij filament-filament contact. Het ontwikkelde model houdt door middel van een Maugis-Dugdale benadering rekening met de bijdrage van adhesie-effecten aan het werkelijke contactoppervlak. Een vertaling van de miscroscopische 
filamentschaal naar de mesoscopische bundelschaal wordt gemaakt op basis van een schatting van het aantal filamenten van een bundel in het contactgebied. De modelvoorspellingen komen zowel in kwalitatief als kwantitatief opzicht overeen met de mesoscopische metingen uit het kaapstaanderexperiment.

Bovendien is het wrijvingsgedrag van een koolstofvezelweefsel experimenteel onderzocht om het mesoscopische bundelgedrag te koppelen aan de macroscopische weefselschaal. Uitgaande van de fysische achtergrond van het contactmodel zou het wrijvingsgedrag van bundels en weefsels vergelijkbaar moeten zijn voor gelijke mesoscopische contactdrukken. Deze hypothese wordt bevestigd door de metingen aan koolstofvezelbundels en -weefsels.

De sub-microscopische wrijving op het niveau van ruwheidstoppen van een metalen oppervlak en rillen op koolstof filamenten heeft een significante invloed op het uiteindelijke macroscopische vervormingsgedrag van droge structuren zoals weefsels. Hiermee is een koppeling gelegd tussen de verschillende lengteschalen, vanaf het niveau van ruwheidstoppen via filamenten en vervolgens vezelbundels tot de weefselschaal. Het ontwikkelde wrijvingsmodel geeft de richting aan waarin men de industriële productie en verwerking van vezelbundels kan verbeteren. 


\section{Nomenclature}

The symbols used in this thesis are classified in a Greek and Roman category. Some symbols appear more than once, their specific meaning follows from their context or from subscripts.

\section{Greek symbols}

\begin{tabular}{|c|c|}
\hline$\alpha$ & twisted strand apex angle \\
\hline$\alpha$ & scaling parameter for the ellipse minor axis $a_{\mathrm{ell}}$ \\
\hline$\beta$ & wedging angle during digging in of filaments \\
\hline$\beta_{\text {small }}, \beta_{\text {large }}$ & radius of curvature of small and large asperities \\
\hline$\beta_{X}, \beta_{Y}$ & $\begin{array}{l}\text { radii of curvature of fitted surface asperities } \\
\text { in } X \text { - and } Y \text {-direction }\end{array}$ \\
\hline$\beta$ & scaling parameter for the ellipse major axis $b_{\mathrm{ell}}$ \\
\hline$\gamma$ & scaling parameter for the indentation depth $\delta$ \\
\hline$\Delta \theta$ & arc segment \\
\hline$\Delta A_{\mathrm{r}}$ & real contact area of a filament segment \\
\hline$\Delta F_{\mathrm{f}}$ & frictional force in an arc length segment \\
\hline$\Delta s$ & $\begin{array}{l}\text { arc length segment of a tow on the capstan } \\
\text { friction drum }\end{array}$ \\
\hline$\Delta t$ & misalignment distance between pressure plates \\
\hline $\bar{\delta}$ & dimensionless compression (Maugis-Dugdale) \\
\hline$\delta, \delta_{i}$ & compression or indentation depth \\
\hline$\delta_{\mathrm{MD}}$ & compression or indentation depth (Maugis-Dugdale) \\
\hline$\zeta$ & ratio of principal radii of curvature $R_{Y}$ and $R_{X}$ \\
\hline$\eta_{\text {small }}, \eta_{\text {large }}$ & $\begin{array}{l}\text { small and large asperity density of friction drum } \\
\text { drum topographies }\end{array}$ \\
\hline$\theta$ & capstan angular coordinate \\
\hline$\theta_{\text {wrap }}$ & capstan tow or filament wrapping angle \\
\hline$\lambda$ & contact mechanics elasticity parameter \\
\hline$\lambda$ & $\begin{array}{l}\text { contact regime transition parameter: ratio of elastic } \\
\text { deformation to the range of surface forces }\end{array}$ \\
\hline$\mu, \mu_{\mathrm{app}}$ & coefficient of friction, apparent coefficient of friction \\
\hline
\end{tabular}




$\mu_{\text {fil-fil,app }}$
$\mu_{\text {tow-tow,app }}$
$\mu_{\text {equ }}$
$\nu$
$\rho$
$\sigma$
$\sigma_{\text {small }}$
$\tau$
$\Phi$
$\phi(z)$
$\omega$

\section{Roman symbols}

$A_{\text {asp }}$
$A_{i}$
$A_{\text {micro }}$
$A_{\text {meso }}$
$A_{\text {macro }}$
$A_{\mathrm{n}}$
$A_{\mathrm{p}}$
$A_{\mathrm{r}}$
$\bar{a}$
$a_{\mathrm{ell}}$
$a_{\text {line }}$
$a_{\mathrm{MD}}$
$a_{\mathrm{p}}$
$b_{\text {ell }}$
$\bar{c}$
$C_{\mathrm{b}}$
$C_{\text {warp }}, C_{\text {weft }}$
$c_{\mathrm{MD}}$
$D$
$D$
$d$
$d$

apparent coefficient of friction between filaments

$[\mathrm{N} / \mathrm{N}]$ apparent coefficient of friction between tows

$[\mathrm{N} / \mathrm{N}]$

Howell fit equivalent coefficient of friction

(transverse) Poisson coefficient

$[\mathrm{N} / \mathrm{N}]$

$[-]$

density

normal stress component of a loaded tow on

$\left[\mathrm{kg} / \mathrm{m}^{3}\right]$

$[\mathrm{Pa}]$

the friction drum

standard deviation of small asperity height

distribution

interfacial shear strength

relative orientation of filaments in oblique contact

normal probability density function of the asperity

height distribution

rotational frequency of the capstan friction drum [m]

[Pa]

$\left[{ }^{\circ}\right]$

$\left[\mathrm{m}^{-1}\right]$

$\left[\mathrm{s}^{-1}\right]$

nominal or real contact area per asperity

$\left[\mathrm{m}^{2}\right]$

area of a single microcontact

contact area at the filament level

$\left[\mathrm{m}^{2}\right]$

contact area at the tow level

$\left[\mathrm{m}^{2}\right]$

$\left[\mathrm{m}^{2}\right]$

projected area a the ply level

$\left[\mathrm{m}^{2}\right]$

nominal contact area per meter filament length

circular contact area of filaments in perpendicular

$\left[\mathrm{m}^{2} / \mathrm{m}\right]$

$\left[\mathrm{m}^{2}\right]$

contact

real contact area per meter filament length

dimensionless Maugis-Dugdale contact radius

semi-minor axis of elliptic contact

half-width of contact for line contact

$\left[\mathrm{m}^{2} / \mathrm{m}\right]$

radius of circular (micro)contact taking adhesion

contribution into account (Maugis-Dugdale)

radius of the circular contact area of filaments in

a perpendicular orientation

semi-major axis of elliptic contact

$[-]$

[m]

[m]

[m]

[m]

dimensionless radius of attraction

plate-friction specimen bulk compressibility

no. of warp/weft tows in a fabric

radius of the adhesive zone of a

(micro)contact (Maugis-dugdale)

linear density (tow)

capstan drum diameter

separation distance between a filament and

the mean plane of a surface topography

$[\mathrm{kg} / \mathrm{m}]$

$[\mathrm{m}]$

[m] 


\begin{tabular}{|c|c|c|}
\hline$d_{i}$ & separation distance increment & {$[\mathrm{m}]$} \\
\hline$d_{\text {tow }}$ & tow width & {$[\mathrm{m}]$} \\
\hline$E_{\text {axial }}, E_{\text {trans }}, E^{\star}$ & axial, transverse and reduced Young's modulus & {$[\mathrm{Pa}]$} \\
\hline & plate-friction gross clamping force & {$[\mathrm{N}]$} \\
\hline$F_{0}$ & plate-friction internal friction force & \\
\hline$F_{\mathrm{f}}$ & frictional force & \\
\hline$g$ & plate-to-plate gap width & \\
\hline$k$ & Howell proportionality fitting parameter & {$\left[\mathrm{N}^{-n}\right]$} \\
\hline$k_{\mathrm{p}}$ & plate-friction clamping mechanism spring stiffness & \\
\hline$l_{\text {wrap }}$ & $\begin{array}{l}\text { wrapped tow or filament length in the capstan } \\
\text { experiment }\end{array}$ & \\
\hline$N_{\mathrm{p}}$ & plate-friction nett clamping force & \\
\hline$N_{\text {tow }}(\theta), N_{\text {fil }}(\theta)$ & local distributed normal tow and filament load & {$[\mathrm{N} / \mathrm{m}]$} \\
\hline$n$ & Howell load index fitting parameter & {$[-]$} \\
\hline$n_{\text {fil }}$ & no. filaments in a tow & \\
\hline$n_{\text {oblique }}$ & $\begin{array}{l}\text { no. of filaments in oblique contact for nearly } \\
\text { parallel tow-tow contact }\end{array}$ & \\
\hline$n_{\mathrm{t}}$ & no. of twists in the twisted tow section & \\
\hline$P$ & ploughing component of frictional force & \\
\hline $\bar{P}$ & dimensionless compressive load (Maugis-Dugdale) & \\
\hline$P_{\text {par }}$ & compressive load in nearly parallel filament & \\
\hline$P_{\text {perp }}$ & compressive load on filaments in perpendicular contact & \\
\hline$p_{\text {micro }}$ & microscopic pressure (using $A_{\text {micro }}$ ) & \\
\hline$p_{\text {meso }}$ & mesoscopic pressure (using $A_{\text {meso }}$ ) & \\
\hline$p_{\text {macro }}$ & macroscopic pressure (using $\left.A_{\text {macro }}\right)$ & {$[\mathrm{Pa}$} \\
\hline & d contact load (Maugis-Dugdale) & \\
\hline$R_{1 \mathrm{x}}, R_{1 \mathrm{y}}, R_{2 \mathrm{x}}, R_{2 \mathrm{y}}$ & radius of curvature of contacting bodies & \\
\hline$R_{\mathrm{m}}$ & mean effective radius of curvature & \\
\hline$R_{\text {drum }}$ & capstan friction drum radius & \\
\hline$R_{\text {fil }}$ & filament radius & \\
\hline$R_{X}, R_{Y}$ & principle relative radius of curvature & \\
\hline$r_{i}$ & least-squares fitting procedure residual & \\
\hline $\mathbf{r}$ & vector of least-squares fitting residuals & \\
\hline$T_{1}, T_{2}, T(\theta)$ & tensional force at tow ends and local tensional force & \\
\hline$T_{1, \exp }, T_{2, \exp }$ & measured tensional tow forces in the capstan experiment & \\
\hline & tensional force in plate-friction experiment & \\
\hline$t_{1}, t_{2}$ & tensional force at filament ends & \\
\hline$t$ & local tow width & \\
\hline$t_{0}$ & plate-friction initial two-ply specimen thickness & \\
\hline$U$ & plate-friction experiment pulling velocity & {$[\mathrm{m} /$} \\
\hline$v$ & sliding velocity of tow or filament on capstan & {$[\mathrm{m} /$} \\
\hline W & dead weight mass & \\
\hline
\end{tabular}




$\begin{array}{llr}W_{\text {area }} & \text { fabric areal weight } & {\left[\mathrm{kg} / \mathrm{m}^{2}\right]} \\ w & \text { work of adhesion } & {\left[\mathrm{J} / \mathrm{m}^{2}\right]} \\ w & \text { filament spacing (digging in phenomenon) } & {[\mathrm{m}]} \\ \mathbf{x} & \text { least-squares fitting parameter vector } & {[-]} \\ z_{0} & \text { interatomic or intermolecular equilibrium spacing } & {[\mathrm{m}]} \\ z_{i} & \text { asperity height coordinate in a surface profile } & {[\mathrm{m}]}\end{array}$

\section{Abbreviations}

$\begin{array}{ll}\text { ASTM } & \text { American society for testing and materials } \\ \text { CFRP } & \text { continuous fibre reinforced polymer } \\ \text { LCM } & \text { liquid composite moulding } \\ \text { MD } & \text { Maugis-Dugdale } \\ \text { PAN } & \text { poly(acrylo nitrile) } \\ \text { RMS } & \text { root mean square } \\ \text { RMSE } & \text { root mean square error } \\ \text { ROI } & \text { region of interest } \\ \text { RTM } & \text { resin transfer moulding }\end{array}$




\section{Contents}

Summary

Samenvatting $\quad$ iii

$\begin{array}{ll}\text { Nomenclature } & \text { v }\end{array}$

1 Introduction $\quad 1$

1.1 Motivation . . . . . . . . . . . . . . . . 1

1.2 From macroscopic deformation to microscopic friction . . . . . . 3

1.3 Scope and outline of this thesis . . . . . . . . . . . . 6

References .................... 8

2 Frictional behaviour of fibrous tows: Friction experiments 11

2.1 Introduction . . . . . . . . . . . . . . . . . 12

2.2 Tow mechanics . . . . . . . . . . . . . . . . . 12

2.3 Friction models . . . . . . . . . . . . . . . . . . . 13

2.4 Experiment. . . . . . . . . . . . . . . . . . 15

2.4.1 The capstan measurement setup . . . . . . . . . . 15

2.4 Materials ................... 16

2.4 .3 Experimental procedure . . . . . . . . . . 18

2.5 Results and discussion . . . . . . . . . . . . . . . 20

2.5.1 Experimental validation . . . . . . . . . . . 21

2.5 .2 Major trends . . . . . . . . . . . . . . 27

2.5 .3 Detailed observations . . . . . . . . . . . . 27

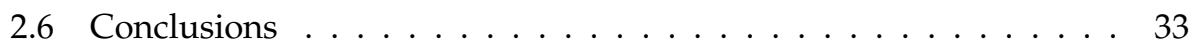

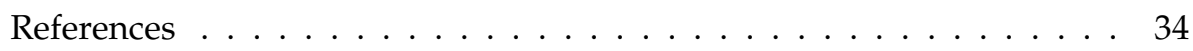


3 A contact mechanics model of tow-metal friction 37

3.1 Introduction . . . . . . . . . . . . . . 38

3.2 Contact mechanics model . . . . . . . . . . . . . . . 39

3.2.1 Scope of the modelling approach . . . . . . . . . . . . 40

3.2.2 From tow to filament load . . . . . . . . . . . . . 43

3.2.3 Counterface topographies . . . . . . . . . . . . . . 44

3.2.4 Nominal contact area - smooth topography . . . . . . . . . 48

3.2.5 Nominal contact area - rough topography . . . . . . . . . . 49

3.2.6 Real contact area - smooth and rough topography . . . . . 50

3.3 Results ...................... 52

3.4 Discussion ........................... 52

3.4.1 Interfacial properties . . . . . . . . . . . . . 52

3.4.2 Comparison with experimental results . . . . . . . . . . 54

3.4.3 Practical value. . . . . . . . . . . . . 56

3.5 Conclusions . . . . . . . . . . . . . . 57

References ......................... 57

3.A Appendix: Derivation of the normal tow load . . . . . . . . . . . 60

3.B Appendix: Simplified elliptic elastic contact - Hertz . . . . . . . . . 60

3.C Appendix: Maugis-Dugdale adhesive contact calculations . . . . . 62

4 A contact mechanics model of tow-tow friction 65

4.1 Introduction . . . . . . . . . . . . . . . . . . 66

4.2 Contact mechanics modelling approach . . . . . . . . . . . . 67

4.2.1 Scope of the modelling approach . . . . . . . . . . . . 67

4.2 .2 Material . . . . . . . . . . . . . . . . . 68

4.2.3 From tow to filament load . . . . . . . . . . . . . . . . . 69

4.2.4 Perpendicular tow contact . . . . . . . . . . . . 71

4.2.5 Parallel tow contact . . . . . . . . . . . . . 73

4.3 Results ....................... 76

4.3.1 Perpendicular orientation . . . . . . . . . 76

4.3 .2 Parallel orientation . . . . . . . . . . . . . . 77

4.4 Discussion . . . . . . . . . . . . . . . . . 79

4.4.1 Comparison with experimental results . . . . . . . . . 79

4.4 .2 Model assumptions . . . . . . . . . . . . . . 81 


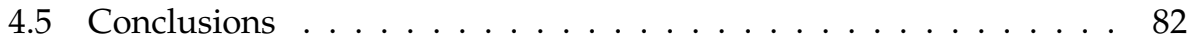

References ...................... 83

4.A Appendix: Derivation of the normal tow load . . . . . . 85

4.B Appendix: Maugis-Dugdale adhesive contact calculations . . . . 86

4.C Appendix: General Hertzian elliptic contact . . . . . . . . . . 87

5 Dry friction characterisation of carbon fibre tow and satin weave fabric 89

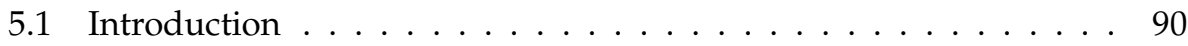

5.2 Materials and methods . . . . . . . . . . . . . . . . . . 91

5.2.1 Tow and fabric material . . . . . . . . . . . . . . . . . 91

5.2 .2 Friction in textile materials . . . . . . . . . . . . . 92

5.2 .3 Capstan friction setup . . . . . . . . . . . . . . 93

5.2 .4 Plate-friction setup . . . . . . . . . . . . . . . . . . 94

5.2 .5 Metal counterfaces . . . . . . . . . . . . . . . . . . . 96

5.3 Friction and contact area . . . . . . . . . . . . . . . . . 96

5.4 Results . . . . . . . . . . . . . . . . . . . . . . . 100

5.5 Discussion . . . . . . . . . . . . . . . . . . . 105

5.5.1 Capstan setup: Tow versus fabric friction . . . . . . . . . 105

5.5.2 Comparison of fabric friction on both setups . . . . . . . 106

5.5.3 Practical use: Capstan versus plate-friction setup . . . . . 110

5.6 Conclusions . . . . . . . . . . . . . . . . . . . . . . . . . . . 110

References . . . . . . . . . . . . . . . . . . . . . . . . . 111

6 Closing the multi-scale loop 115

6.1 Discussion . . . . . . . . . . . . . . . . . . 116

6.2 Conclusions . . . . . . . . . . . . . . . . . . . . 120

6.3 Recommendations . . . . . . . . . . . . . . . . . . . . . 121

6.4 Future trends in friction modelling . . . . . . . . . . . . . . . 123

References . . . . . . . . . . . . . . . . . . . . . . 123

$\begin{array}{ll}\text { Dankwoord } & 125\end{array}$

$\begin{array}{ll}\text { Publications } & 127\end{array}$ 



\section{Chapter 1}

\section{Introduction}

\subsection{Motivation}

Since their introduction in the 70s of the last century, the use of Continuous Fibre Reinforced Polymers (CFRPS) has seen a substantial growth. The combination of a high strength and high stiffness fibrous reinforcement with a low density thermoset or thermoplastic polymer matrix results in synergy advantages. These synergy benefits make CFRPs attractive for many applications where a combination of low weight and high strength or high stiffness is desired.

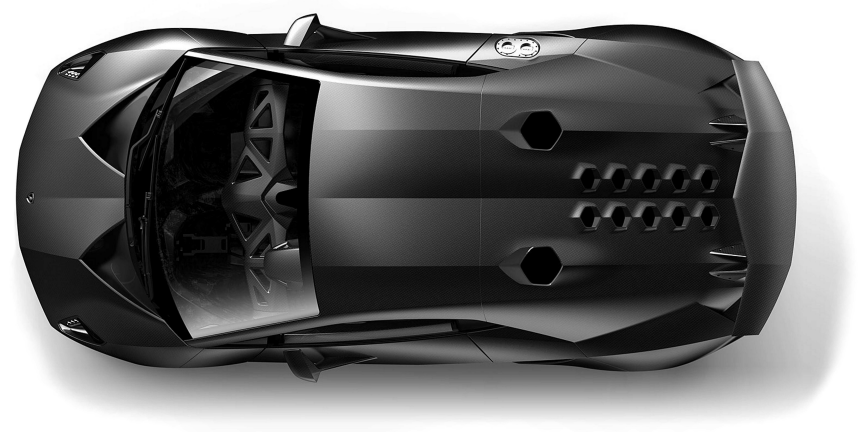

Figure 1.1 In October 2010 Lamborghini introduced the Sesto Elemento concept car, a technology demonstrator with $80 \%$ of its total weight of $999 \mathrm{~kg}$ made of carbon CFRP. Besides the monocoque, several structural parts were made of carbon CFRP: the transmission shaft, the front subframe, the crash boxes, and parts of the suspension. Photo: Automobili Lamborghini S.p.A. (with permission). 
The Boeing 777 commercial jet airliner, which entered service in 1995, contained $10 \%$ wt composite materials, whereas the share of CFRPS in the Boeing 787 Dreamliner, entering service in 2009, amounts up to 50\%wt [1-3]. In 2010, Lamborghini introduced the Sesto Elemento, a concept car with $80 \%$ wt CFRP, illustrated in Figure 1.1. Interestingly, the design philosophy behind this project is a first time right approach with a complete virtualisation of the design, production and safety performance program suitable for use in series manufacturing [4].

The manufacturing costs of composite products, however, still form a hurdle for adoption in mass production. The cycle times of CFRP forming processes are still relatively high compared to more conventional processes like metal forming. The cycle time of a typical composite product ranges from several minutes to hours depending on the process, whereas the cycle time of sheet metal forming is a matter of seconds. Thus, the trade-off between economical and mechanical performance often tips the scale in favour of more conventional materials like metals. Nowadays, the main challenge for the composites industry therefore lies in improving the technology and cost-effectiveness of composites manufacturing [5]. Optimisation of existing manufacturing processes and the development of new technologies are expected to facilitate this objective. Virtualisation of the entire production chain is an important part of this process, requiring simulation of processes based on detailed material models. A thorough understanding of the deformation behaviour of CFRPS and its constituents is essential to achieve this improvement.

Larger series production of CFRPS with a thermoset matrix typically takes place with a Liquid Composite Moulding (LCM) process, consisting of a preforming and a matrix impregnation step. The dry tows in the arrangement reorient and deform during the preforming step. One of the poorly understood phenomena in this process is the frictional behaviour of the fibrous tows. The production of fibrous tow materials for applications in tape or fabric-type reinforcement architectures is another example where dry friction plays an important role. The spreading behaviour of fibrous tows during handling and processing is influenced by frictional interactions with the guiding material. An improper choice of material or process conditions often leads to excessive filament failure or variations in product properties.

This thesis addresses the characterisation of the frictional behaviour of dry fibrous materials during processing in CFRP production. The aim is to provide a thorough and at least qualitative insight in the frictional behaviour of dry tow arrangements during processing by means of experimental and predictive modelling work. 


\subsection{Multi-scale approach: from macroscopic deforma- tion to microscopic friction}

Commonly applied tow materials in CFRPs are carbon, aramid, and glass. These materials are all produced as continuous filaments with a typical diameter in the order of $10 \mu \mathrm{m}$. Several hundreds to thousands of filaments are combined into a tow, which is the basic constituent of reinforcement architectures like woven, braided or knitted fabrics. Fibrous tows can be applied to a preform directly as well, for example in the filament winding and tow placement process [6].

Figure 1.2 illustrates the length scales of a typical composite product. In this example a laminate, which consists of several layers or plies, represents the macroscopic scale. The mesoscopic scale typically concerns the tow level. The filament level defines the microscopic scale. Finally, the sub-microscopic scale $\left(10^{-8}-10^{-6} \mathrm{~m}\right)$ denotes the level of asperities which determine the surface topography of both filaments and counterfaces, for example tooling metal (not included in the illustration).

To avoid any confusion in the following chapters, the term tow is considered equivalent to the term yarn or bundle; likewise, filament is considered equivalent to fibre. A tow is considered to be an entity, disregarding subcompositions encountered in, for example, rovings or strands.

The aforementioned multi-scale perspective for the characterisation of CFRPs is inherent to frictional behaviour as well. The characterisation of the processinduced friction forces that occur when the tows are loaded in processing is necessary to accurately predict the tow deformation in dry and impregnated fabrics, as well as in individual tow or tape material. Generally, friction is treated as a dominant phenomenon in characterising the forming phase of composite materials. The dominance of friction mechanisms at the macro-mesoscopic interaction level has been acknowledged [7-10]. At the meso-microscopic level, however, friction has been a less studied phenomenon [11-14].

The description of the macro-mesoscopic deformation mechanisms for a single

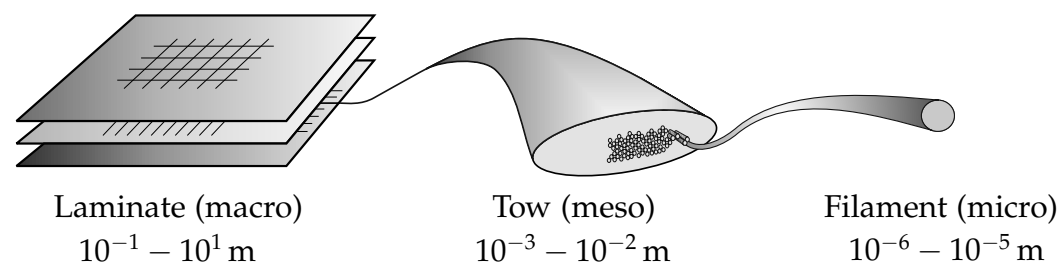

Figure 1.2 Hierarchical structure of a typical composite product and its constituents with their characteristic length scales. 
Table 1.1 Multi-scale breakdown of macro deformations applied to a single woven ply. The schematic overview of macroscopic deformation mechanisms was reproduced from the approach proposed by Long and Clifford [15].

\begin{tabular}{|c|c|c|}
\hline ply / macro level & tow / meso level & filament / micro level \\
\hline$\stackrel{\rightleftarrows}{\rightleftarrows}$ & $\begin{array}{l}\text { Relative sliding along } \\
\text { the longitudinal axis } \\
\text { Rotation-induced } \\
\text { sliding at crossovers } \\
\text { Tension in tow affects } \\
\text { compaction at } \\
\text { crossovers }[16,17]\end{array}$ & $\begin{array}{l}\text { Relative sliding along } \\
\text { the longitudinal axis } \\
\text { Rearrangement, } \\
\text { transverse sliding }\end{array}$ \\
\hline $\begin{array}{l}\text { Intra-ply } \\
\text { extension }\end{array}$ & $\begin{array}{l}\text { Compaction at crossovers [18] } \\
\text { Decrease of undulation } \\
\text { along the longitudinal axis [19] } \\
\text { Extension along the } \\
\text { longitudinal axis }\end{array}$ & $\begin{array}{l}\text { Rearrangement, } \\
\text { transverse sliding } \\
\text { Relative sliding along } \\
\text { the longitudinal axis } \\
\text { Extension along the } \\
\text { longitudinal axis }\end{array}$ \\
\hline Ply bending & $\begin{array}{l}\text { Flexure } \\
\text { Compaction (mainly) } \\
\text { at crossovers }\end{array}$ & $\begin{array}{l}\text { Flexure } \\
\text { Relative sliding along } \\
\text { the longitudinal axis } \\
\text { Rearrangement, } \\
\text { transverse sliding }\end{array}$ \\
\hline Compaction & $\begin{array}{l}\text { Flattening, mainly } \\
\text { at crossovers [20] } \\
\text { Decrease of undulation }\end{array}$ & $\begin{array}{l}\text { Rearrangement, } \\
\text { transverse sliding } \\
\text { Longitudinal sliding }\end{array}$ \\
\hline
\end{tabular}

ply of woven fabric proposed by Long and Clifford is decomposed into a (non-exhaustive) collection of deformations to which the tows and filaments are subjected on the meso- and the microscopic scale [15]. Table 1.1 lists the deformations at the macro-, meso, and microscopic level, respectively. As listed in Table 1.1, the microscopic deformation mechanisms mainly consist of longitudinal and transversal sliding of filaments with respect to each other, in which friction plays a large role. The longitudinal and transverse sliding deformation mechanisms on the filament level are schematically illustrated in Figure 1.3.

Apart from shear, extension, bending, and compaction, twist is a fifth deformation mechanism that can be identified on the tow level. This mechanism occurs when a torsional load is applied on a tow along its longitudinal axis. In 


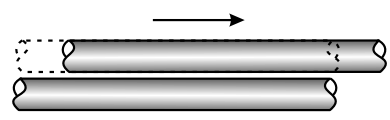

longitudinal sliding

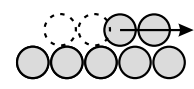

transverse sliding

Figure 1.3 Schematic illustration of longitudinal (left) and transverse (right) sliding of filaments with respect to the filament axis.

the resulting deformation, the filaments in the tow spiral around a virtual centre running along the longitudinal axis of the tow. Firstly, twist involves transverse sliding of filaments due to compaction, which results in filament migration. Secondly, longitudinal sliding occurs as a result of length differences between the helical filament paths on the outside and the paths towards the centre of the tow [21-23].

The complete set of five distinct deformation mechanisms describes the tow deformation behaviour during composite forming processes. All of the aforementioned deformation mechanisms involve friction between filaments. From the meso-microscopic perspective, the mechanisms acting at these scales clearly affect the aforementioned mechanisms on the macroscopic ply or laminate scale.

The aim of this study is to provide a qualitative and, where possible, a quantitative relation between the microscopic filament friction and the effects on the macroscopic scale. The mesoscopic frictional behaviour of tow materials provides the link between the aforementioned scales.

The role of friction already manifests itself in the production phase of the basic tow material. For example, freshly drawn E-glass tows have a tensile strength exceeding 3.5 GPa, but the strength drops to values between $1.7-2.1 \mathrm{GPa}$ due to the occurrence of micro-defects on the surface of the filaments. These defects are caused by abrasion of filaments in rubbing contact with each other or in contact with equipment during transport [1]. The tows are damaged further during handling and processing, for example in contact with guide rings during weaving or braiding.

A surface finish or sizing is typically applied to protect the filaments against processing damage and to improve bonding with the matrix material. A wide variety of sizing types exists, but a main division can be made based on the matrix material, which is either a thermoset or a thermoplastic polymer. The mechanical properties of the selected sizing are usually tuned to achieve a maximum compatibility with the matrix material [24]. Often, a film former in the sizing acts as a lubricant to decrease friction during processing. The term $d r y$ in the context of this thesis refers to the absence of a hydrodynamic film between the two interacting materials. Mixed or hydrodynamic lubrication occurs from the moment of impregnation by a thermoset or thermoplastic resin. 
Typically, dry friction between sliding materials is represented with a Coulomb friction approach. Herein, the friction force is linearly proportional to the applied normal load on the contacting materials. This kind of behaviour typically applies to most metals, which show a proportional relation between the applied load and the resulting contact area [25]. However, fibrous tows demonstrated a rather nonlinear, load-dependent frictional behaviour $[25,26]$. In this thesis, the nonlinear nature of the frictional behaviour of fibrous tows is addressed.

\subsection{Scope and outline of this thesis}

This work addresses the frictional behaviour of fibrous tows sliding on metal counterfaces and relative to each other. Therefore, the investigation is limited to dynamic friction. Several researchers investigated static friction and stickslip phenomena of fibrous materials, for which the reader is kindly referred to references as [27-30]. The theoretical framework of this thesis is based on the assumption that the frictional behaviour of dry tows is velocity-independent, which was found to be correct within the measured range in experiments. Furthermore, the real contact area $A_{\mathrm{r}}$ at the sub-microscopic scale between filaments and each other, or a metal counterface and the interfacial shear strength $\tau$ are considered as the determining factors in the build-up of the frictional force $F_{\mathrm{f}}$ :

$$
F_{\mathrm{f}}=A_{\mathrm{r}} \tau \text {. }
$$

In this work, the dynamic friction is described with the real contact area $A_{\mathrm{r}}$ in which an interfacial shear strength $\tau$ has to be overcome to induce sliding. Because velocity-independent behaviour is assumed, the load-dependent contact areas required for the prediction of friction forces were calculated on the basis of static loading conditions. The material properties stated in this work were obtained from tow manufacturers' data and literature sources. Not all properties were unambiguously quantified. For example, the interfacial shear strength of similar and dissimilar materials in contact and the quantification of the surface energies of the fibrous materials are the subject of ongoing investigation [31-34]. Experimental work to improve the accuracy of these data was, however, not part of this study.

The four chapters in the body of this thesis, i.e. Chapters $2-5$, were published or submitted for publication in scientific journals and are presented in reproduced form in this thesis. These chapters contain some overlap in the introductory and theoretical parts. Nevertheless, the chapters are self-contained and can be read as such. Figure 1.4 illustrates how the chapters of the body of the thesis are interrelated. 


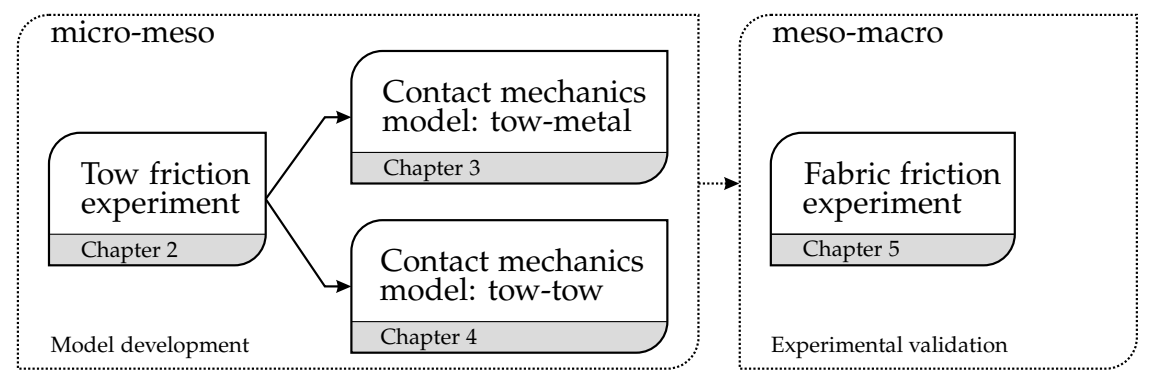

Figure 1.4 Schematic outline of the body of this thesis.

Chapter 2 presents experiments on the frictional behaviour of aramid, carbon, and E-glass fibrous tows. The frictional behaviour of these tows on two metal counterfaces representing tooling material was studied on a capstantype experimental setup. Furthermore, the frictional behaviour of each of the aforementioned tow materials in direct contact with the same material was studied. Additional measurements on different experimental setups provided validation of the experiment as well as a better understanding of the measured tow friction on the capstan setup.

The experimental results and insights provided the framework for the theoretical models of the frictional behaviour of tows in contact with metal counterfaces in Chapter 3, and of tows in direct contact with each other in Chapter 4 . These models are based on interactions of the filaments down to the sub-microscopic level with an extension to the frictional behaviour on the mesoscopic tow scale. The model predictions of friction on the mesoscopic scale are compared with the experimental results described in Chapter 2. Based on the developed theoretical models, this approach can be extended to the macroscopic friction of tow arrangements such as fabrics as well.

Chapter 5 describes the experimental work that was performed to verify the hypothesis of multi-scale applicability of the friction model for contact of fibrous material with a metal counterface. The frictional behaviour of woven carbon fabric is compared to that of individual tows of the same material. The frictional behaviour of the fabrics was studied on two different experimental setups, i.e. the already mentioned capstan-type setup and a plate-plate friction setup, to provide a validation of the employed measurement methods.

The general discussion, conclusions, and recommendations for future experimental and modelling work are presented in Chapter 6. 


\section{References}

[1] P.K. Mallick. Fiber-reinforced composites: materials, manufacturing and design. CRC Press, 3rd edition, 2008.

[2] Fact sheet 777. Boeing Commercial Airplanes. URL http://www.boeing.com/commercial/777family/pf/pf_facts.html, Retrieved 16 Oct. 2012.

[3] Fact sheet 787 Dreamliner. Boeing Commercial Airplanes. URL http://www.boeing.com/commercial/787family/programfacts.html, Retrieved 16 Oct. 2012.

[4] G. Gardiner. Sixth Element: Lamborghini accelerates CFRP. Composites World, 2012. URL http://www.compositesworld.com/articles/sixth-element-lamborghini-accelerates-cfrp, Retrieved 16 Oct. 2012.

[5] M. Del Pero and S. Speak. Strategically accelerating the adoption of advanced composites beyond aerospace. Reinforced Plastics, 56(1):44-45, 2012.

[6] P. Morgan. Carbon fibers and their composites. Taylor \& Francis, 2005.

[7] S.V. Lomov, A.V. Gusakov, G. Huysmans, A. Prodromou, and I. Verpoest. Textile geometry preprocessor for meso-mechanical models of woven composites. Compos Sci Technol, 60(11):2083-2095, 2000.

[8] P. Boisse. Meso-macro approach for composites forming simulation. J Mater Sci, 41(20):6591-6598, 2006.

[9] N. Hamila and P. Boisse. A meso-macro three node finite element for draping of textile composite preforms. Appl Compos Mater, 14(4):235-250, 2007.

[10] E. Vidal-Sallé and P. Boisse. Modelling the structures and properties of woven fabrics. In: Modelling and predicting textile behaviour. Woodhead Publishing, 2010.

[11] S.A. Grishanov, S.V. Lomov, T. Cassidy, and R.J. Harwood. The simulation of the geometry of a two-component yarn part II: Fibre distribution in the yarn cross-section. J Text Inst, 88(4):352-367, 1997.

[12] S.V. Lomov, G. Huysmans, Y. Luo, R.S. Parnas, A. Prodromou, I. Verpoest, and F.R. Phelan. Textile composites: Modelling strategies. Compos Part A Appl Sci Manuf, 32(10):1379-1394, 2001.

[13] P. Potluri, I. Parlak, R. Ramgulam, and T.V. Sagar. Analysis of tow deformations in textile preforms subjected to forming forces. Compos Sci Technol, 66(2):297-305, 2006.

[14] Damien Durville. Simulation of the mechanical behaviour of woven fabrics at the scale of fibers. Int J Mater Form, 3:1241-1251, 2010.

[15] A.C. Long and M.J. Clifford. Composites forming mechanisms and materials characterization. In: A.C. Long (editor), Composites forming technologies. chapter 1, 1-21, Woodhead Publishing, 2007.

[16] S.H. Chang, S.B. Sharma, and M.P.F. Sutcliffe. Microscopic investigation of tow geometry of a dry satin weave fabric during deformation. Compos Sci Technol, 63(1):99-111, 2003.

[17] P. Harrison. Normalisation of biaxial bias extension test results considering shear tension coupling. Compos Part A Appl Sci Manuf, 43(9):1546-1554, 2012. 
[18] K. Buet-Gautier and P. Boisse. Experimental analysis and modeling of biaxial mechanical behavior of woven composite reinforcements. Exp Mech, 41(3):260-269, 2001.

[19] P. Boisse, A. Gasser, and G. Hivet. Analyses of fabric tensile behaviour: determination of the biaxial tension-strain surfaces and their use in forming simulations. Compos Part A Appl Sci Manuf, 32(10):1395-1414, 2001.

[20] P. Potluri and T.V. Sagar. Compaction modelling of textile preforms for composite structures. Compos Struct, 86(1-3):177-185, 2008.

[21] J. W. S. Hearle, H. M. A. E. El-Behery, and V. M. Thakur. 6-The mechanics of twisted yarns : Tensile properties of continuous-filament yarns. J Text Inst Trans, 50(1):T83-T111, 1959.

[22] J. W. S. Hearle, H. M. A. E. El-Behery, and V. M. Thakur. 23-The mechanics of twisted yarns : Further studies of the tensile properties of continuous-filament yarns. J Text Inst Trans, 51(8):T299-T316, 1960.

[23] N. Pan and D. Brookstein. Physical properties of twisted structures. II. Industrial yarns, cords, and ropes. J Appl Polym Sci, 83(3):610-630, 2002.

[24] J.L. Thomason and L.J. Adzima. Sizing up the interphase: An insider's guide to the science of sizing. Compos Part A Appl Sci Manuf, 32(3-4):313-321, 2001.

[25] F.P. Bowden and D. Tabor. Friction, lubrication and wear: A survey of work during the last decade. Br J Appl Phys, 17(12):1521-1544, 1966.

[26] A.S. Lodge and H.G. Howell. Friction of an elastic solid. Proc Phys Soc B, 67(2):89-97, 1954.

[27] B.J. Briscoe and A. Winkler. A statistical analysis of the frictional forces generated between monofilaments during intermittent sliding. J Phys D, 18(11):2143-2167, 1985.

[28] N. Behary, C. Caze, A. Perwuelz, and A. El Achari. Tribology of sized glass fibers Part II: Using an electronic microbalance technique to study stick-slip behavior. Text Res J, 71(3):187-194, 2001.

[29] M.H. Müser, L. Wenning, and M.O. Robbins. Simple microscopic theory of Amontons's laws for static friction. Phys Rev Lett, 86(7):1295-1298, 2001.

[30] C.-F. Tu and T. Fort. A study of fiber-capstan friction. 2. Stick-slip phenomena. Tribol Int, 37(9):711-719, 2004.

[31] Klaus J. Hüttinger, Sabine Höhmann-Wien, and Georg Krekel. Works of adhesion at the carbon fiber-liquid interface determined using a modified wetting technique. Carbon, 29(8):1281-1286, 1991.

[32] E. Mäder. Study of fibre surface treatments for control of interphase properties in composites. Composites Science and Technology, 57(8):1077-1088, 1997.

[33] M.J. Adams, B.J. Briscoe, J.Y.C. Law, P.F. Luckham, and D.R. Williams. Influence of vapor condensation on the adhesion and friction of carbon-carbon nanocontacts. Langmuir, 17(22):6953-6960, 2001.

[34] Y. Luo, Y. Zhao, Y. Duan, and S. Du. Surface and wettability property analysis of CCF300 carbon fibers with different sizing or without sizing. Mater Design, 32(2):941-946, 2011. 



\title{
Chapter 2
}

\section{Frictional behaviour of high performance fibrous tows: Friction experiments ${ }^{1}$}

\begin{abstract}
Tow friction is an important mechanism in the production and processing of high performance fibrous tows. The frictional behaviour of these tows is anisotropic due to the texture of the filaments as well as the tows. This work describes capstan experiments that were performed to measure the frictional behaviour of aramid, carbon and E-glass tows, both in tow-metal and tow-tow contact. The effects of anisotropy and other processingrelated parameters on the frictional behaviour of the tows are discussed. The surface topography of the counterface plays a dominant role in tow-metal friction. For tow-tow contact, the relative orientation of the tows dominates the frictional behaviour.
\end{abstract}

\footnotetext{
${ }^{1}$ Reproduced from: B. Cornelissen, B. Rietman, R. Akkerman, Frictional behaviour of high performance fibrous tows: Friction experiments, Composites: Part A 44(1):95-104, 2013.
} 


\subsection{Introduction}

The mechanical properties of continuous fibre reinforced polymers or composite parts are determined to a large extent during the forming phase. Such composite parts consist of a thermosetting or thermoplastic matrix, which is reinforced with continuous fibrous tows, that typically consist of several thousands of filaments. The continuous fibrous tows deform during the forming phase of production processes. They conform to the local shape of the tool surface on which the composite part is being manufactured. Local cross-sectional changes occur in the tow due to the induced loads. The tow orientation and filament distribution determine the mechanical properties of the composite part to a large extent. Knowledge of the tow orientation and tow deformation behaviour is therefore essential to understand and control the desired product quality in terms of e.g. mechanical performance, dimensional accuracy and visual appearance.

The dominant mechanism behind the deformation of fibrous tows is friction; its characterisation is the main focus of this paper. Several parameters influencing the observed frictional behaviour were addressed. The effect of variations in tow-metal and tow-tow interfaces were studied for carbon, aramid and E-glass tow material. Furthermore, validation experiments were performed to verify assumptions regarding environmental and wear effects as well as assumptions related to the studied friction interfaces.

The following sections describe the theoretical background, the experimental approach, followed by the results and a discussion of the friction measurements. Finally, the conclusions section provides an overview of the relevance of the studied parameters on the frictional behaviour of fibrous tows.

\subsection{Tow mechanics}

Composite materials can be represented in a hierarchical structure. A classification is generally made in three scales, as illustrated in Figure 2.1: macro, meso and micro to represent the composite part, tow and filament scale, respectively. The frictional behaviour of individual filaments, i.e. on

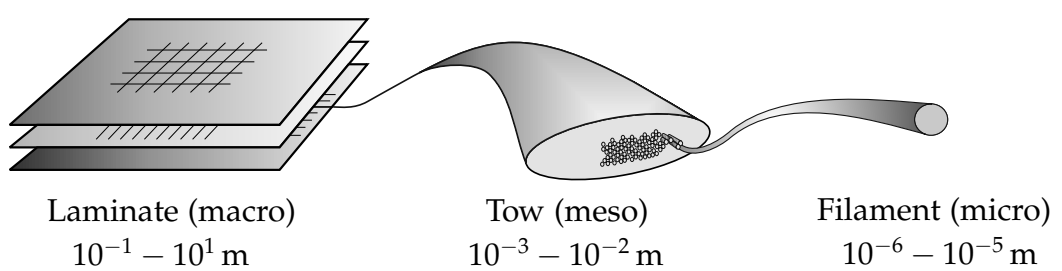

Figure 2.1 Hierarchical structure of composite materials with characteristic length scales. 
the microscale, was investigated in earlier research [1-3]. However, little work has been done to provide an approach to relate the material behaviour on the microscale to that on the meso and macroscale. Here, the frictional properties of fibrous tows are examined on the combined micro-mesoscale, with the aim to provide a relation between the micro and macroscale deformation behaviour.

The hierarchical approach does not imply that deformation mechanisms are isolated on a single scale level. For example, filaments moving relatively to each other within a tow on the microlevel will result in a change in crosssectional properties of the tow on the mesolevel. Meso and macroscale effects are interrelated as well. An example is the formation of wrinkles in a doubly curved rubber-pressed composite product. These wrinkles develop due to tow orientation dependent inter-ply friction and shear [4].

Previous modelling efforts of forming processes, in which macro and mesoscale effects are related to each other, show that friction mechanisms are an important factor in the deformation behaviour of tows and plies [4-6]. One can, for instance, account for friction in forming analyses of woven fabric composites on the macrolevel by assuming a lubricated contact with mesoscopic information [7]. Knowledge of the meso-microscale interactions is needed to incorporate friction mechanisms on the mesoscale. The dominant interactions (on all scales) are shear and compaction. However, bending and twist are expected to play a role as well on the micro-mesoscale, but these are not treated in this work. A physically sound model based on aforementioned elementary deformation mechanisms is expected to provide the required information.

The deformations that occur during the forming phase of composite products induce loads on the tows and filaments. These loads result in frictional forces at different interfaces. The determination of the involved friction mechanisms of the tows and filaments with respect to each other and to mould materials such as tooling steel is necessary to accurately predict the tow deformation in dry as well as impregnated fabrics, individual tows and tape materials. We define this area as tow mechanics, aiming to develop a theoretical approach which covers the loading conditions encountered during composite processing. Experimental work is necessary to obtain the physical basis for this modelling approach.

\subsection{Friction models}

This paper deals with the friction of dry tow material. The term $d r y$ in this context refers to the absence of a full hydrodynamic film between the two interacting materials. The well-known Coulomb friction model in Equation (2.1) is the most straightforward approach to characterise the dry friction between two sliding materials. The frictional force $F_{\mathrm{f}}$ is considered to be directly proportional 
to the applied normal load $N$ through the coefficient of friction $\mu$ :

$$
F_{\mathrm{f}}=\mu N \text {. }
$$

However, the coefficient of friction has been observed to vary with the applied normal load on the tow, whereas the Coulomb friction implies a constant value $[8,9]$. Howell's equation is a widely accepted relation between the normal load and the resulting frictional force, given as [2, 9-15]:

$$
F_{\mathrm{f}}=k N^{n},
$$

where $k$ is an experimentally determined proportionality constant, which relates the normal load $N$ to the frictional force $F_{\mathrm{f}}$. The load index $n$ is a fitting parameter that relates to the deformation mechanism, which ranges from $n=\frac{2}{3}$ for fully elastic deformation to $n=1$ for fully plastic deformation of contacting asperities. For the latter value, Equation (2.2) thus reduces to the Coulomb friction relation in Equation (2.1). Several modifications of Equation (2.2) exist, however, this paper will not elaborate on these modified relations.

Many friction characterisation studies were performed in the twentieth century, a large number originating from processes in the textile industry. An overview was produced by Yuksekkaya [9]. Different measurement methods were proposed of which the capstan method is one of the most straightforward and versatile methods. Early research on the frictional behaviour of fibrous tows mostly concerned low-modulus materials, such as nylon, viscose rayon and natural materials like wool $[8,13,16]$. Efforts to characterise the frictional behaviour of carbon tow material by means of the capstan relation focused on single filaments $[2,3,14]$. The frictional behaviour of individual E-glass filaments was studied by Behary and others by means of Atomic and Lateral Force Microscopy (AFM/LFM) measurements [17]. The frictional properties of aramid tows were mainly investigated from the perspective of ballistic performance in the form of woven fabrics [18-20].

Each tow consists of up to several thousands of filaments. The comparison between single filament friction and the results from the frictional measurements on tow material provides a more thorough understanding of the frictional mechanisms that occur both within fibrous tows and between the tows and other interface materials.

In this research, we describe the frictional behaviour of fibrous tows with an apparent coefficient of friction $\mu_{\mathrm{app}}$. This coefficient is derived from the measured capstan frictional force and is an integral quantity. The capstan measuring approach provides a straightforward comparison of the frictional behaviour of several tow materials and testing parameters. The pressure dependency of the frictional force is inherently part of the apparent coefficient of friction, which is a tow-counterface system parameter. 
The capstan approach was applied to sized as well as unsized (no sizing applied) and desized (the sizing was removed physically or chemically) tow material. In this context the term sizing refers to the mixture of components that allows good processability and filament-matrix adhesion of the tows in composite materials. This sizing typically consists of a lubricant to prevent filament damage during processing, a coupling agent for filament-matrix adhesion and a film former to keep the filaments together in the tow. An anti-static agent is added as well in the case of aramid and E-glass tows.

\subsection{Experiment}

This section provides a description of the experimental setup that was built to measure the frictional behaviour of fibrous tows. The measurement procedure and data analysis are presented as well.

\subsubsection{The capstan measurement setup}

A capstan-type measurement setup, as illustrated in Figure 2.2, was designed, based on the ASTM D3108-07 [21] and ASTM D3412-07 [22] standard test methods. A tow specimen is draped with an angle of $\pi$ rad over a metal drum $(\varnothing 50.0 \mathrm{~mm})$. The drum and shaft are machined from one single part and the shaft ends are fitted with ball bearings, which are supported by mounts on a single aluminium base plate. One end of the drum shaft is connected to a motor-gearhead combination with a cardanic coupling in between to compensate possible radial and angular misalignments between the motor and drum. The motor support is mounted on the same base plate as the bearing supports. This part of the setup is mounted approximately $40 \mathrm{~cm}$ above an aluminium slab on

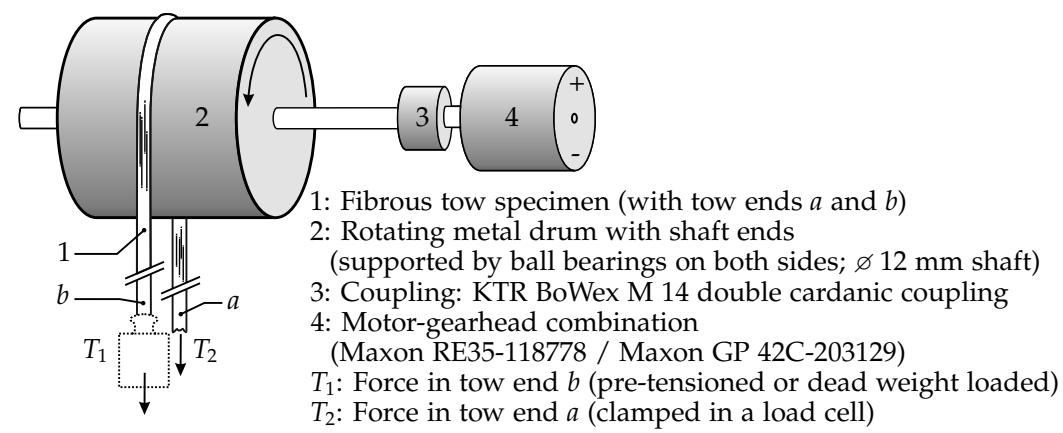

Figure 2.2 Schematic description of the capstan experiment for friction characterisation of fibrous tows. 
Table 2.1 Experimental parameters.

\begin{tabular}{llll}
\hline Description & Symbol & Unit & Value \\
\hline Capstan drum diameter & $d$ & $\mathrm{~mm}$ & $50 \pm 0.02$ \\
Tow draping angle on drum & $\theta$ & $\mathrm{rad}$ & $0.5 \pi^{a} ; \pi^{b} \pm 0.01$ \\
Rotational frequency & $\omega$ & $\mathrm{Hz}$ & $0.21 \pm 0.01$ \\
Corresponding sliding velocity & $v$ & $\mathrm{~mm} / \mathrm{s}$ & $33.0 \pm 1.6$ \\
Load case: dead weights & $W$ & $\mathrm{~g}$ & $300.0 \pm 0.1$ \\
Load case: pre-tensioned & $\mathrm{T}$ & $\mathrm{g}$ & $500.0 \pm 0.1$ \\
\hline
\end{tabular}

${ }^{a}$ For E-glass specimens; ${ }^{b}$ For carbon and aramid specimens.

which two load cells (HBM SP4C3-MR single point load cells; range: $0-30 \mathrm{~N}$ ) equipped with clamps are mounted. One of them is mounted in a vertically movable fixture to enable pre-tensioning of the tow specimen.

Table 2.1 summarises the relevant parameters and settings of the capstan experiment. The capstan relation

$$
\mu_{\mathrm{app}}=\ln \left(\frac{T_{2}}{T_{1}}\right) \frac{1}{\theta},
$$

gives the apparent coefficient of friction as a function of the tensional forces $T_{1}$ and $T_{2}$ in both the tow ends and the wrapping angle $\theta$ of the tow specimen on the drum.

The tow friction experiments were performed for tow-metal and tow-tow contact. Fibrous tows touch different counterfaces during the manufacturing of composite products. The frictional interfaces that were considered in this research were chosen from a production perspective. The metal capstan drums represent metal tooling like Resin Transfer Moulding (RTM) moulds or vacuum forming tools. Ply-ply friction is of course involved in multi-ply products, which results in tow-tow friction on the mesoscale. Two relative orientations of the carbon tow specimens were considered, to take the expected orientation dependency of tow-tow friction into account. A parallel tow orientation results in line contacts between the filaments; a perpendicular tow orientation gives circular contact areas between the filaments.

\subsubsection{Materials}

The friction characterisation was performed on fibrous tow materials that are typically used in structural composite materials: carbon, aramid and Eglass. Table 2.2 lists these tow materials and their relevant properties. The 
Table 2.2 Manufacturer data of the fibrous tow materials used in the capstan friction experiment.

\begin{tabular}{|c|c|c|c|c|c|c|}
\hline Description & Symbol & Unit & & & & \\
\hline Material code & & & C03k & $\mathrm{C} 12 \mathrm{k}$ & Gla & Ara \\
\hline Material & & & PAN-Carbon & PAN-Carbon & E-Glass & Twaron \\
\hline Manufacturer & & & Torayca & Toho-Tenax & $\begin{array}{l}\text { PPG } \\
\text { Fiber Glass }\end{array}$ & $\begin{array}{l}\text { Teijin } \\
\text { Aramid }\end{array}$ \\
\hline Type & & & $\begin{array}{l}\text { T300JB } \\
300040 B\end{array}$ & $\begin{array}{l}\text { HTS40 } \\
\text { F13 }\end{array}$ & $\begin{array}{l}\text { Hybon } \\
2001\end{array}$ & D1000 \\
\hline Sizing/Finish & & & $\begin{array}{l}\text { Epoxy } \\
\text { based }\end{array}$ & $\begin{array}{l}\text { Polyurethane } \\
\text { based }\end{array}$ & $\begin{array}{l}\text { Silane, } \\
\text { aqueous }\end{array}$ & $\begin{array}{l}\text { Non-ionogenic } \\
\text { compound }\end{array}$ \\
\hline Linear density & $\mathrm{D}$ & tex & 198 & 800 & 300 & $336^{1}$ \\
\hline Twist & & $\mathrm{t} / \mathrm{m}$ & 0 & 0 & 0.12 & 0 \\
\hline No. of filaments & $n_{\text {fil,total }}$ & 3000 & 12000 & 750 & 2000 & \\
\hline Filament dia. & $d_{\text {fil }}$ & $\mu \mathrm{m}$ & 7.0 & 7.0 & 14.0 & 12.2 \\
\hline Axial E-modulus & $\mathrm{E}_{\text {axial }}$ & $\mathrm{GPa}$ & 230 & 240 & 73 & 75 \\
\hline Transverse E-modulus & $E_{\text {trans }}$ & $\mathrm{GPa}$ & 15 & 15 & 73 & 1.6 \\
\hline Density & $\rho$ & $\mathrm{kg} / \mathrm{m}^{3}$ & 1780 & 1770 & 2600 & 1440 \\
\hline
\end{tabular}

measurements were performed on both sized and desized or unsized materials. The desized tows received a sizing removal treatment (PAN-carbon and E-glass), the unsized aramid tows were not treated with sizing during the manufacturing process. The carbon tows were desized at Ten Cate Advanced Composites. The sizing of the E-glass was removed by heating the specimens in a tube oven for 30 minutes at $625^{\circ} \mathrm{C}$. All tests were performed on commercially available materials, kindly provided by the manufacturers. As a consequence, the as-received tow materials have various linear densities (Table 2.2).

A closer look at Table 2.2 shows that the fibrous materials differ mainly in their stiffness as well as their stiffness ratios, i.e. the axial versus transverse (or radial) elastic moduli. These ratios are 15, 47 and 1 for the carbon, aramid and E-glass tows, respectively.

Furthermore, the sizings on the tow materials differ in chemical composition and function. However, all sizings have a common purpose: protecting the fibrous tows during handling and providing acceptable filament-matrix adhesion at the same time. The exact composition and frictional properties of the finish and sizing materials were not provided by the manufacturers. Several authors performed in-depth analyses of typical coatings of fibrous tow materials [23-26]. This work will not elaborate on the characteristics of the sizings; however, a distinction between the tow materials with and without the sizing is made.

Two metal friction drums were used for the measurements with a 'smooth' and 'rough' surface texture, respectively (see Figure 2.4(a) and (b)). The drums have different surface topographies to identify the effect of counterface texture on the developed frictional force. The Root Mean Square (RMS) or Rq roughness of the drum surface topographies were $0.020 \pm 0.003 \mu \mathrm{m}$ for the smooth and $1.1 \pm 0.4 \mu \mathrm{m}$ with a finer 'superimposed' roughness of $0.016 \pm 0.003 \mu \mathrm{m}$ for the rough topography. These values were measured on a Keyence VK-9710 laser confocal microscope. The drum surfaces can be considered as consisting of many 


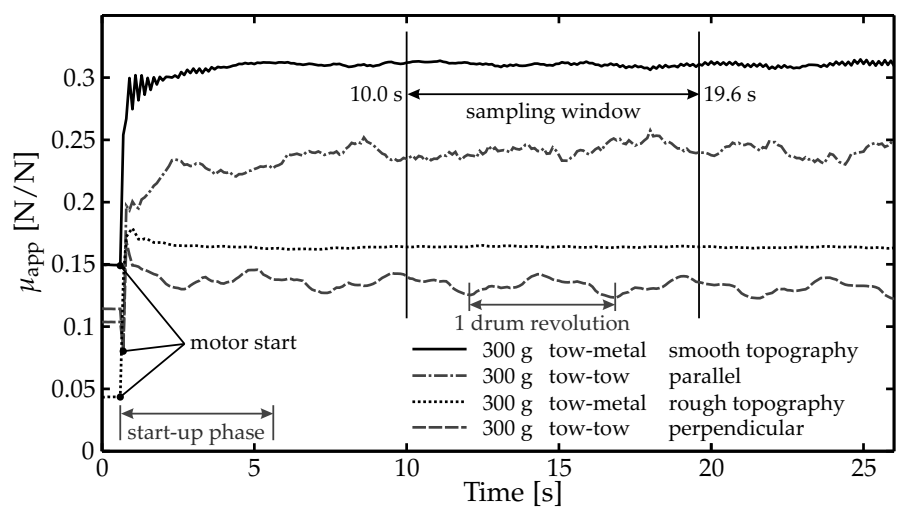

Figure 2.3 Typical friction measurements for desized C03k carbon fibre tows. The graph shows the apparent coefficients of friction $\mu_{\mathrm{app}}$ as a function of time.

spherically shaped asperities, which are assumed to affect the observed frictional behaviour. The average radius of curvature of the asperities was approximately $13.9 \mu \mathrm{m}$ for the smooth drum and $40 \mu \mathrm{m}$ and $2.2 \mu \mathrm{m}$ ('superimposed' asperities) for the rough drum topography.

The tow-tow friction measurements were performed for two relative tow orientations, being parallel (symbol: $\|$ ) and perpendicular (symbol: $\perp$ ). Section 2.4.3 describes the measurement procedures followed and explains how the perpendicular and parallel tow-tow contacts were realised.

\subsubsection{Experimental procedure}

Before each measurement, the drum surface was first cleaned with an acetone and then with an ethanol-impregnated textile wipe. Then, a tow specimen was draped over the metal friction drum and tow end $a$ (shown in Figure 2.2) was clamped in the appropriate load cell measuring $T_{2}$. Subsequently, end $b$ of the tow was attached to either a dead weight or clamped in the other load cell (measuring $T_{1}$ ). In the latter case, the fixture containing the load cell was displaced to prestress the tow specimen. The resulting load in the prestressed tow end varied from 5 to $16 \mathrm{~N}$ for carbon tows and from 6 to $12 \mathrm{~N}$ for aramid tows. The variations depend mainly on the type of friction interface, even though the pre-tensioning procedure was performed by hand (by applying a constant displacement on the load cell holder of tow end $b$ ).

The load cell output was sampled with a frequency of $10 \mathrm{~Hz}$. The motor was switched on at a prescribed rotational frequency of $0.21 \mathrm{~Hz}$, equivalent to a drum surface velocity of $33.0 \pm 1.6 \mathrm{~mm} \mathrm{~s}^{-1}$. The measured load(s) reached a more or less steady state approximately $5 \mathrm{~s}$ after starting the motor. The coefficient of 

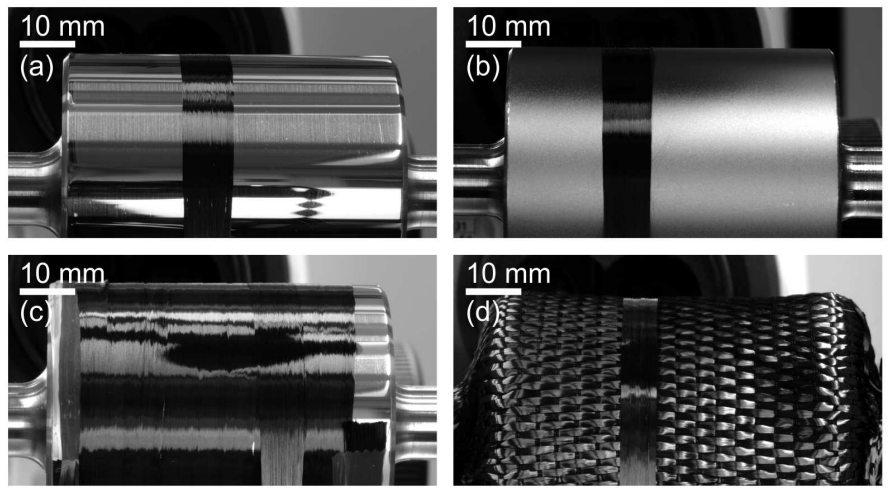

Figure 2.4 Four friction interface types with a $12 k$ carbon tow specimen: (a) tow-metal smooth topography; (b) tow-metal rough topography; (c) tow-tow parallel; (d) tow-tow perpendicular.

friction was determined by averaging the sampled signals between $10.0 \mathrm{~s}$ and $19.6 \mathrm{~s}$, which is equivalent to two complete revolutions of the capstan drum at the prescribed rotational frequency of $0.21 \mathrm{~Hz}$. This particular interval was chosen to account for the periodicity in the measurement signal due to small geometrical and alignment variations in the setup. Figure 2.3 shows the apparent coefficient of friction $\mu_{\mathrm{app}}$ as a function of time for a few typical measurements on desized C03k carbon fibre tow material. A sample of five measurements was used for every experimental setting, with a new tow specimen per measurement.

A similar procedure was followed for the parallel tow-tow measurements, but before draping the tow specimen over the drum, a separate tow specimen was wound onto the drum, with the ends attached to the drum surface by means of adhesive tape. This configuration applied to all measurements involving parallel tow orientation. The tows did not contact each other in an exactly parallel fashion, caused by the pitch of the wound tow specimen, visible in Figure 2.4c.

Another type of specimen was attached to the metal drum for perpendicular tow-tow frictional measurements (on carbon tows only). The separate specimen consisted of a fabric with carbon tows held together by a lycra thread. The fabric was stitched together at opposing edges to form a tubular structure with the carbon tows in the axial direction, which could then be mounted on the metal drum (with minor stretch of the lycra threads). The contribution of the lycra threads to the measured friction proved to be negligible in a preliminary measurement, where the threads were removed in the contact area of the tow specimen. Figure 2.4(d) shows the layer with the carbon tows in the axial drum orientation.

Additional measurements were performed for validation purposes including friction measurements that were performed with a stationary tow specimen on 
Table 2.3 Experimental matrix of the capstan friction measurements. Tow-metal smooth and rough represent the smooth and rough drum surface topographies, respectively; $\|$ and $\perp$ indicate parallel and perpendicular relative tow orientations, respectively. The friction drum is either rotating (Rot.) or stationary (Stat.).

\begin{tabular}{lcccccc}
\hline & \multicolumn{2}{c}{ Tow-metal smooth } & \multicolumn{2}{c}{ Tow-metal rough } & Tow-tow $\|$ & Tow-tow $\perp$ \\
& Rot. & Stat. & Rot. & Stat. & Rot. & Rot. \\
\hline Carbon 3k & $\mathrm{a}, \mathrm{c}$ & $\mathrm{b}$ & $\mathrm{a}, \mathrm{b}, \mathrm{c}$ & $\mathrm{b}$ & $\mathrm{a}, \mathrm{c}$ & $\mathrm{a}, \mathrm{c}$ \\
Carbon 12k & $\mathrm{a}^{*}, \mathrm{~b}^{*}, \mathrm{c}$ & $\mathrm{b}$ & $\mathrm{a}, \mathrm{b}, \mathrm{c}$ & $\mathrm{b}$ & $\mathrm{a}, \mathrm{b}^{*}, \mathrm{c}$ & $\mathrm{a}, \mathrm{c}$ \\
Aramid 2k & $\mathrm{a}, \mathrm{b}, \mathrm{c}$ & $\mathrm{b}$ & $\mathrm{b}$ & $\mathrm{b}$ & $\mathrm{a}, \mathrm{c}$ & \\
E-Glass 0.75k & $\mathrm{a}, \mathrm{b}$ & & $\mathrm{a}, \mathrm{b}$ & & $\mathrm{a}$ & \\
\hline
\end{tabular}

Load cases $\mathrm{a}, \mathrm{b}, \mathrm{c}: \mathrm{a}=300 \mathrm{~g}, \mathrm{~b}=500 \mathrm{~g}$ dead weight; $\mathrm{c}=$ pre-tensioned.

${ }^{*}$ Measurements performed for various environmental humidities.

a rotating drum as well as a moving tow specimen on a stationary drum. Other validation measurements were performed at low and high relative humidity environmental conditions. Further details are presented in Section 2.5.1.

Table 2.3 shows the experimental matrix of the performed tow-metal and tow-tow friction measurements. The first two columns represent the towmetal friction cases for the two different drum surface topographies. The last two columns show the obtained data for tow-tow friction for parallel and perpendicular relative orientation of the tows.

The friction measurements on carbon and aramid tow specimens were performed on both sized and desized/unsized material. The friction measurements on E-glass tow specimens could not be performed on desized material, because it immediately failed upon loading. The thermal sizing removal process resulted in fully exposed microcracks on the filament surface, thereby increasing the notch sensitivity of the filaments. Therefore, stress localisation in the microcracks resulted in failure at loads far below the load that was applied on the sized E-glass tows.

\subsection{Results and discussion}

Figures 2.5 to 2.7 show the apparent coefficients of friction per tow material obtained during the capstan experiments. The error bars in the graphs indicate one standard deviation of each set of five measurements. Figure 2.5 shows the results for the two different linear densities of the carbon tow specimens $\mathrm{C} 03 \mathrm{k}$ and C12k, containing 3000 and 12000 filaments, respectively. Figure 2.6 shows the apparent coefficient of friction data for both unsized and sized aramid tow material. Figure 2.7 shows the measurement results for sized E-glass tows.

This section deals first with the validation experiments that were performed to determine the influence of humidity, temperature and wear on the tow-metal 
measurements and the validation of the parallel tow-tow friction measurements on the capstan setup with an alternative method. Next, the main trends of the experimental observations are presented in Section 2.5.2, followed by a discussion of the observations in detail in Section 2.5.3.

\subsubsection{Experimental validation}

Various aspects of the experiment needed a critical evaluation in order to treat the results with confidence. Different setups and conditions were used to verify the validity of the measured apparent friction coefficients

\section{Rotating versus stationary drum}

The stationary tow specimens in the capstan experiment are expected to show adhesive wear, since the same part of the specimen is in continuous contact with the friction drum. An increase in temperature in the tow can be expected to occur as well, due to heat development in the friction interface. As a consequence, the frictional behaviour should vary as well. However, apart from running-in effects in the first $5 \mathrm{~s}$ of a friction measurement run, the apparent coefficient of friction showed little variation in the time range of the measurement. These running-in effects are expected to relate to filament realignment and load redistribution.

A straightforward validation experiment to confirm the low effect of wear and heating on the tow friction consisted of inverting the stationary and moving parts of the capstan setup. This inversion ensured that any wear effects in the tow specimen were minimised, since the tow was continuously renewed. A temperature increase due to the friction at the metal-tow interface is minimised as well, again because the tow specimen is continuously renewed and the friction drum can be safely assumed to act as a heat sink.

Several measurements were performed with the C03k and C12k carbon tows and the aramid tows on the smooth and rough friction drums. Overall, the observed coefficients of friction (grey areas in Figures 2.5 and 2.6) did not show significant deviations compared to the measurements with a rotating drum. For example, the frictional behaviour of the sized aramid tows on the rotating drum compares very well to that on the stationary drum, this was observed for both drum topographies. Therefore, it was concluded that in the range of the performed measurements, wear and temperature effects on the developed friction can be neglected. In addition, these validation experiments showed that the reproducibility of the capstan friction measurement method is satisfactory. 


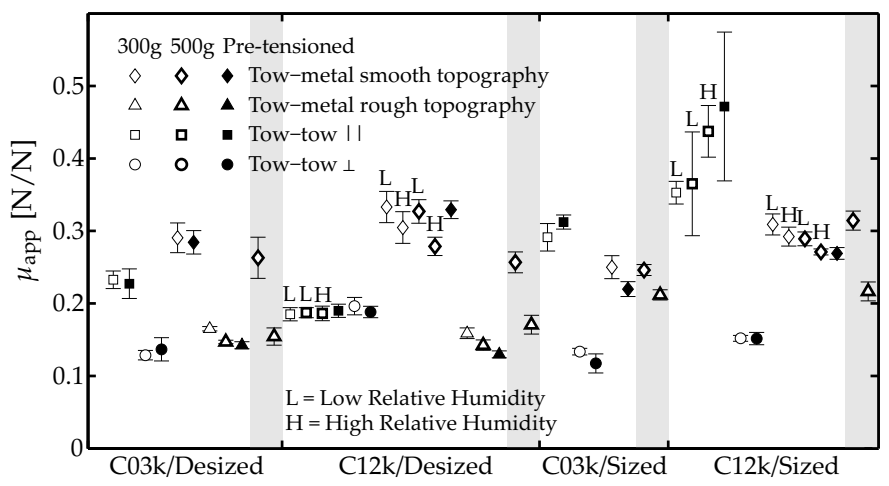

Figure 2.5 Apparent coefficients of friction of PAN-based carbon tows for various interfaces. Results with a grey background were obtained with a stationary (stat.) friction drum. The error bars represent the standard deviation.

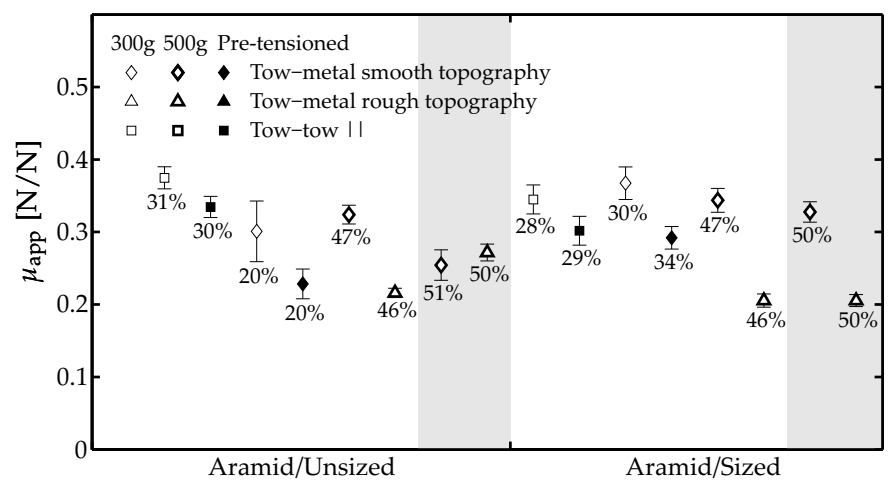

Figure 2.6 Apparent coefficients of friction of aramid tows for two metal drum topographies and a parallel tow-tow interface. Results with a grey background were obtained with a stationary (stat.) friction drum. The percentages indicate the average relative humidity of the environment during the measurements $(\% R H)$. The error bars represent the standard deviation. 


\section{Load case dependency}

Most measurements were performed with two different load cases: dead weight loading and displacement controlled pre-tensioning. The results in Figure 2.5 show small variations between the obtained apparent coefficients of friction. These variations are usually not larger than the standard deviation in the case of carbon tows.

Nevertheless, the constrained degrees of freedom and loads are different for both load cases. The tow end carrying the dead weight has the freedom to slide laterally (in the direction of the drum axis) and the free hanging part of the tow end between the surface and the weight can rotate freely. Shifting causes an increase in the tensional force measured by the load cells. The amount of lateral sliding for the pre-tensioned load case is limited, compared to that of the dead weight load case.

The aramid tow specimens show a stronger dependency on the load case than those of the carbon tow measurements. The aramid tows are assumed to behave as fully elastic materials in the applied load and velocity regime. A higher coefficient of friction for both sized and desized aramid tow material was observed for the $300 \mathrm{~g}$ load case than the pre-tensioned load case, as illustrated in Figure 2.6. A closer look at the specific measurements revealed that the load variations during the pre-tensioned load case were significant. These variations occur due to the nature of the load application by displacement, the repeatability within a set of 5 measurements was satisfactory.

\section{Environmental humidity}

The environmental lab conditions were monitored, but not actively controlled. The room temperature varied from $20.8^{\circ} \mathrm{C}$ to $25.0^{\circ} \mathrm{C}\left( \pm 0.1^{\circ} \mathrm{C}\right)$, the relative humidity during the measurements ranged between $15.1 \% \mathrm{RH}$ and $47.7 \% \mathrm{RH}( \pm 0.1 \% \mathrm{RH})$ (excluding additional measurements at high humidity). The temperature during verification measurements with a stationary friction drum varied from $23.2^{\circ} \mathrm{C}$ to $25.0^{\circ} \mathrm{C}\left( \pm 0.1^{\circ} \mathrm{C}\right)$, the relative humidity during these measurements ranged from $37.7 \% \mathrm{RH}$ to $51.7 \% \mathrm{RH}( \pm 0.1 \% \mathrm{RH})$.

Every fibrous tow material attains a moisture balance with its environment in a certain amount of time. In the case of carbon filaments, the effect of water adsorption is limited and does not obey the commonly used BETequation (Brunauer, Emmett, and Teller) to describe the adsorption isotherm for water vapour [27]. To assess the moisture sensitivity, measurements on sized and desized $\mathrm{C} 12 \mathrm{k}$ carbon tows were performed in both low and high relative humidity conditions, $15.4-34.1 \% \mathrm{RH}$ and $66.3-74.3 \% \mathrm{RH}( \pm 0.1 \% \mathrm{RH})$, respectively. The results in Figure 2.8 show that the influence of environmental humidity on the measured coefficient of friction is of the same order of 


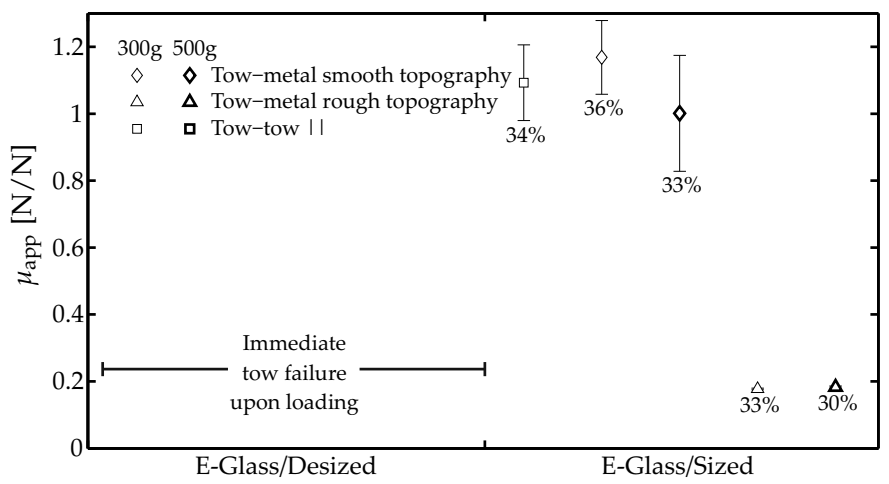

Figure 2.7 Apparent coefficients of friction of E-glass tows for two metal drum topographies and the parallel tow-tow interface. The percentages indicate the average relative humidity of the environment during the measurements $(\% R H)$. The error bars represent the standard deviation.

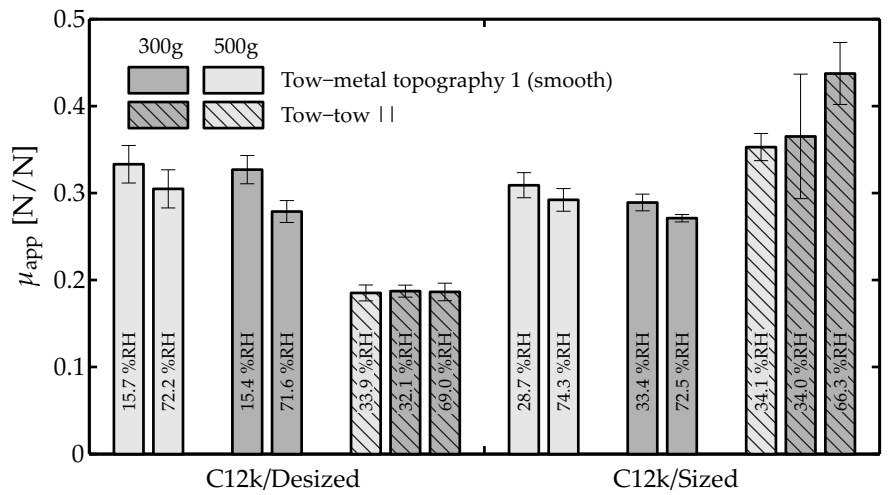

Figure 2.8 Measurements on sized and desized $12 k$ carbon tow specimens at low and high relative humidities $(\% R H)$. The plain and hatched bars show the apparent coefficient of friction for tow-metal (topography 1) and tow-tow parallel contact, respectively. The error bars represent the standard deviation. 
magnitude as the measurement accuracy itself. The friction measurements on sized carbon tows showed larger variations in the measured coefficient of friction under similar circumstances. The measured standard deviation increased as well. Despite the low statistical relevance, the experimental results at least suggest trends for the tow-metal friction and desized tow-tow friction.

The coefficient of friction for the tow-metal interface decreased consistently with increasing humidity, for both the sized and desized tow specimens. This suggests that the moisture interaction between the tow and the metal drum counterface is dominated by the metal surface.

For parallel tow-tow contact, the sized tow specimens showed an increase in the measured coefficient of friction with increasing humidity, whereas the measured coefficient of friction for the desized specimens remained unaffected. These observations suggest that the moisture dependency of tow-tow friction is determined by the sizing material. Furthermore, the sizing is not evenly distributed along the length of the tow. Variations in the amount of sizing are believed to cause a larger standard deviation of the friction measurements. Because part of the frictional system is determined by the properties of the metal contact surface for tow-metal friction, the influence of the sizing material is less apparent.

The main conclusion from these measurements is that the frictional behaviour depends only weakly on the relative humidity of the environment for desized carbon tows. The frictional behaviour of the studied sized carbon tows shows humidity-dependent behaviour in the case of tow-tow contact.

\section{Parallel tow contact measurements}

The twisted strand method as described by the ASTM D3412-07 standard, option 1 , is an alternative to the capstan parallel tow-tow measurement method (option 2 of the same standard) [22]. The twisted strand method allows further validation of the capstan measurement method. During the twisted strand test, the friction is generated in a single piece of twisted tow in a pulley system, as illustrated in Figure 2.9. Filaments have the tendency to migrate to the centre line of the twisted tow arrangement due to the tension in the tow and the twisted geometry. Consequently, one would expect a closest packing arrangement of the filaments in the tow, with a constant amount of digging in, as will be discussed in Section 2.5.3.

The loads in the tow ends are measured in the same manner as for the capstan measurement. The apparent coefficient of friction is calculated according to the 


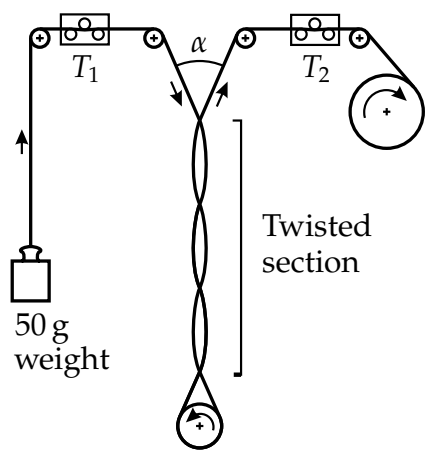

Figure 2.9 Schematic illustration of the twisted strand measurement method. Parallel tow-tow contact occurs in the twisted section. The tow loads $T_{1}$ and $T_{2}$ are measured before and after passing the twisted section.

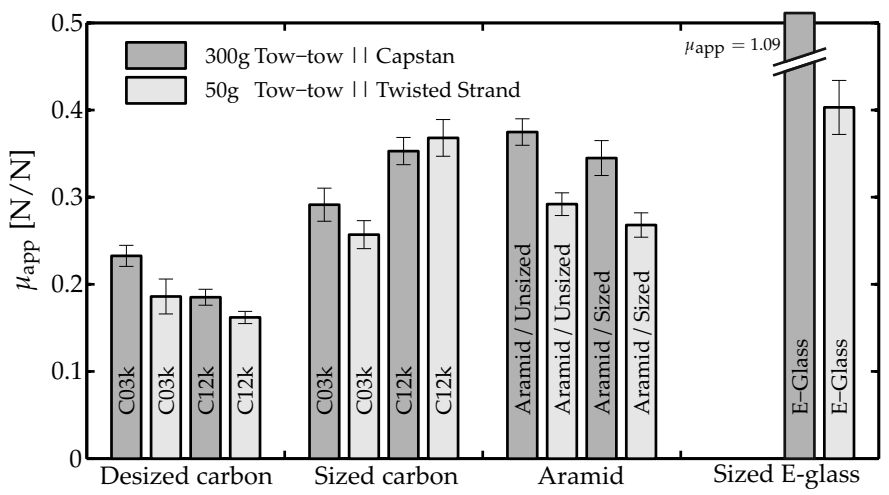

Figure 2.10 Comparison of two measurement methods for parallel tow-tow contact. The error bars represent the standard deviation. 
following relation ${ }^{2}$ [22]:

$$
\mu_{\mathrm{app}}=\ln \left(\frac{T_{2}}{T_{1}}\right) \frac{1}{2 \pi n_{\mathrm{t}} \alpha}
$$

with the number of twists in the tow $n_{\mathrm{t}}$, the apex angle $\alpha$ and the ingoing and outgoing tow forces $T_{1}$ and $T_{2}$, respectively.

\subsubsection{Major trends}

Evaluating the results presented in Figures 2.5 to 2.7 we observe four major trends:

1. The capstan friction experiments show the general trend of significantly higher friction for tow-metal contact on the smooth drum than on the rough drum.

2. The results in Figure 2.5 show that the apparent coefficients of friction for the parallel tow orientation are generally higher than or at least equal to the perpendicularly oriented tows.

3. The parallel tow orientation measurements showed variation with respect to the material-sizing combination; the $\mathrm{C} 12 \mathrm{k}$ sized carbon tow friction coefficients were relatively high compared to the those from measurements without the polyurethane-based sizing.

4. The apparent coefficients of friction for the silane sized E-glass tows in parallel orientation as well as on the smooth drum were high, but they could not be compared to desized tow specimens, due to brittleness of the material after the sizing removal treatment.

\subsubsection{Detailed observations}

Several experimentally observed phenomena required a closer examination to explain the results. The following subsections discuss these phenomena.

\section{Tow-metal contact}

The friction measurements of carbon tows illustrated in Figure 2.5 show that the behaviour of $\mathrm{C} 03 \mathrm{k}$ and $\mathrm{C} 12 \mathrm{k}$ tows is generally comparable for both tow-metal friction interfaces. The increased contact area of the wider $\mathrm{C} 12 \mathrm{k}$ tows compared to the C03k tows did not result in significantly higher apparent coefficients of

\footnotetext{
${ }^{2}$ Corrected version of the equation presented in ASTM D3412-07 [22]
} 
friction. The additional measurements at high and low humidities on $\mathrm{C} 12 \mathrm{k}$ carbon tows were discussed in Section 2.5.1.

The apparent coefficients of friction of the sized aramid tow material on the rough counterface are significantly lower than on the smooth counterface and the parallel tow-tow contact (Figure 2.6).

The frictional behaviour of tow-metal contact of the unsized aramid tows shows a different trend. The observed friction of tow-metal contact on the stationary drums (grey background for the Aramid/Unsized part of Figure 2.6) was rather unexpected. The outgoing tow force decreased during the first $20 \mathrm{~s}$ of the $60 \mathrm{~s}$ measurements with the unsized tow on the stationary smooth counterface. This behaviour was not observed for the same measurements on sized aramid tows, nor for the unsized tow measurements with a rotating drum. This behaviour could be caused by wear effects, resulting in sizing or aramid deposits on the stationary drum surface. However, no significantly different amounts of deposit on the drum were observed with the naked eye, compared to the same measurements with a rotating drum.

The E-glass measurements were performed for a tow wrapping angle of $0.5 \pi \mathrm{rad}$ instead of $\pi \mathrm{rad}$. The force $T_{2}$ in tow end $a$ (Figure 2.2) exceeded the load cell capacity of $30 \mathrm{~N}$ for the latter wrapping angle due to the high coefficient of friction between the smooth counterface and the E-glass tow material.

The frictional behaviour of the E-glass tow material shows a high dependency on the counterface topography. Figure 2.7 shows that there is up to a factor of 5 to 6 difference between the measured friction of the sized tow on the smooth topography drum and the friction on the rough topography drum. The Eglass tow material has a significantly higher transversal stiffness than the carbon and aramid tows, resulting in less conformation of the filaments to the metal counterface and a smaller area of contact for a given contact pressure. This could explain the large relative difference in observed friction.

The strong dependency of the measured coefficient of friction on the drum surface topography was characterised for single carbon filaments by Roselman and Tabor [3]. These authors found friction coefficients for carbon filaments on stainless steel (EN58B/1.4541) that showed up to three times higher values for a low surface roughness. The lowest surface roughness was $0.01 \mu \mathrm{m} \mathrm{Ra}$ (arithmetic average roughness), the highest $\mathrm{Ra}$ roughness value was $0.95 \mu \mathrm{m}$.

Their measurements on a drum with a Ra roughness of $0.05 \mu \mathrm{m}$ showed a steep decrease in measured friction compared with the $0.01 \mu \mathrm{m}$ drum, whereas the difference in coefficient of friction between the $0.05 \mu \mathrm{m}$ and the higher roughness values of $0.26 \mu \mathrm{m}$ and $0.95 \mu \mathrm{m}$ was relatively small.

Roselman and Tabor explained this phenomenon from a surface topography perspective [3]. The frictional force $F_{\mathrm{f}}$ is determined by the shear strength $\tau$ of 
the materials in the interface and the real contact area $A_{\mathrm{r}}$ between them $[2,3]$ :

$$
F_{\mathrm{f}}=A_{\mathrm{r}} \tau+P \text {. }
$$

The real contact area $A_{\mathrm{r}}$ of a filament on the drum with a low roughness is larger than that of the drum with a high roughness at equal load. The ploughing component $P$ of adhesive friction in Equation (2.5) plays a minor role in the case of a hard counter-surface like that of the steel drums.

The surface roughness of the smooth counterface in this experiment (Table 2.1) is comparable to the smoothest drum used by Roselman and Tabor. The rough topography friction drum can be compared with their roughest counterface.

In our current results for tows we observe the same trend of a decreasing friction with a decreasing real contact area as Roselman and Tabor observed previously for single filaments. This trend was observed for all the tested tow materials, as illustrated in Figures 2.5 to 2.7.

\section{Tow-tow contact}

The case of desized $\mathrm{C} 12 \mathrm{k}$ forms an exception to the general observations mentioned in Section 2.5.2; here, the observed coefficients of friction were comparable for both tow orientations.

Figure 2.6 shows that the frictional properties of the sized aramid specimens are generally comparable for the parallel tow-tow friction interface and the metal friction drum with the smooth counterface. The frictional behaviour of the unsized tows shows more variaton than the sized tows. The relative humidities were comparable for these measurements, which eliminates moisture dependency of the results.

The parallel tow-tow friction measurements of E-glass were performed for sized specimens only, as shown in Figure 2.7. The measured coefficient of friction on the capstan setup was comparable to the smooth counterface tow-metal friction. However, a much larger amount of filaments failed during the tow-tow friction measurements. This failure of filaments could be related to an increase in friction due to digging in of filaments. This mechanism is explained in the next subsection.

\section{Digging in of filaments}

During parallel tow-tow friction measurements the tows contacted each other under a small angle (below $5^{\circ}$ ) as shown in Figure 2.4(c). The stationary tow specimens (on top of the arrangement) were displacing laterally during the experiment, suggesting a spindle-like movement. This means that conformation of filaments, leading to digging in must have taken place, i.e. the filaments of the 


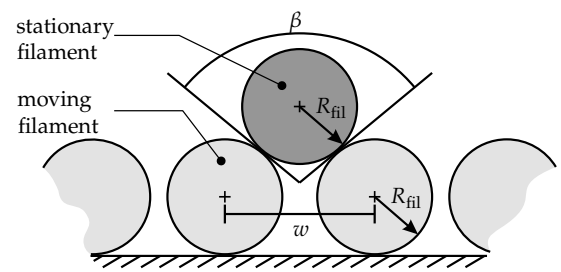

Figure 2.11 Digging in of filaments during parallel tow-tow friction measurements caused an increase in the contact area between the filaments (with the filament radius $R$ and a wedge angle $\beta$ that follows from the filament spacing $w$ ).

stationary tow specimen were digging in to the tow of the moving counterface layer.

The amount of digging in, also called wedging, is determined by the angle $\beta$ between the contacting filaments depicted in Figure 2.11. Assuming a close packing of the filaments with radius $R_{\text {fil }}$ in the interface of the moving and stationary tows, hence the filament spacing term $w=2 R_{\text {fil }}$, a hexagonal packing of the filaments is the only stable solution. This results in a wedge angle $\beta=$ $120^{\circ}$.

If we consider the contact for a virtual capstan experiment between two filaments only, digging in cannot take place and the observed apparent coefficient of friction for the filament loads $t_{1}$ and $t_{2}$ is:

$$
\mu_{\text {fil-fil, app }}=\ln \left(\frac{t_{2}}{t_{1}}\right) \frac{1}{\theta} .
$$

For the tow-tow contact situation, the hexagonal packing leads to an increase in the outgoing tension $t_{2}$ of an individual filament, analogous to the v-belt equation [28]:

$$
t_{2}=t_{1} \exp \left(\theta \mu_{\text {fil-fil, app }}\right) \sin ^{-1}\left(\frac{\beta}{2}\right) .
$$

Hence, for the tow-tow contact with the hexagonal packing of filaments the observed tow-tow coefficient of friction becomes (for a tow wrapping angle $\theta=$ $\pi)$ :

$$
\mu_{\text {tow-tow, app }}=\ln \left(\frac{T_{2}}{T_{1}}\right) \frac{1}{\pi}=1.15 \mu_{\text {fil-fil, app }}
$$

were $T_{1}$ and $T_{2}$ denote the measured tow end forces.

Lateral displacement of the filaments (and thus an increase of $w$ ) in the moving 
tow will lead to a smaller value of $\beta$ and a further increased value of $\mu_{\text {tow-tow, app. }}$ The measured coefficient of friction thus increases with the amount of digging in.

This mesoscopic analysis (based on simple Coulomb friction) implies that towtow friction in the filament direction is higher than in non-aligned tow-tow configurations and is also higher than the friction between two individual filaments. Indeed, in accordance with major trend 2 in Section 2.5.2, the results in Figure 2.5 show that the parallel orientation leads to higher values of the apparent coefficient of friction, with the desized C12k carbon tows as the only exception with virtually equal values for the different tow orientations.

\section{Pressure dependency}

The capstan measurements of tow-metal contact for different load cases showed that apparent coefficient of friction (based on Coulomb friction) decreased with increasing normal load on the tow. This implies a pressure dependency of the developed frictional force $F_{\mathrm{f}}$ on the capstan friction drums.

The measured ingoing and outgoing tow end loads $T_{1, \exp }$ and $T_{2, \exp }$, respectively, were used for a nonlinear least-squares fitting procedure, according to the more accurate Howell power-law relation of Equation (2.2). Table 2.4 shows the measured tow end forces and the equivalent normal contact forces of the tow on the friction drum. The fitting data are the averages of five measurements for the $300 \mathrm{~g}$ and $500 \mathrm{~g}$ load cases. For the pre-tensioned load case, the tow end forces of the individual measurements were used as input for the fitting procedure, due to variations of the ingoing loads.

The power-law fit was obtained by performing a nonlinear least-squares fitting procedure, with the following minimisation procedure:

$$
\min \sum_{i} r_{i}^{2}=\min _{x} \sum_{i}\left(T_{2}^{i}\left(\mathbf{x}, T_{1, \exp }^{i}\right)-T_{2, \exp }^{i}\right)^{2},
$$

with the vector of residuals $\mathbf{r}$ and fitting coefficient vector $\mathbf{x}=[k, n]$.

The objective function for the tow end force $T_{2}$ is:

$$
T_{2}^{i}\left(\mathbf{x}, T_{1, \exp }^{i}\right)=T_{1, \exp }^{i}\left(1+(1-n) k \pi R^{1-n}\left(T_{1, \exp }^{i}\right)^{n-1}\right)^{1 /(1-n)} .
$$

Finally, the fitting procedure leads to a pressure dependent expression for the equivalent coefficient of friction:

$$
\mu_{\mathrm{equ}}=\frac{F_{\mathrm{f}}}{N}=k N^{n-1} .
$$


Table 2.4 Measurement data selection from the capstan experiments for least-squares fitting of the Howell power-law relation.

\begin{tabular}{lccccccc}
\hline Friction & Load & \multicolumn{2}{c}{ Tow end tension } & \multicolumn{2}{c}{ Equivalent Normal force } & \multicolumn{2}{c}{ Coulomb approx. } \\
interface & case & $T_{1, \exp }(\mathrm{N})$ & $T_{2, \exp }(\mathrm{N})$ & $N_{1}(\mathrm{~N} / \mathrm{m})$ & $N_{2}(\mathrm{~N} / \mathrm{m})$ & $\bar{N}(\mathrm{~N} / \mathrm{m})$ & $\mu_{\text {apparent }}$ \\
\hline \multirow{2}{*}{ C12k/Sized } & $a$ & 2.94 & 7.79 & 118 & 312 & 199 & 0.31 \\
smooth drum & $b$ & 4.91 & 12.21 & 196 & 488 & 321 & 0.29 \\
& $c$ & $8.3-9.1$ & $18.9-21.0$ & $332-364$ & $756-840$ & $516-569$ & 0.27 \\
C12k/Desized & $a$ & 2.94 & 4.84 & 118 & 194 & 153 & 0.16 \\
rough drum & $b$ & 4.91 & 7.69 & 196 & 308 & 248 & 0.14 \\
& $c$ & $10.4-15.5$ & $15.5-23.2$ & $416-620$ & $620-927$ & $511-763$ & 0.13 \\
Aramid/Sized & $a$ & 2.94 & 9.31 & 118 & 372 & 221 & 0.37 \\
smooth drum & $b$ & 4.91 & 14.47 & 196 & 579 & 354 & 0.34 \\
& $c$ & $7.5-8.0$ & $18.8-19.8$ & $300-320$ & $750-792$ & $488-521$ & 0.29 \\
\hline
\end{tabular}

Load cases a,b,c: a = 300 g, b=500 g dead weight; c = pre-tensioned; $\bar{N}=$ average equivalent normal force.

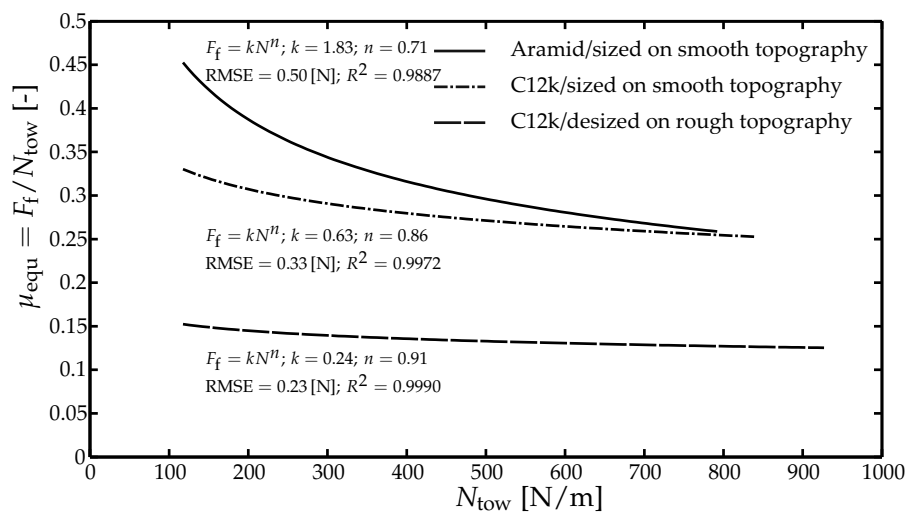

Figure 2.12 The power-law least-squares fits of the developed frictional force $F_{\mathrm{f}}$ as a function of the distributed normal force show the pressure dependency of sized/desized $C 12 k$ and sized aramid tows on the smooth and rough metal friction drums. The fitted power-law coefficients $k$ and $n$ are shown for each friction interface (RMSE: Root Mean Square Error of least-squares fit for the predicted outgoing tow end force $T_{2}, R^{2}$ : R-squared value based on linear regression theory). 
Figure 2.12 illustrates the effect of different tow materials and counterface surface topographies on the frictional behaviour. The plasticity index $n=$ 0.71 for aramid is close to $n=\frac{2}{3}$, which implies almost fully elastic deformation behaviour, whereas the values of 0.86 and 0.91 indicate elasticplastic deformations of the carbon tow material. For the carbon tow material, the surface topography appears to have a larger effect on the value of the proportionality constant $k$ than on the plasticity index $n$.

\subsection{Conclusions}

The frictional behaviour of high performance fibrous tows was characterised by means of a qualitative comparison of several material and experimental parameters.

Summarising the main trends for the tow-metal interfaces, we find:

\begin{tabular}{lc}
\hline Parameter & Relevance \\
\hline Surface topography & + \\
Presence/absence of siz- & - \\
ing & \\
Environmental humidity & $\circ$ \\
Load case & $\circ$ \\
\hline
\end{tabular}

The surface topography of the counterface is the main parameter affecting the frictional behaviour of tow-metal contact. The sizing on the carbon and aramid tows had a very limited influence on the observed friction. Measurements at different humidity levels on carbon tows showed that the sensitivity for towmetal contact was low for both sized and desized tows. The load case variations showed that the developed frictional force is pressure dependent, following a power-law behaviour.

Summarising the main trends for the tow-tow interfaces, we find:

\begin{tabular}{lc}
\hline Parameter & Relevance \\
\hline Relative tow orientation & + \\
Presence/absence of siz- & $\circ$ \\
ing & \\
Environmental humidity & $\circ$ \\
Load case & $\circ$ \\
\hline
\end{tabular}


The relative orientation of the tows on tow-tow contact is the dominant factor affecting the frictional behaviour. The lowest observed friction occurred for perpendicular tow orientation, a parallel orientation resulted in higher observed friction. The results showed large scatter for parallel tow-tow measurements of sized carbon and E-glass. The influence of humidity on carbon tow-tow friction was high for sized material, whereas the friction of desized carbon tows in direct contact remained unaffected. The observed friction of tow-tow contact varied with the load case; however, a clear trend was not found.

\section{References}

[1] N. Gralen. Friction between single fibres. Proc R Soc Lon Ser A, 212(1111):491-495, 1952.

[2] I.C. Roselman and D. Tabor. The friction of carbon fibres. J Phys D, 9(17):2517-2532, 1976.

[3] I.C. Roselman and D. Tabor. The friction and wear of individual carbon fibres. $J$ Phys D, 10(8):1181-1194, 1977.

[4] R.H.W. ten Thije, Finite element simulations of laminated composite forming processes. Ph.D. thesis, University of Twente, URL http://purl.utwente.nl/publications/57908., 2007.

[5] P. Boisse, B. Zouari, and A. Gasser. A mesoscopic approach for the simulation of woven fibre composite forming. Compos Sci Technol, 65(3-4):429-436, 2005.

[6] S.V. Lomov and I. Verpoest. Model of shear of woven fabric and parametric description of shear resistance of glass woven reinforcements. Compos Sci Technol, 66(7-8):919-933, 2006.

[7] R.H.W. ten Thije, R. Akkerman, L. van der Meer, and M. Ubbink. Tool-ply friction in thermoplastic composite forming. Int J Mater Form, 1(0):953-956, 2008.

[8] C. Rubenstein. Review on the factors influencing the friction of fibres, yarns and fabrics. Wear, 2(4):296-310, 1959.

[9] M.E. Yuksekkaya. More about fibre friction and its measurements. Text Prog, 41(3):141-193, 2009.

[10] B.J. Briscoe and F. Motamedi. Role of interfacial friction and lubrication in yarn and fabric mechanics. Text Res J, 60(12):697-708, 1990.

[11] C. Rubenstein. A general theory of the surface friction of solids. Proc Phys Soc B, 69(9):921-933, 1956.

[12] D. Tabor. Friction, lubrication and wear of synthetic fibres. Wear, 1(1):5-24, 1957.

[13] J.D. Huffington and H.P. Stout. The friction of fibre assemblies. Wear, 3(1):26-42, 1960.

[14] M.M. Robins, R.W. Rennell, and R.D. Arnell. The friction of polyester textile fibres. J Phys D, 17(7):1349-1360, 1984.

[15] I.F. Brown and C.J. Burgoyne. The friction and wear of kevlar 49 sliding against aluminium at low velocity under high contact pressures. Wear, 236(1-2):315-327, 1999. 
[16] J.D. Huffington. Internal friction in fibre assemblies. Br J Appl Phys, 12(3):99-102, 1961.

[17] N. Behary, A. Ghenaim, A. El Achari, and C. Caze. Tribological analysis of glass fibers using atomic force microscopy (afm)/lateral force microscopy (lfm). J Appl Polym Sci, 75(8):1013-1025, 2000.

[18] B.J. Briscoe and F. Motamedi. The ballistic impact characteristics of aramid fabrics: The influence of interface friction. Wear, 158(1-2):229-247, 1992.

[19] S. Rebouillat. Tribological properties of woven para-aramid fabrics and their constituent yarns. J Mater Sci, 33(13):3293-3301, 1998.

[20] X.S. Zeng, V.B.C. Tan, and V.P.W. Shim. Modelling inter-yarn friction in woven fabric armour. Int J Numer Methods Eng, 66(8):1309-1330, 2006.

[21] ASTM, D3108-07 standard test method for coefficient of friction - yarn to solid material, 2007.

[22] ASTM, D3412-07 standard test method for coefficient of friction - yarn to yarn, 2007.

[23] J.L. Thomason and L.J. Adzima. Sizing up the interphase: An insider's guide to the science of sizing. Compos Part A Appl Sci Manuf, 32(3-4):313-321, 2001.

[24] R. Plonka, E. Mäder, S.L. Gao, C. Bellmann, V. Dutschk, and S. Zhandarov. Adhesion of epoxy/glass fibre composites influenced by aging effects on sizings. Compos Part A Appl Sci Manuf, 35(10):1207-1216, 2004.

[25] C. Jia, P. Chen, B. Li, Q. Wang, C. Lu, and Q. Yu. Effects of twaron fiber surface treatment by air dielectric barrier discharge plasma on the interfacial adhesion in fiber reinforced composites. Surf Coat Technol, 204(21-22):3668-3675, 2010.

[26] Y. Luo, Y. Zhao, Y. Duan, and S. Du. Surface and wettability property analysis of CCF300 carbon fibers with different sizing or without sizing. Mater Design, 32(2):941-946, 2011.

[27] M.J. Adams, B.J. Briscoe, J.Y.C. Law, P.F. Luckham, and D.R. Williams. Influence of vapor condensation on the adhesion and friction of carbon-carbon nanocontacts. Langmuir, 17(22):6953-6960, 2001.

[28] A. van Beek. Advanced engineering design: Lifetime performance and reliability. TU Delft, 3rd edition, 2009. 



\title{
Chapter 3
}

\section{Frictional behaviour of high performance fibrous tows: A contact mechanics model of tow-metal friction ${ }^{1}$}

\begin{abstract}
Composites forming processes involve mechanical interactions on the ply, tow, and filament level. The deformations that occur during forming processes are governed by friction between tows and tooling material on the mesoscopic level and consequently between filaments and a counterface on the microscopic level. A thorough understanding of the frictional properties on the level of individual filaments is important to understand and predict the macroscopic deformations of a fabric during forming. The contact mechanics based friction model in this work confirms an experimentally observed decrease of frictional forces with an increasing roughness of the counterface. The developed model provides a qualitative understanding of the frictional behaviour of filaments on a cylindrical metal counterface.
\end{abstract}

\footnotetext{
${ }^{1}$ Reproduced from: B. Cornelissen, M.B. de Rooij, B. Rietman, R. Akkerman, Frictional behaviour of high performance fibrous tows: A contact mechanics model of tow-metal friction, Submitted to: Wear, 2012.
} 


\subsection{Introduction}

The mechanical properties of continuous fibre reinforced polymers or composite parts are determined to a large extent during the forming phase. Such composite parts consist of a thermosetting or thermoplastic matrix, which is reinforced with continuous fibrous tows that typically consist of several thousands of filaments. The continuous fibrous tows deform during the forming phase of production processes. They conform to the local shape of the tool surface on which the composite part is being manufactured. Local cross-sectional changes occur in the tow due to the induced loads. The tow orientation and filament distribution determine the mechanical properties of the composite part to a large extent. Knowledge of the tow orientation and tow deformation behaviour is therefore essential to control the desired product quality in terms of e.g. mechanical performance, dimensional accuracy and visual appearance.

Composite materials can be represented in a hierarchical structure. A classification is generally made in three scales, as illustrated in Figure 3.1: macro, meso and micro, to represent the composite laminate, tow and filament scale, respectively.

The hierarchical approach does not imply that deformation mechanisms are isolated on a single scale level. For example, filaments moving relatively to each other within a tow on the microscopic level will result in a change in crosssectional properties of the tow on the mesoscopic level. Meso- and macroscale effects are interrelated as well. An example is the formation of macroscopic wrinkles in a doubly curved rubber-pressed composite product. These wrinkles develop due to tow orientation-dependent inter-ply friction and shear on the mesoscopic level [1].

The deformations that occur in composites forming processes mainly result in compaction and shear loads, which both depend on the frictional behaviour of fibrous tows $[2,3]$. The deformations of the individual tows influence their crosssectional shape, which in turn has an effect on the formability of, for example, stacked plies of woven fabric. The macroscopic deformation behaviour of the composite part is thus determined by the individual tow properties.

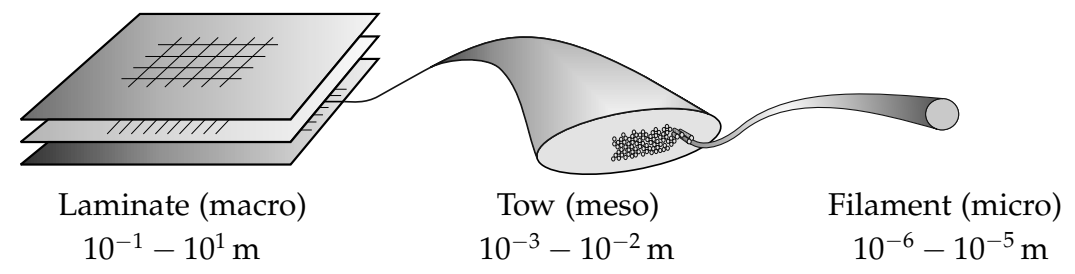

Figure 3.1 Hierarchical structure of composite materials with characteristic length scales. 


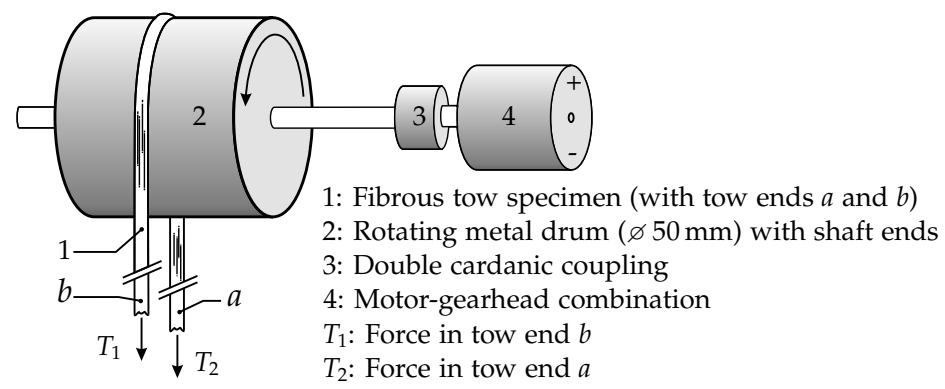

Figure 3.2 Schematic description of the capstan experiment for friction characterisation of fibrous tows.

The frictional behaviour of fibrous tows during processing typically involves intra-tow (on the microscopic filament scale), inter-tow, and tow-metal interactions. In the latter case, filaments are in sliding contact with the counterface of the metal tooling material during forming processes. This work deals with the dry frictional behaviour of the tow-metal system.

Capstan experiments on carbon, aramid and E-glass tows showed that the measured coefficient of friction between a fibrous tow specimen and a metal counterface varied strongly with the surface topography of the metal surface [4] (Chapter 2). The experiment consisted of measuring forces in the ends of fibrous tow specimens while wrapped around a rotating friction drum, as illustrated in Figure 3.2.

To date, little work has been done to provide an approach to relate the material behaviour on the microscopic scale to that on the macroscopic scale. Here, the frictional properties of fibrous tows are examined on the combined micro and mesoscopic scale, with the aim of providing a relation between the micro, meso and macroscopic frictional behaviour. This relation is based on a theoretical understanding of the frictional behaviour of fibrous tows. With this modelling effort, we aim to support the experimental findings in a qualitative manner [4] (Chapter 2).

Section 3.2 presents a theoretical model to predict the frictional forces as a function of the applied normal load on the tows. The model results are presented in Section 3.3 and subsequently discussed and compared with the outcome of the tow friction experiments in Section 3.4.

\subsection{Contact mechanics model}

Here, an analytical contact mechanics modelling approach is proposed to describe the frictional behaviour of fibrous tows in contact with a metal 
counterface. After the relevant contact loads in the system have been determined, the proposed model consists of a two-step process to determine the contact area between filaments and the counterface.

First, a nominal contact between a filament and the counterface is calculated with Hertzian contact assumptions. In this step of the process nominal contact refers to the contact for a counterface microgeometry that is assumed to be perfectly flat in this first step of the process.

Secondly, the real area of contact, i.e. now including the surface topography of the counterface microgeometry, is calculated with either a Hertzian or a MaugisDugdale (MD) approach [5, 6]. The latter approach includes the effect of adhesion of filaments in contact with the metal counterface. The effect of adhesion on the real contact area depends on the surface energy of the contacting materials, their elastic properties and the geometry of the contacting bodies. The contribution of adhesion effects to the contact is expected to be significant, based on the small diameter of the filaments and their transverse elastic properties.

The proposed contact model assumes that there are no irregularities on the filament surfaces, but takes the characteristics of the surface topography of the metal counterface into account by means of a statistical multi-asperity approach [7-9]. The assumption regarding the filament surfaces is allowed, because the dimensions of the irregularities on the filament surface are at least an order of magnitude lower than those of the metal counterface topographies. In addition, the filaments are soft compared to the metal counterfaces, i.e. any irregularities are expected to conform easily to the hard metal counterface microgeometry.

\subsubsection{Scope of the modelling approach}

The contact mechanics approach of tow deformation behaviour is based on the relation between the developed friction and the applied pressure on a filament. The area of contact between the filament and the metal counterface is load dependent. This in turn results in a load dependency of the frictional force between the tow and the counterface represented by the empirical Howell relation [10]:

$$
F_{\mathrm{f}}=k N^{n}
$$

where $N$ is the applied normal load on the contacting body (in this case a tow that consists of many filaments). Gupta and Mogahzy gave the empirical fitting parameters $k$ and $n$ a theoretical background [11, 12]. The index $n$ is governed by the (visco)elastic properties of the junctions in the contacting asperities under compression. The value of $k$ is determined by chemical, physical and morphological properties of the filament material and the filament-counterface contact dimensions. 


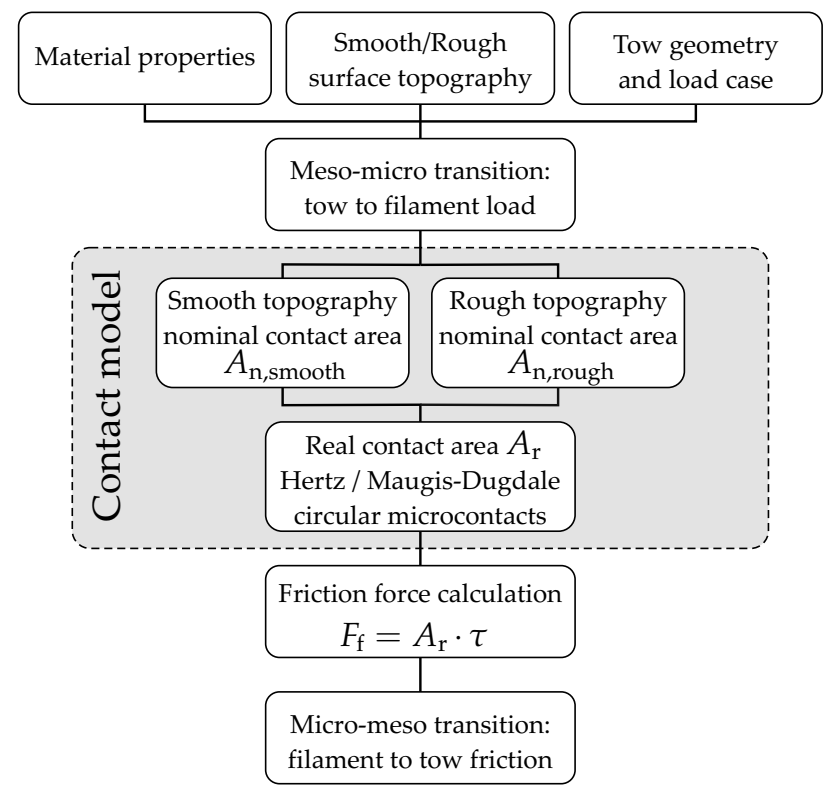

Figure 3.3 Schematic illustration of the contact mechanics modelling approach to describe the frictional behaviour of fibrous tows contacting a metal counterface.

Roselman and Tabor stated that the frictional force $F_{\mathrm{f}}$ is determined by the product of the interfacial shear strength $\tau$ of the contacting materials with the real contact area $A_{\mathrm{r}}$ between them and a ploughing term represented by $P[13,14]$ :

$$
F_{\mathrm{f}}=A_{\mathrm{r}} \tau+P .
$$

The ploughing component $P$ of adhesive friction in Equation (3.2) is expected to play a minor role in the system under consideration and is therefore omitted in the current model. This is supported by the observation that after more than 100 measurements with carbon fibre tows of which the properties are stated in Table 3.2, the drum surface appeared unaffected [4] (Section 2.5). Deposit of carbon on the drum surface was not observed, suggesting that neither of the materials had an abrasive effect on the other. This observation was also reported by Roselman and Tabor for a similar type of carbon filaments [14].

Furthermore, the slenderness of filaments leads to a relatively low bending stiffness, which leads to good conformation of filaments to the counterface asperities, thereby minimising ploughing effects. Only the E-glass filaments showed mildly abrasive behaviour on the smooth counterface.

The strong dependence of the measured coefficient of friction on the surface 


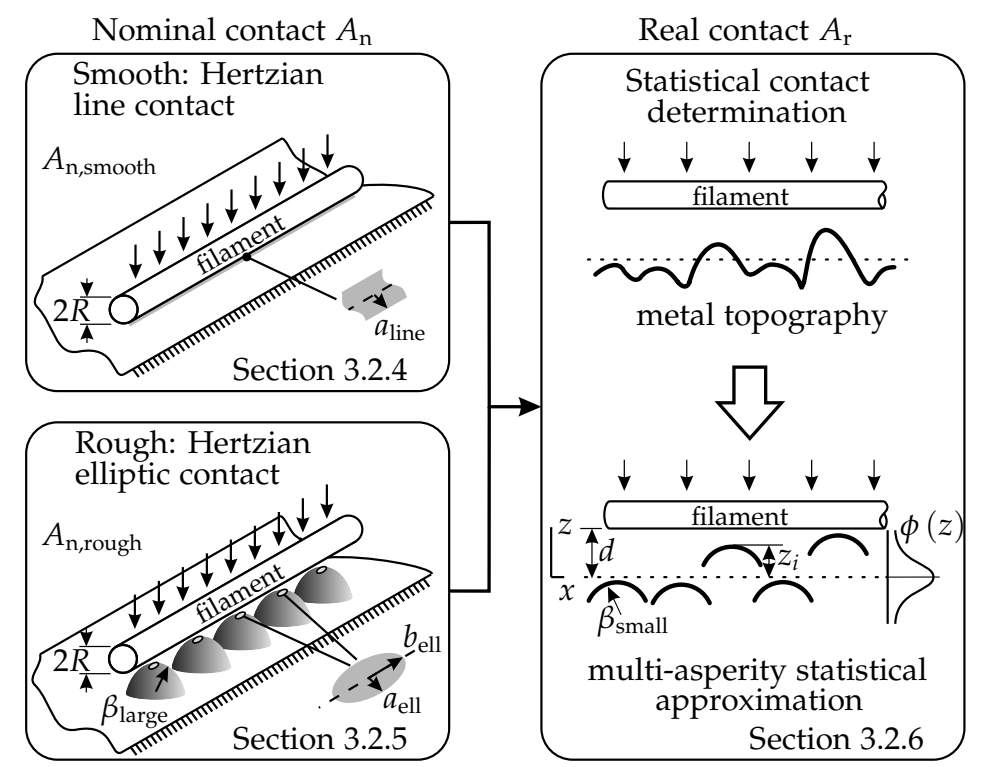

Figure 3.4 Overview of the analytical-statistical determination of the real contact area between a filament and a metal counterface. The nominal contact area dimensions are represented by either the contact half-width $a_{\mathrm{line}}$ or the ellipse semi-axis dimensions $a_{\mathrm{ell}}$ and $b_{\mathrm{ell}}$. The parameters for the statistical topography approximation are: the separation distance $d_{i}$, the relative asperity height $z_{i}$, the average asperity radius of curvature $\beta$ and the Gaussian distribution function of asperity heights $\phi(z)$.

topography was characterised for single carbon filaments by Roselman and Tabor [14]. More specifically, these authors found friction coefficients for carbon filaments on stainless steel (EN58B/1.4541) that showed up to three times higher values for a low surface roughness. The lowest surface roughness was $0.01 \mu \mathrm{m}$ $\mathrm{Ra}$ (arithmetical mean deviation), the highest Ra roughness value was $0.95 \mu \mathrm{m}$. The authors explained this phenomenon from a surface topography perspective. The real contact area of a filament on the drum with a low roughness is larger than that of the drum with a high roughness at equal load.

The real contact area $A_{\mathrm{r}}$ between a filament and the metal counterface is required to describe the frictional behaviour of the tow, based on Equation (3.2). Figure 3.3 outlines the proposed modelling procedure to determine this real contact area of fibrous tows on a metal counterface. Figure 3.4 gives a detailed overview of the analytical-statistical contact model procedure in the grey area of Figure 3.3. A detailed description of the contact area determination for a given load is given in Sections 3.2.4 to 3.2.6. 


\subsubsection{From tow to filament load}

The typical compressive load acting on a single filament is derived from experimental results, obtained from a capstan friction experiment [4]. Figure 3.2 gives a schematic illustration of the experiment. A fibrous tow was draped on a metal friction drum, with a known wrapping angle $\theta_{\text {wrap }}=\pi$ (for E-glass tows $\theta_{\text {wrap }}=0.5 \pi$ ). The tensile tow end loads $T_{1}$ at $\theta_{1}=0$ and $T_{2}$ at $\theta_{2}=\theta_{\text {wrap }}$ were measured during rotation of the friction drum. An apparent coefficient of friction $\mu_{\mathrm{app}}$ can be obtained from the basic capstan relation:

$$
\mu_{\mathrm{app}}=\ln \left(\frac{T_{2}}{T_{1}}\right) \frac{1}{\theta_{\mathrm{wrap}}} .
$$

Amontons' law is the main underlying assumption in the capstan equation, stating that the frictional force $F_{\mathrm{f}}$ between the tow and the friction drum is directly proportional to the normal load $N(\theta)$ exerted on the tow by the friction drum:

$$
F_{\mathrm{f}}=\mu_{\mathrm{app}} N(\theta)
$$

The tensile tow load $T(\theta)$ at any arbitrary angle $\theta$ follows from the known ingoing tensile load $T_{1}$ and the apparent coefficient of friction given by Equation (3.3):

$$
T(\theta)=T_{1} \exp \left(\mu_{\mathrm{app}} \theta\right) .
$$

The estimation of $T(\theta)$ in Equation (3.5) assumes Coulomb friction $\left(F_{\mathrm{f}}=\right.$ $\left.\mu_{\text {app }} N\right)$, although a non-Coulomb type of behaviour for tow friction was mentioned before in Section 3.2, Equation (3.1). The main reason for the use of Equation (3.5) is that the load range in which the individual capstan measurements took place was relatively small and thus the difference between the uniform apparent coefficient of friction $\mu_{\mathrm{app}}$ and the Howell behaviour of Equation (3.1) is relatively small as well.

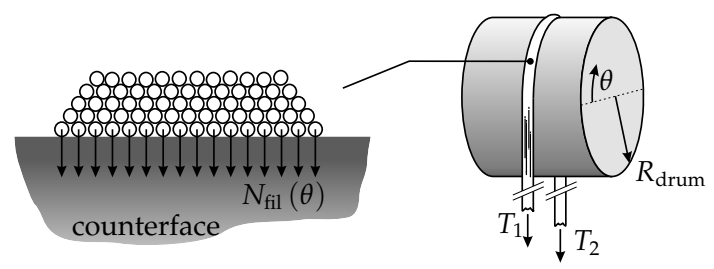

Figure 3.5 Averaged normal load distribution on the contacting filaments of the tow in contact with the metal counterface (cross-sectional view of the tow). 
The distributed normal load $N_{\text {tow }}$ in the contact between the tow and the metal counterface follows directly from load equilibrium of an infinitesimal part of the tow on the drum:

$$
N_{\text {tow }}(\theta)=\frac{T_{\text {tow }}(\theta)}{R_{\text {drum }}} .
$$

Finally, an estimation of the number of filaments in direct contact with the metal counterface is required to calculate the compressive load per contacting filament $N_{\text {fil }}(\theta)$. Assuming a close packing of filaments, the compressive load is transferred from one layer of filaments to the layer beneath. The bottom layer of filaments, i.e. the layer in direct contact with the counterface, transfers the accumulated normal load, as illustrated in Figure 3.5. The amount of contacting filaments $n_{\text {fil }}$ for each tow material was estimated for both counterfaces, based on observations during capstan experiments [4]. The average, first order approximated compressive load $N_{\text {fil }}(\theta)$ carried by a single filament as a function of the angular drum coordinate $\theta$ then becomes:

$$
N_{\text {fil }}(\theta)=\frac{N_{\text {tow }}(\theta)}{n_{\text {fil }}}
$$

Here, $N_{\text {fil }}(\theta)$ and $N_{\text {tow }}(\theta)$ are distributed normal loads, in $N / m$ arc length of contacting filament and tow, respectively. The real area of contact between filaments and the counterface follows from the contact mechanics analysis for the derived compressive load and the surface topographies of the contacting bodies.

\subsubsection{Counterface topographies}

The experimental friction results from the capstan measurements showed that the outgoing tow end force $T_{2}$ varies with the topographical properties of the counterface material [4]. The counterface microgeometry characteristics strongly affected the measured apparent coefficient of friction. Therefore, these characteristics need to be included in the proposed modelling approach. Two different surface microgeometries or topographies were used to measure the frictional behaviour of the fibrous tows. Figure 3.6 represents both topographies, which are denoted smooth and rough, according to their typical texture.

Different approaches exist for the representation of an arbitrary surface topography. When measuring the surface roughness, the result typically depends on the scale at which the roughness measurement took place $[9,15,16]$. The sampling interval of a typical roughness measurement must be small enough to detect asperities in the range of the desired accuracy, which is two orders of magnitude smaller than the typical filament diameter of $10 \mu \mathrm{m}$ 

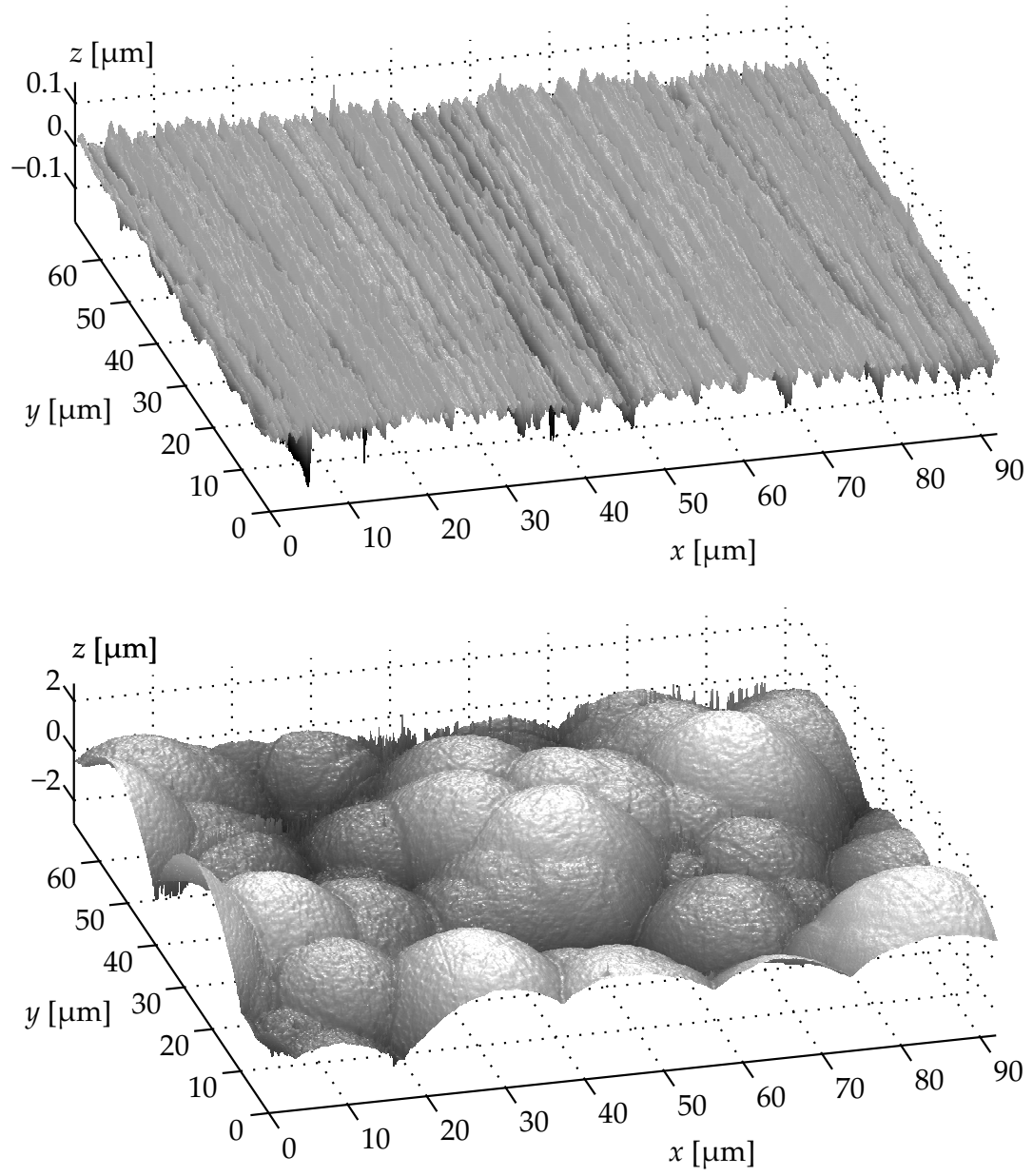

Figure 3.6 Laser confocal images $(92 \times 69 \mu \mathrm{m})$ of the metal friction drum surface topographies (magnification $150 \times ; 1$ pixel represents $0.045 \times 0.045 \mu \mathrm{m}$ ). Top: Smooth topography. Bottom: Rough topography. The $z$-scale is magnified with respect to the $x$-and $y$-scale. Note the vertical scales of the surface plots, illustrating the difference in roughness scales between the two topographies. 
Table 3.1 Topography properties of the smooth and rough metal friction drum topographies. The topography properties were based on manual asperity selection in laser confocal microscopy images.

\begin{tabular}{lcccc}
\hline Description & Symbol & Unit & Smooth & Rough \\
\hline Small asperity density & $\eta_{\text {small }}$ & $10^{10} \mathrm{~m}^{-2}$ & 74 & 150 \\
Small asperity radius & $\beta_{\text {small }}$ & $\mu \mathrm{m}$ & 13.95 & 2.25 \\
Small asperity height deviation & $\sigma_{\text {small }}$ & $\mu \mathrm{m}$ & 0.020 & 0.016 \\
Large asperity density & $\eta_{\text {large }}$ & $10^{10} \mathrm{~m}^{-2}$ & - & 0.05 \\
Large asperity radius & $\beta_{\text {large }}$ & $\mu \mathrm{m}$ & - & 40 \\
\hline
\end{tabular}

[17]. The surface topographies were measured by means of a Keyence VK9710 laser confocal microscope to obtain the required detail of the topography. Subsequently, a statistical description of the counterface topographies is a practical and straightforward approach for contact modelling purposes $[7,8,17]$.

In this statistical approach a Gaussian distribution $\phi(z)$ of asperity heights is assumed with a standard deviation $\sigma$ equal to the $\mathrm{Rq}$ (root mean square) roughness of the topography. As a first approximation, the asperities were assumed to have a spherical tip, with a constant radius of curvature $\beta$. The asperity density $\eta$ gives a measure of the amount of asperities per unit area.

The smooth topography is characterised by a single set of parameters, $\eta_{\text {small }}, \beta_{\text {small }}, \sigma_{\text {small }}$, given in Table 3.1. The rough topography is characterised by assuming the surface consists of a landscape of large asperities with superimposed smaller asperities [7]. The large asperities have an average radius of curvature $\beta_{\text {large }}$ and an asperity density $\eta_{\text {large, }}$, the superimposed asperities have properties $\beta_{\text {small }}, \eta_{\text {small }}$ and $\sigma_{\text {small }}$ (see Table 3.1 ). The large asperity heights are considered equal for modelling purposes, therefore $\sigma_{\text {large }}=0$.

The surface topography properties, presented in Table 3.1, were obtained by manually selecting equivalent asperities from the laser confocal microscopy data as shown in Figure 3.6. This manual procedure allowed for selection of equivalent asperities instead of summits, where a summit is regarded as a point higher than its immediate neighbours and not necessarily representing an asperity [9].

The topography properties were obtained from ten equally spaced profiles each in the $x$ - and $y$-direction of the confocal measurements shown in Figure 3.6. The large asperity radii were determined from the profile by 3-point arc fitting, as illustrated in Figure 3.7. Subsequently, a polynomial fit through the large asperities was subtracted from the measured profile, and the small asperities were manually selected from the resulting profile, again by 3-point arc fitting.

Figure 3.8 shows a typical statistical analysis of the counterface topography

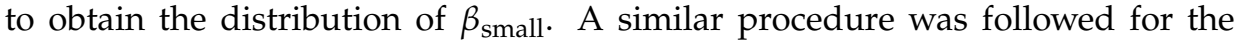




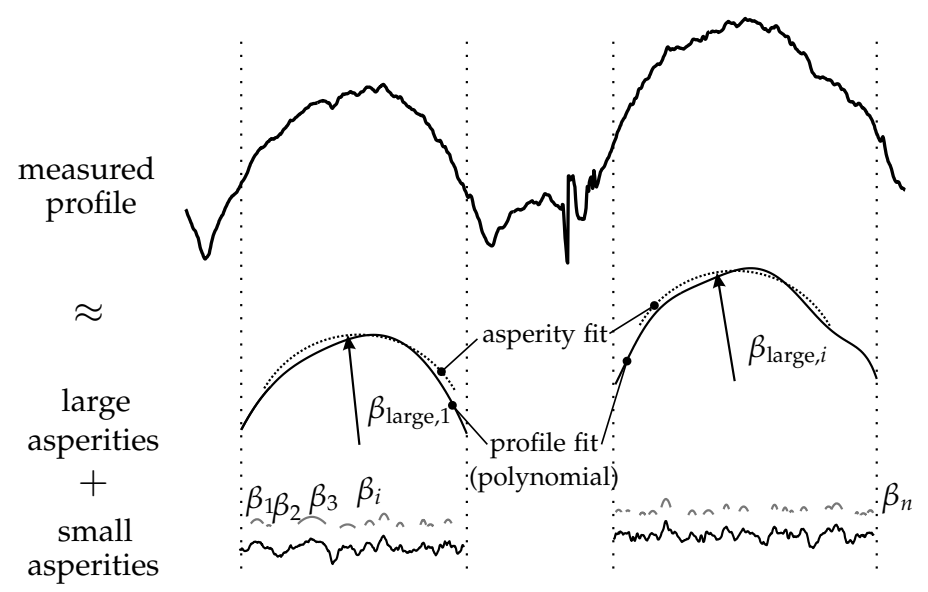

Figure 3.7 The rough topography is modelled by superimposing small asperities with an average radius of curvature $\beta_{\text {small }}$ on large asperities with a radius of curvature $\beta_{\text {large }}$. The asperities on both levels were selected manually.

smooth topography, however, the obtained mean $x$ - and y-radii were $3.84 \mu \mathrm{m}$ and $50.64 \mu \mathrm{m}$, respectively. The smooth topography is thus anisotropic, as can be clearly seen in Figure 3.6. Nevertheless, even non-isotropic topographies can be represented relatively well by an isotropic Rayleigh distribution of asperity radii, as described by Greenwood [17]. In the case of the smooth and rough topographies, a log-normal distribution was fitted to the manually determined small asperity radii. This fit appeared to represent the measurements better than the expected Rayleigh distribution, however, the differences were small. The actual averages $\beta_{\mathrm{x}}, \beta_{\mathrm{y}}$ of the measurements were used for the model calculations. The mean and standard deviation values of the distribution fits were only used to determine the most representative distribution type.

An isotropic description of the average small asperity radius for both topographies was obtained by averaging the radii in the $\mathrm{x}$ - and $\mathrm{y}$-direction:

$$
\beta_{\text {small }}=\sqrt{\left|\beta_{\mathrm{x}}\right| \cdot\left|\beta_{\mathrm{y}}\right|},
$$

leading to the values listed in Table 3.1.

Figure 3.7 illustrates the approximation procedure to obtain the small and large asperity radii for the rough topography $\beta_{\text {small }}$ and $\beta_{\text {large, }}$ respectively.

The contact mechanics model presented in this work is similar to the deformation model of Greenwood and Tripp [8], who also considered two length scales to model contact deformation. The present model is based on the assumptions of Greenwood and Williamson [7]: all deformations are elastic, the contact areas are assumed independent of surface tractions, asperities do not 


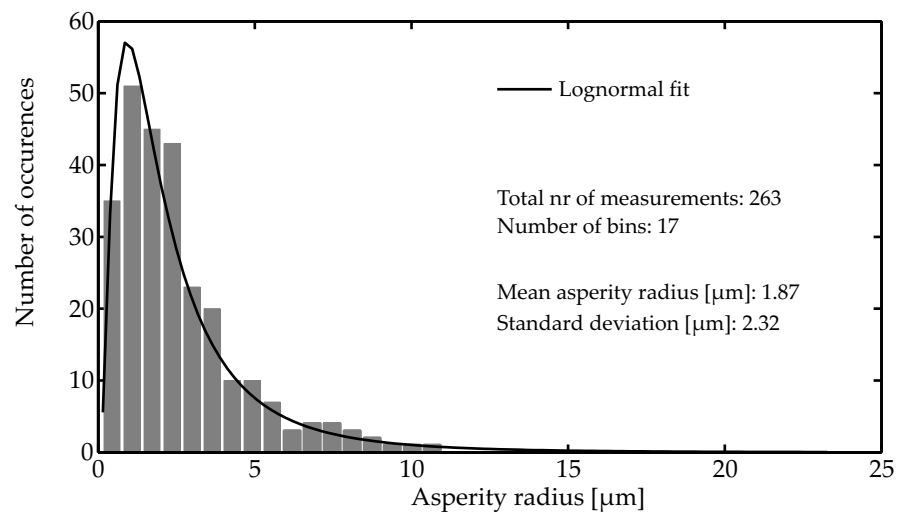

Figure 3.8 Lognormal fit of manually selected small asperities in the $x$-direction of the rough topography confocal measurement (comparable results in y-direction: 320 measurements, mean radius $=1.37 \mu \mathrm{m}$, standard deviation $=2.47 \mu \mathrm{m})$.

Table 3.2 Manufacturer (M) and literature data of the fibrous tow materials used in the contact model. The distributed normal filament load range corresponds to the tests reported in [4].

\begin{tabular}{|c|c|c|c|c|c|c|}
\hline Description & Symbol & Unit & Carbon & Aramid & E-glass & Ref. \\
\hline Density & $\rho$ & $\mathrm{kg} / \mathrm{m}^{3}$ & 1780 & 1440 & 2600 & M \\
\hline Filament radius & $R_{\text {fil }}$ & $\mu \mathrm{m}$ & 3.5 & 6.1 & 7.0 & [18], M \\
\hline Normal filament load & $N_{\text {fil }}$ & $\mathrm{N} / \mathrm{m}$ & & $10-$ & 1.0 & \\
\hline Axial elastic modulus & $E_{\text {axial }}$ & GPa & 230 & 75 & 73 & [4] \\
\hline Transverse elastic modulus & $E_{\text {trans }}$ & GPa & 15 & 1.6 & 73 & [19], M \\
\hline $\begin{array}{l}\text { Transverse Poisson } \\
\text { coefficient }\end{array}$ & $v$ & - & 0.445 & 0.445 & 0.18 & [18], M \\
\hline $\begin{array}{l}\text { Interatomic / } \\
\text { intermolecular spacing }\end{array}$ & $z_{0}$ & $\AA$ & 1.54 & 7.90 & 2.00 & {$[20,21]$} \\
\hline $\begin{array}{l}\text { Work of adhesion } \\
\text { filament-metal }\end{array}$ & $w$ & $\mathrm{~mJ} / \mathrm{m}^{2}$ & & 100 & & [22] \\
\hline
\end{tabular}

interact with each other, the asperities have spherical tips with an equal radius of curvature, and the asperity heights follow a Gaussian distribution. As already mentioned in Section 3.2, the filaments that contact the metal counterfaces are assumed to have a negligible roughness compared to the metal counterfaces.

\subsubsection{Nominal contact area - smooth topography}

The nominal contact area $A_{\mathrm{n}}$ of a filament on the smooth topography is calculated by assuming a Hertzian contact between the cylindrically shaped filament and the metal counterfaces. For the smooth topography, this area is formed by a line contact, assuming both the filament and the counterface are perfectly smooth bodies in this first step of the procedure (the small asperity 
properties are not yet taken into account):

$$
a_{\text {line }}=\left(\frac{4 N_{\mathrm{fil}} R_{\mathrm{m}}}{\pi E^{\star}}\right)^{1 / 2},
$$

where $a_{\text {line }}$ is the half-width of contact and $N_{\text {fil }}$ represents the distributed normal filament load (Figure 3.4). The mean effective radius of curvature $R_{\mathrm{m}}$ is:

$$
R_{\mathrm{m}}=\left(\frac{1}{R_{1 \mathrm{x}}}+\frac{1}{R_{1 \mathrm{y}}}+\frac{1}{R_{2 \mathrm{x}}}+\frac{1}{R_{2 \mathrm{y}}}\right)^{-1},
$$

with the filament radius of curvature in transverse direction $R_{1 \mathrm{x}}=R_{\text {filament }}$, in axial direction $R_{1 \mathrm{y}}=\infty$ and the counterface is represented by a flat surface, so $R_{2 \mathrm{x}}=R_{2 \mathrm{y}}=\infty$, and thus $R_{\mathrm{m}}=R_{\mathrm{fil}}$.

The equivalent Young's modulus $E^{\star}$ is defined as:

$$
E^{\star}=\left(\frac{1-v_{1}^{2}}{E_{1}}+\frac{1-v_{2}^{2}}{E_{2}}\right)^{-1},
$$

with the filament properties $v_{1}, E_{1}$ listed in Table 3.2 as $E_{\text {trans }}$ and $v$ for various materials. For the metal counterface, the transverse Poisson coefficient $v_{2}=0.30$ and the Young's modulus $E_{2}=210 \mathrm{GPa}$.

From Equation (3.9) the nominal contact area $A_{\mathrm{n}}=2 a_{\text {line }}$ per unit filament length (unit $\mathrm{m}^{2} / \mathrm{m}$ ). The nominal contact area for a smooth contact is proportional to the square-root of the distributed normal load:

$$
A_{\mathrm{n}, \mathrm{smooth}} \propto N_{\text {fil }}^{1 / 2}
$$

where $N_{\text {fil }}$ is the applied load on the filament contacting the smooth topography.

\subsubsection{Nominal contact area - rough topography}

The nominal contact area for the rough topography is derived in a different manner. Due to the large asperities with dimensions in the range of the filament radius, the nominal contact is formed by several large elliptic contacts, as illustrated in Figure 3.4. The total nominal contact area $A_{n}$ is a summation of the large asperity contact areas, which were obtained with the simplified case of the Hertzian elliptic contact calculation for the contact between a sphere and a cylinder with aligned principal axes [23, 24]. The derivation of the elliptic contact area is presented in Appendix 3.B. A single filament of one metre length contacts approximately $2.36 \cdot 10^{4}$ asperities, based on the manual analysis of the confocal microscopy images of the rough topography. Since the contact area per 
large asperity is uniform for a given distributed normal load $N_{\text {fil }}(\theta)$, the nominal contact area per metre filament length on the rough topography is:

$$
A_{\mathrm{n}, \mathrm{rough}}=n_{\mathrm{asp}} A_{\mathrm{asp}}=2.36 \cdot 10^{4} \cdot \pi a_{\mathrm{ell}} b_{\mathrm{ell}},
$$

with $n_{\text {asp }}$ being the number of contacting large asperities per metre filament length. The elliptic contact area is denoted by the semi-minor radius $a_{\text {ell }}$ and the semi-major radius $b_{\text {ell }}$, as illustrated in Figure 3.4.

The normal load in unit $\mathrm{N}$ on each asperity becomes:

$$
N_{\text {asp }}(\theta)=\frac{N_{\text {fil }}(\theta)}{n_{\text {asp }}},
$$

where $N_{\text {asp }}(\theta)$ is in unit $\mathrm{N}$ and $N_{\text {fil }}(\theta)$ in unit $\mathrm{N} / \mathrm{m}$. For the sum of the large elliptic contacts $A_{\mathrm{asp}}$, the nominal contact area $A_{\mathrm{n}, \text { rough }}=\sum_{i=1}^{n} A_{\mathrm{asp}, i}$ between a filament and the rough topography has the following non-linear relation with the distributed normal load filament load $N_{\text {fil }}(\theta)$ (see Equation (3B.2) for the derivation):

$$
A_{\text {n,rough }} \propto N_{\text {fil }}^{2 / 3} \text {. }
$$

Note the difference in proportionality between the smooth and rough surface in Equation (3.12) and Equation (3.15), respectively. The nominal contact areas for both topographies form the basis for the real contact area calculation.

\subsubsection{Real contact area - smooth and rough topography}

The real area of contact $A_{\mathrm{r}}$ within the nominal contact area $A_{\mathrm{n}}$ is determined by the distribution of micro asperity heights with the standard deviation $\sigma_{\text {small }}$, the average asperity density $\eta_{\mathrm{small}}$ and the average asperity radius of curvature $\beta_{\text {small }}$. The real contact area $A_{\mathrm{r}}$ increases with increasing load and thus a decreasing separation distance $d$ of the surfaces, as illustrated in Figure 3.4.

The real area of contact $A_{\mathrm{r}}$ is a function of the probability of an asperity contacting the approaching reference surface, which is the filament surface. The radius of curvature of the filament is assumed to be very large compared to the contact area dimensions and therefore the filament surface is approximated by a flat surface, as illustrated in Figure 3.9. As the separation distance $d$ decreases, the supported load and the real contact area increase [7]:

$$
A_{\mathrm{r}}=\pi A_{\mathrm{n}} \eta_{\mathrm{small}} \beta_{\text {small }} \int_{d}^{\infty}(z-d) \phi(z) d z
$$

where $\phi(z)$ is the normal probability density function of the distribution of 


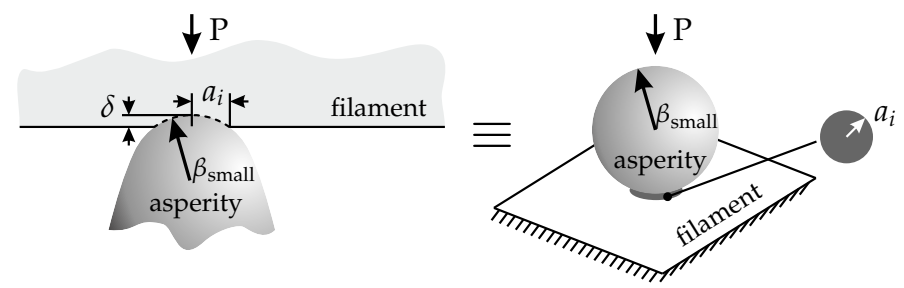

Figure 3.9 The analogy of the contact between a small individual asperity and the contacting filament under a compressive load $P$ is that of a rigid sphere on an elastic half plane. The asperity is assumed to have a spherical tip with a constant radius of curvature $\beta_{\text {small. }}$. The resulting contact is circular with the contact radius $a_{i}$.

asperity heights with $\sigma=\sigma_{\text {small }}[7,23]$ :

$$
\phi(z)=\frac{1}{\sigma \sqrt{2 \pi}} \exp \left(\frac{-z^{2}}{2 \sigma^{2}}\right) .
$$

Upon loading, the asperities of the metal counterface are pressed into the filament by a distance $\delta_{i}=z_{i}-d$ causing microcontacts, as illustrated in Figure 3.9. The sum of the individual microcontacts then represents the real contact area between a filament and the metal counterface:

$$
A_{\mathrm{r}, \text { total }}=\sum_{i=1}^{n} A_{i},
$$

where $n$ denotes the number of microcontacts with their individual contact area $A_{i}=\pi \beta_{\text {small }} \delta_{i}$. The real contact area is a fraction of the nominal contact area within the applied load range, which is listed in Table 3.2. The separation distance $d$ was incrementally decreased until the supported load was in equilibrium with the applied load.

Adhesion between the filaments and the counterface results in a non-zero real contact area $A_{\mathrm{r}}>0$ without externally applied load. In addition to the Hertzian procedure, the Maugis-Dugdale approach was used to calculate the real contact area taking into account adhesion effects [25]. Appendix 3.C shows the system of equations that was solved numerically to obtain the microcontact radius $a_{\mathrm{MD}}$ of the small asperities with the contacting filament, taking adhesion effects into account. The statistical procedure is analogous to that of Equation (3.16). The radius of influence of attraction $c_{\mathrm{MD}}$ is only a few percent larger than $a_{\mathrm{MD}}$ and is assumed not to contribute to the adhesive friction, since intimate contact is required. 


\subsection{Results}

The contact mechanics model provides the real area of contact for the smooth and rough topographies for three different filament materials: carbon, aramid and E-glass. Furthermore, the contribution of adhesion to the contact area was addressed. Figures 3.10 and 3.11 illustrate the relation between the distributed normal filament load and the resulting real contact area. The results are presented per topography, where Figure 3.10 shows the real contact area for the smooth topography and Figure 3.11 for the rough topography. The relevant properties for the contact calculations were stated previously in Tables 3.1 and 3.2 in Section 3.2.3 and Section 3.2.4, respectively.

The real contact area $A_{\mathrm{r}}$ for all filament materials is larger for the smooth topography than for the rough topography. The ratios of the rough and smooth topography real contact area $A_{\mathrm{r} \text { rough }} / A_{\mathrm{r}, \mathrm{smooth}}$ are nearly constant for all materials for the Hertz regime, i.e. roughly $30-35 \%$ (variations with $N_{\text {fil }}$ occur). The ratios for the areas taking the adhesion effects into account (MD regime) are for carbon $\approx 27 \%$, for aramid $\approx 17 \%$, and for E-glass $\approx 30 \%$.These ratios apply for $N_{\text {fil }}=0.10-1.0 \mathrm{~N} / \mathrm{m}$. Section 3.4 provides an interpretation of these model predictions.

\subsection{Discussion}

The predicted values for the real contact area, combined with the friction interface properties, give a measure of the tow-metal friction. This section addresses the interfacial properties, a model validation by means of comparison with experimental results and the practical interpretation of the obtained results.

\subsubsection{Interfacial properties}

As illustrated in Figures 3.10 and 3.11, the Maugis-Dugdale (MD) calculations indicate that the adhesion effects are minimal for E-glass filaments on the metal counterfaces and the contribution of adhesion to the friction of aramid is highest of the three materials under consideration. This is directly related to the contact area, which is highest for aramid.

The work of adhesion $w$ in the friction interface is an important parameter in the MD calculations. An attempt was made to measure the surface free energy of the individual carbon, aramid and E-glass filaments using wetting measurements by means of the Wilhelmy method [26, 27]. Although the measured properties of, for example, carbon filaments were comparable with the literature [28, 29], their reliability was low. The small diameter of the filaments resulted in wetting forces 


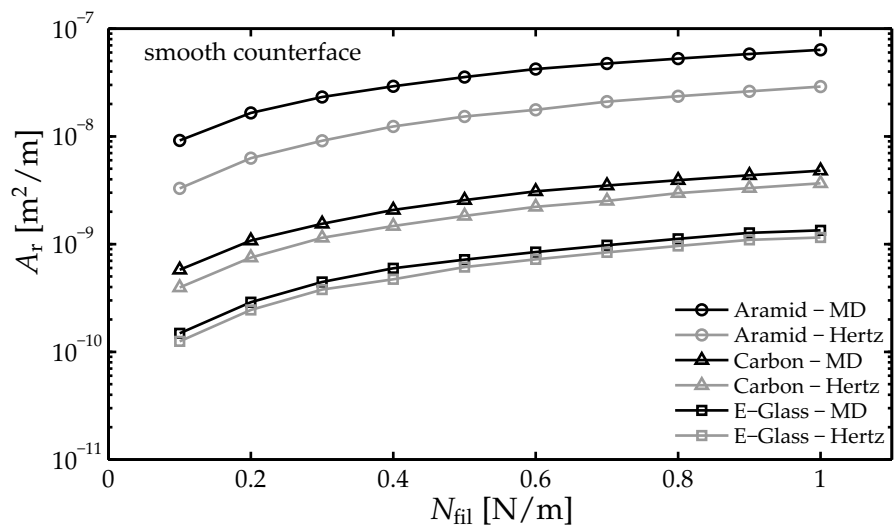

Figure 3.10 Real contact area $A_{\mathrm{r}}$ of a filament on the smooth topography as a function of the distributed normal filament load for carbon, aramid and E-glass filaments. With adhesion $\left(M D, w=100 \mathrm{~mJ} / \mathrm{m}^{2}\right)$ and without adhesion (Hertz).

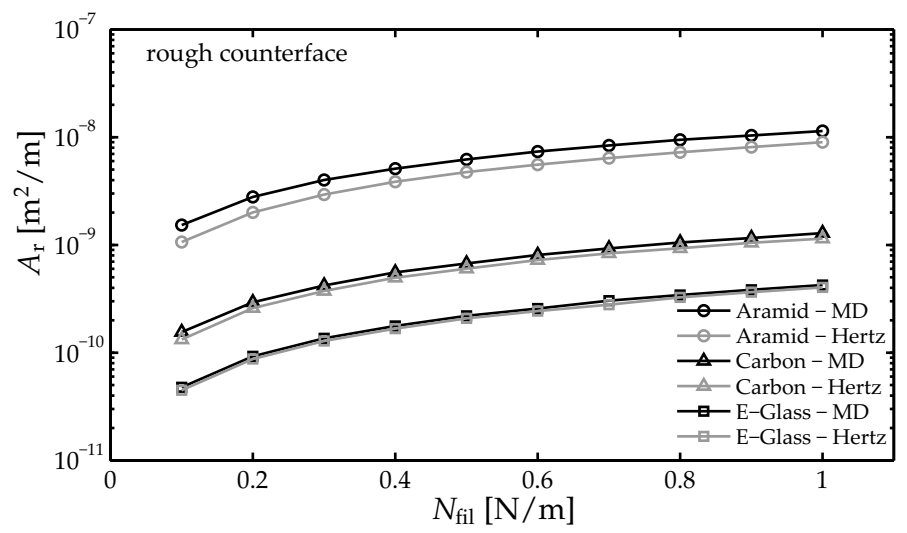

Figure 3.11 Real contact area $A_{\mathrm{r}}$ of a filament on the rough topography as a function of the distributed normal filament load for carbon, aramid and E-glass filaments. With adhesion $\left(M D, w=100 \mathrm{~mJ} / \mathrm{m}^{2}\right)$ and without adhesion (Hertz). 
within the measurement accuracy range of the testing equipment itself and thus high deviations from the mean of the measured forces.

Instead, the work of adhesion between the metal counterface and the various filament materials was approximated by assuming the work of adhesion is dominated by Van der Waals-interactions of contaminated surfaces in air [30-32]. The results presented in Figures 3.10 and 3.11 were calculated using an estimated value of the work of adhesion $w=100 \mathrm{~mJ} / \mathrm{m}^{2}[29,33]$.

The interfacial shear strength $\tau$ is an important parameter for the frictional force prediction. To the author's knowledge, accurate measurements of interfacial shear strengths for the discussed system have not been published yet. In this model, an educated guess was made for the range of $\tau$ values. For example, values found in literature range from $20 \mathrm{MPa}$ to $100 \mathrm{MPa}$ for carbon fibre tows sliding against different counterfaces $[14,34]$. An even higher theoretical upper bound value is $600 \mathrm{MPa}$, which is the basal plane shear strength of graphite crystals. The softer aramid filaments are expected to have a significantly smaller value of $\tau$ than the carbon filaments, whereas the interfacial shear strength for E-glass on metal is likely to be higher, based on the fact that high frictional forces were observed in the friction experiments despite the low contact areas for both topographies.

\subsubsection{Comparison with experimental results}

The model predictions can be related to the experimental observations by comparing the measured frictional force $F_{\mathrm{f}}=T_{2}-T_{1}$ with a frictional force prediction based on Equation (3.2).

The normal loads on the filaments derived in Section 3.2.2 were used to predict the frictional force for a small arc length segment $\Delta s=\Delta \theta R_{\text {drum }}$ of the filaments on the counterface:

$$
\Delta F_{\mathrm{f}}=k N(\theta)^{n}
$$

where the power-law parameters $k$ and $n$ were estimated from the statistical contact model results by means of a least-squares procedure. The total frictional force along the wrapped length of the filament was obtained by summation of the segment frictional forces from Equation (3.19).

Figure 3.12 shows the results of this comparison for various values of the interfacial shear strength $\tau$, both with (MD) and without (Hertz) the contribution of adhesion between the filaments and the counterface. The graphs in Figure 3.12 show that the predicted frictional force mainly depends on the interfacial shear strength parameter $\tau$. Here, we assume that the parameter is interface specific, but independent of the surface topography. As a consequence, the same value of $\tau$ should be used for both the smooth and rough topographies. Compared 
smooth topography
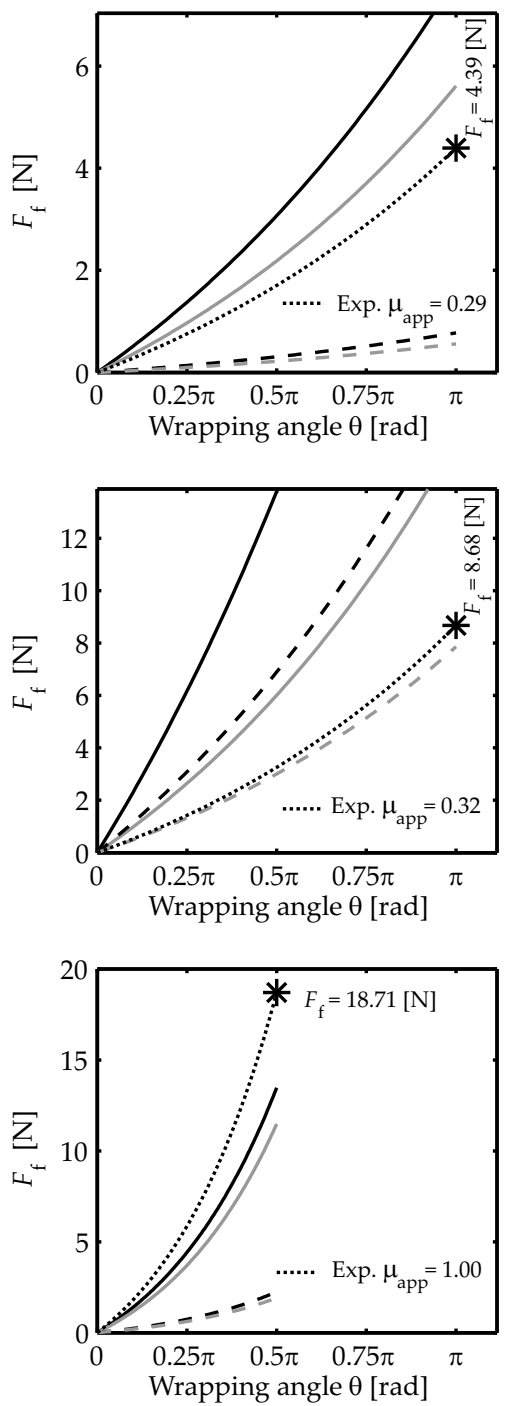

rough topography
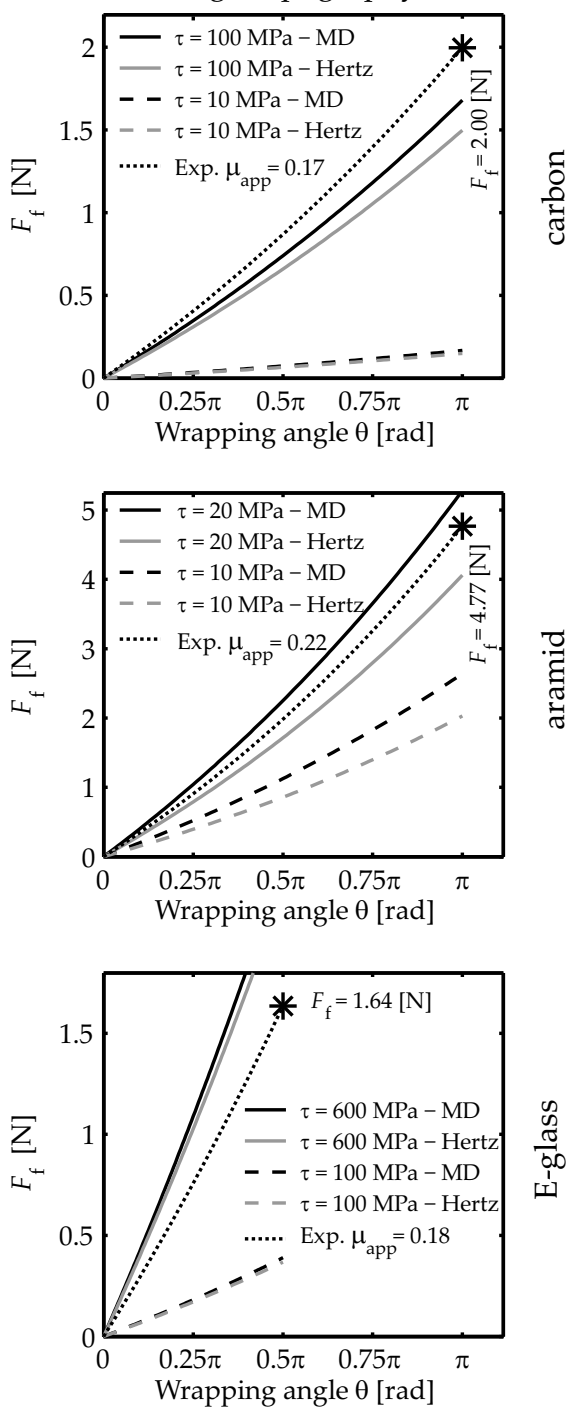

Figure 3.12 Predicted frictional force $F_{\mathrm{f}}$ as a function of the wrapping angle on the capstan setup for various $\tau$ values. The star-symbol indicates the measured force in the experiment; the dotted line shows the calculated frictional force based on Equation (3.5) with $\mu_{\mathrm{app}}$. Top left: Carbon tow on smooth topography, $300 \mathrm{~g}$ dead weight. Top right: Carbon tow on rough topography, $300 \mathrm{~g}$ dead weight $\left(T_{1}=2.94 \mathrm{~N}\right)$. Middle left: Aramid tow on smooth topography, $500 \mathrm{~g}$ dead weight. Middle right: Aramid tow on rough topography, $500 \mathrm{~g}$ dead weight $\left(T_{1}=4.91 \mathrm{~N}\right)$ Bottom left: E-glass tow on smooth topography, $500 \mathrm{~g}$ dead weight. Bottom right: E-glass tow on rough topography, $500 \mathrm{~g}$ dead weight $\left(T_{1}=4.91 \mathrm{~N}\right)$. 
to the experimental frictional force, the value of $\tau=100 \mathrm{MPa}$ for carbon filaments appears to give a reasonable frictional force estimate for both the smooth and rough topographies. The frictional force for the smooth topography is overestimated, whereas that for the rough topography is underestimated.

The frictional force predictions for aramid tow material show that the adhesion effects have a strong contribution to the frictional force for the smooth topography. The value of $\tau=20 \mathrm{MPa}$ required to obtain the measured friction is significantly lower than for the carbon tows, as expected. Again, the frictional forces for the smooth topography were generally overestimated and those for the rough topography were generally underestimated. The high sensitivity to the $\tau$ parameter of the aramid filaments is related to the low transverse elastic modulus of the material, resulting in a relatively large deformation compared to the carbon and E-glass filaments.

Finally, the predictions for E-glass tow material compare reasonably well to the measured frictional force. For this material, the differences between the two topographies are relatively large, more than a factor ten. For E-glass, the frictional force on the smooth topography is underestimated, whereas the value for the rough topography was slightly overestimated.

However, drawing firm conclusions based on these results is not possible. This is mainly caused by the fact that both the interfacial shear strength and the work of adhesion parameters are only known by approximation. Nevertheless, the fact that qualitative agreement was reached shows that the physical background of the frictional behaviour of fibrous tows on a metal counterface provides a good basis for further work.

\subsubsection{Practical value}

With the proposed modelling approach it is possible to provide theoretical support for the experimentally observed frictional behaviour of several fibrous tow materials. However, a large experimental effort would be required to achieve better quantitative accuracy of the work of adhesion and interfacial shear strength properties.

This work rather shows the physical properties that determine the frictional behaviour of fibrous tows. The proposed model is of practical use for those who aim to improve the reliability of their production process. For example, during the transport of fibrous tows in production, the friction between the tows and guiding rings can be minimised by decreasing the real contact area. At the same time, the local stresses in the filaments should not exceed the critical value as a result of increased normal loads on the filaments.

Furthermore, tool-ply (where the ply consists of fibrous tows) forming simulations based on the finite element method (FEM) can be performed more accurately when taking the pressure and counterface-dependent frictional 
behaviour of the tows into account. The presented model provides the physical relations that are necessary for a more accurate calculation of frictional forces in the FEM simulation. Together with tow-tow contact models, a complete toolply and ply-ply forming simulation of dry fibrous materials with increased accuracy would be possible. The contact mechanics-based modelling of tow-tow interactions is part of Chapter 4 of this thesis.

\subsection{Conclusions}

A contact mechanics approach that accounts for variations in metal counterface topographies for filament contact has been developed. A qualitative agreement was found between the model and observations from a capstan experiment. The model is sensitive to the interfacial shear strength as well as to adhesional properties of the materials. However, more precise data are required to increase the accuracy of the model predictions. The statistical representation of the counterface topographies can further improve the model accuracy, for instance, by accounting for height variations of large asperities in the case of topographies with superimposed roughness levels. The current approach assumes an equal height for all these large asperities.

The proposed model provides a physically sound understanding of the friction between tows and a metal counterface. The mesoscopic frictional behaviour of fibrous tows was explained by taking microscopic characteristics of the constituents into account.

\section{References}

[1] R.H.W. ten Thije and R. Akkerman. A multi-layer triangular membrane finite element for the forming simulation of laminated composites. Compos Part A Appl Sci Manuf, 40(6-7):739-753, 2009.

[2] P. Boisse, B. Zouari, and A. Gasser. A mesoscopic approach for the simulation of woven fibre composite forming. Compos Sci Technol, 65(3-4):429-436, 2005.

[3] S.V. Lomov and I. Verpoest. Model of shear of woven fabric and parametric description of shear resistance of glass woven reinforcements. Compos Sci Technol, 66(7-8):919-933, 2006.

[4] B. Cornelissen, B. Rietman, and R. Akkerman. Frictional behaviour of high performance fibrous tows: Friction experiments. Compos Part A Appl Sci Manuf, 44:95-104, 2013.

[5] K.L. Johnson and J.A. Greenwood. An adhesion map for the contact of elastic spheres. J Colloid Interface Sci, 192(2):326-333, 1997.

[6] E. Barthel. Adhesive elastic contacts: JKR and more. J Phys D, 41(16):1-20, 2008. 
[7] J.A. Greenwood and J. B. P. Williamson. The contact of nominally flat surfaces. Proc R Soc Lon Ser A, 295(1442):300-319, 1966.

[8] J. A. Greenwood and J. H. Tripp. The elastic contact of rough spheres. J Appl Mech, 34(1):153-159, 1967.

[9] J.A. Greenwood and J.J. Wu. Surface roughness and contact: An apology. Meccanica, 36(6):617-630, 2001.

[10] H.G. Howell and J. Mazur. Amontons' law and fibre friction. J Text Inst Trans, 44(2):T59-T69, 1953.

[11] B.S. Gupta and Y.E. El Mogahzy. Friction in fibrous materials. Part I: Structural model. Text Res J, 61(9):547-555, 1991.

[12] Y.E. El Mogahzy and B.S. Gupta. Friction in fibrous materials. Part II: Experimental study of the effects of structural and morphological factors. Text Res J, 63(4):219-230, 1993.

[13] I.C. Roselman and D. Tabor. The friction of carbon fibres. J Phys D, 9(17):2517-2532, 1976.

[14] I.C. Roselman and D. Tabor. The friction and wear of individual carbon fibres. J Phys D, 10(8):1181-1194, 1977.

[15] J. F. Archard. Elastic deformation and the laws of friction. Proc R Soc Lon Ser A, 243(1233):190-205, 1957.

[16] M. Benz, K.J. Rosenberg, E.J. Kramer, and J.N. Israelachvili. The deformation and adhesion of randomly rough and patterned surfaces. J Phys Chem B, 110(24):11884-11893, 2006.

[17] J.A. Greenwood. Unified theory of surface roughness. Proc $R$ Soc Lon Ser A, 393(1804):133-157, 1984.

[18] M. Ueda and T. Takiguchi. Measurement of transverse Young's modulus of carbon fibres by angular characteristics of ultrasonic scattering. In: Proceedings of the IEEE 1990 Ultrasonics Symposium. volume 2, 1081-1085, Publ by IEEE, Honolulu, HI, USA, 1990.

[19] R. Maurin, P. Davies, N. Baral, and C. Baley. Transverse properties of carbon fibres by nano-indentation and micro-mechanics. Appl Compos Mater, 15(2):61-73, 2008.

[20] J.F. Shackelford. Introduction to materials science for engineers. Prentice-Hall, 4th edition, 1996.

[21] M.G. Northolt and J.J. van Aartsen. On the crystal and molecular structure of poly-(p-phenylene terephthalamide). J Polym Sci B Polym Lett Ed, 11(5):333-337, 1973.

[22] J.N. Israelachvili. Intermolecular and surface forces. 3rd ed. Academic Press, 3rd edition, 2011.

[23] K.L. Johnson. Contact Mechanics. Cambridge University Press, 9th print edition, 1985.

[24] H. Moes. Lubrication and beyond. University of Twente, 2000. URL http://www.utwente.nl/ctw/tr/Research/Publications/Books/, Retrieved 11 Sept. 2012.

[25] D. Maugis. Adhesion of spheres: The JKR-DMT transition using a Dugdale model. J Colloid Interface Sci, 150(1):243-269, 1992. 
[26] C.A. Fuentes, L.Q.N. Tran, C. Dupont-Gillain, W. Vanderlinden, S. De Feyter, A.W. Van Vuure, and I. Verpoest. Wetting behaviour and surface properties of technical bamboo fibres. Colloids Surf A Physicochem Eng Asp, 380(1-3):89-99, 2011.

[27] L.Q.N. Tran, C.A. Fuentes, C. Dupont-Gillain, A.W. Van Vuure, and I. Verpoest. Wetting analysis and surface characterisation of coir fibres used as reinforcement for composites. Colloids Surf A Physicochem Eng Asp, 377(1-3):251-260, 2011.

[28] N. Dilsiz and J. P. Wightman. Surface analysis of unsized and sized carbon fibers. Carbon, 37(7):1105-1114, 1999.

[29] Y. Luo, Y. Zhao, Y. Duan, and S. Du. Surface and wettability property analysis of CCF300 carbon fibers with different sizing or without sizing. Mater Design, 32(2):941-946, 2011.

[30] K.N.G. Fuller and D. Tabor. The effect of surface roughness on the adhesion of elastic solids. Proc R Soc Lon Ser A, 345:327-342, 1975.

[31] K. Kendall. Molecular adhesion and its applications. Kluwer Academic / Plenum Publishers, New York, 2001.

[32] B.N.J. Persson, O. Albohr, U. Tartaglino, A.I. Volokitin, and E. Tosatti. On the nature of surface roughness with application to contact mechanics, sealing, rubber friction and adhesion. J Phys Condens Matter, 17(1):R1-R62, 2005.

[33] S. Zhang, M. Zhang, and K. Li. Adhesion force between aramid fibre and aramid fibrid by AFM. Polym Bull, 66(3):351-362, 2011.

[34] M.J. Adams, B.J. Briscoe, J.Y.C. Law, P.F. Luckham, and D.R. Williams. Influence of vapor condensation on the adhesion and friction of carbon-carbon nanocontacts. Langmuir, 17(22):6953-6960, 2001. 


\section{A Appendix: Derivation of the normal tow load}

Figure 3A.1 depicts the loads on a small part of the tensioned wrapped tow on the counterface. The normal load in unit $\mathrm{N}$ is expressed as the product of the normal stress component $\sigma$ with the projected area formed by $t R_{\text {drum }} d \theta$, where $t$ is the local tow width and $R_{\text {drum }} d \theta$ is the arc length of the tow section. The vertical force equilibrium $\Sigma F_{\mathrm{y}}=0$ in the tow section then yields:

$$
\sigma t R_{\text {drum }} d \theta-T(\theta+d \theta) \sin \left(\frac{d \theta}{2}\right)-T(\theta) \sin \left(\frac{d \theta}{2}\right)=0
$$

The term $\sin (d \theta / 2) \approx d \theta / 2$ for infinitesimally small $d \theta$. Likewise, $d T$ is small, so $T(\theta+d \theta) \approx T(\theta)$. Then, the following equilibrium exists:

$$
\sigma t R_{\mathrm{drum}} d \theta=2 T(\theta) \frac{d \theta}{2}
$$

Bringing the arc length $R_{\text {drum }} d \theta$ to the right-hand side of Equation (3A.2) gives the distributed normal load $N_{\text {tow }}(\theta)=\sigma t$ in unit $\mathrm{N} / \mathrm{m}$ arc length:

$$
N_{\text {tow }}(\theta)=\frac{T(\theta)}{R_{\text {drum }}}
$$

Thus, the local distributed normal load on the wrapped tow was derived using the tensile load in the tow and the capstan drum geometry.

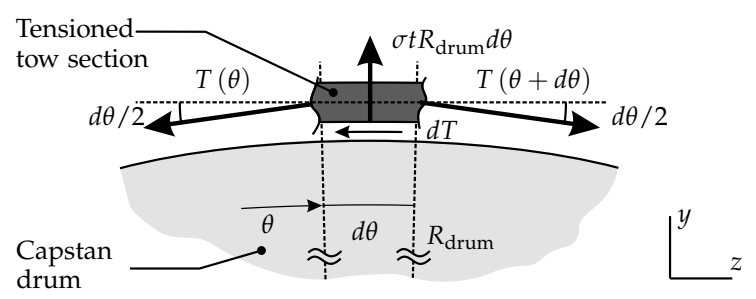

Figure 3A.1 Schematic illustration of the tow contact on the capstan friction drum.

\section{B Appendix: Simplified elliptic elastic contact - Hertz}

The contact between a cylindrical filament and the large asperities of the rough topography yields elliptical contact areas. The contact analogy is that of a cylinder and a sphere [23]. Then, the solution of the simplified Hertzian elliptic contact problem proposed by Reussner and reproduced by Moes [24] can be applied. 
The variables for the calculations are: the filament radii of curvature $R_{1 x}=R_{\text {fill }}$, $R_{1 y}=\infty$; the large asperity radii of curvature $R_{2 x}=R_{2 y}=\beta_{\text {large, }}$, the reduced modulus $E^{\star}$ and the normal load per large asperity $N_{\text {asp. }}$. The mean effective radius of curvature $R_{m}$ of the two contacting bodies is defined as:

$$
R_{m}=\left(\frac{1}{R_{1 \mathrm{x}}}+\frac{1}{R_{1 \mathrm{y}}}+\frac{1}{R_{2 \mathrm{x}}}+\frac{1}{R_{2 \mathrm{y}}}\right)^{-1}
$$

The normal approach $\delta$ and the semi-minor radius $a_{\text {ell }}$ and semi-major radius $b_{\text {ell }}$ of the elliptic contact area are:

$$
\begin{aligned}
a_{\mathrm{ell}} & =\alpha\left(\frac{3 N_{\mathrm{asp}} R_{\mathrm{m}}}{2 E^{\star}}\right)^{1 / 3}, \\
b_{\mathrm{ell}} & =\beta\left(\frac{3 N_{\mathrm{asp}} R_{\mathrm{m}}}{2 E^{\star}}\right)^{1 / 3}, \\
\delta & =\gamma\left(\frac{9 N_{\mathrm{asp}}^{2}}{32 E^{\star 2} R_{\mathrm{m}}}\right)^{1 / 3},
\end{aligned}
$$

where $\alpha, \beta$ and $\gamma$ in Equation (3B.3) are dimensionless quantities, which yield unity for a circular contact, represented by

$$
\begin{aligned}
& \alpha=\kappa^{1 / 3}\left[\frac{2}{\pi} \mathbf{E}(m)\right]^{1 / 3}, \\
& \beta=\kappa^{-2 / 3}\left[\frac{2}{\pi} \mathbf{E}(m)\right]^{1 / 3}, \\
& \gamma=\kappa^{2 / 3}\left[\frac{2}{\pi} \mathbf{E}(m)\right]^{-1 / 3} \frac{2}{\pi} \mathbf{K}(m) .
\end{aligned}
$$

The ellipticity ratio $\kappa=a_{\mathrm{ell}} / b_{\mathrm{ell}}$ for $a_{\mathrm{ell}}<b_{\mathrm{ell}}$ is approximated by:

$$
\begin{aligned}
& \kappa \approx\left[1+\sqrt{\frac{\ln 16 / \zeta}{2 \zeta}}-\sqrt{\ln 4}+0.16 \ln \zeta\right]^{-1}, \\
& \zeta=\frac{R_{x}}{R_{y}} \text { with } 0<\zeta \leq 1,
\end{aligned}
$$

where the first and second principal radii of curvature $R_{\mathrm{x}}$ and $R_{\mathrm{y}}$, respectively, 
are:

$$
\begin{aligned}
& R_{\mathrm{x}}=\left(\frac{1}{R_{1 \mathrm{x}}}+\frac{1}{R_{2 \mathrm{x}}}\right)^{-1}, \\
& R_{\mathrm{y}}=\left(\frac{1}{R_{1 \mathrm{y}}}+\frac{1}{R_{2 \mathrm{y}}}\right)^{-1} .
\end{aligned}
$$

The complete elliptic integrals of the first and second kind $\mathbf{K}(m)$ and $\mathbf{E}(m)$, respectively, were approximated by Reussner and presented in the work of Moes [24]:

$$
\begin{aligned}
\mathbf{K}(m) \approx & \frac{\pi}{2}(m-1)\left[1+\frac{2 m}{\pi(1-m)} \ln \left(\frac{4}{\sqrt{1-m}}\right)\right. \\
& \left.-\frac{3}{8} \ln (1-m)\right], \\
\mathbf{E}(m) \approx & \frac{\pi}{2}(m-1)\left[1+\frac{2 m}{\pi(1-m)}-\frac{1}{8} \ln (1-m)\right],
\end{aligned}
$$

with $m=1-\kappa^{2} . \mathbf{K}(m)$ and $\mathbf{E}(m)$ were solved numerically using Matlab for verification. The variations with respect to the approximations in Eqs. (3B.6) and (3B.7) were within $0.25 \%$ of the numerically obtained values. Finally, the elliptic area of contact between the large asperity and the filament is:

$$
A_{\text {asp }}=\pi a_{\mathrm{ell}} b_{\mathrm{ell}}
$$

The sum of areas is then the nominal contact area between a cylindrical filament and the large asperities of a rough topography with superimposed microasperities.

\section{C Appendix: Maugis-Dugdale adhesive contact calcu- lations}

The reduced elasticity modulus $E^{\star}$ is defined as:

$$
E^{\star}=\left(\frac{1-v_{1}^{2}}{E_{1}}+\frac{1-v_{2}^{2}}{E_{2}}\right)^{-1}
$$

The following non-dimensional parameters are introduced to facilitate the 
contact calculations [5]:

$$
\begin{aligned}
& \bar{a} \equiv a_{\mathrm{MD}}\left(\frac{4 E^{\star}}{3 \pi w \beta_{\mathrm{small}}^{2}}\right)^{1 / 3}, \\
& \bar{c} \equiv c_{\mathrm{MD}}\left(\frac{4 E^{\star}}{3 \pi w \beta_{\mathrm{small}}^{2}}\right)^{1 / 3}, \\
& \bar{\delta} \equiv \delta_{\mathrm{MD}}\left(\frac{16 E^{\star 2}}{9 \pi^{2} w^{2} \beta_{\mathrm{small}}^{2}}\right)^{1 / 3}, \\
& \bar{P} \equiv \frac{N_{\mathrm{asp}}}{\pi w \beta_{\mathrm{small}}}
\end{aligned}
$$

where $w$ is the work of adhesion listed in Table 3.2 and $N_{\text {asp }}$ represents the asperity contact load in unit N. The parameter $\lambda$ is defined as [5]:

$$
\lambda \equiv\left(\frac{w}{0.97 z_{0}}\right)\left(\frac{9 \beta_{\text {small }}}{2 \pi w E^{\star 2}}\right)^{1 / 3},
$$

where the maximum attractive force $\sigma_{0}=w /\left(0.97 z_{0}\right)$ and $z_{0}$ is the interatomic or intermolecular equilibrium spacing [5].

The following non-linear system of equations is solved numerically to obtain the contact parameters being the dimensionless intimate contact radius $\bar{a}$ and the dimensionless radius of adhesion $\bar{c}$, respectively, with $m=c_{\mathrm{MD}} / a_{\mathrm{MD}}[5,25]$ :

$$
\begin{aligned}
& \frac{\lambda \bar{a}^{2}}{2}\left[\left(m^{2}-2\right) \arccos \left(\frac{1}{m}\right)+\sqrt{m^{2}-1}\right] \\
& +\frac{4 \lambda^{2} \bar{a}}{3}\left[\sqrt{m^{2}-1} \arccos \left(\frac{1}{m}\right)-m+1\right]=1, \\
& \bar{\delta}=\bar{a}^{2}-\frac{4 \lambda \bar{a}}{3} \sqrt{m^{2}-1} \\
& \bar{P}=\bar{a}^{3}-\lambda \bar{a}^{2}\left[\sqrt{m^{2}-1}+m^{2} \arccos \left(\frac{1}{m}\right)\right] .
\end{aligned}
$$

The absolute dimension of the circular contact area $A_{\text {asp }}$ is then obtained from the radius of the contact area $a_{\mathrm{MD}}$ in Equation (3C.2):

$$
A_{\mathrm{asp}}=\pi a_{\mathrm{MD}}^{2}
$$





\title{
Chapter 4
}

\section{Frictional behaviour of carbon fibre tows: $A$ contact mechanics model of tow-tow friction ${ }^{1}$}

\begin{abstract}
Composites forming processes involve mechanical interactions on the ply, tow, and filament level. The deformations that occur during forming processes are governed by friction between the contacting tows on the mesoscopic level and consequently between filaments on the microscopic level. A thorough understanding of the frictional properties on the level of individual filaments is essential to understand and to predict the macroscopic deformations of a textile reinforcement during forming. This work presents a contact mechanics modelling approach to provide a theoretical background of the frictional behaviour of dry fibrous tows in contact with each other. The predicted friction behaviour is in qualitative and quantitative agreement with experimentally observed frictional forces of carbon fibre tows in sliding contact. The relative orientation of the contacting tows is of great importance for the developed frictional forces in the contact.
\end{abstract}

\footnotetext{
${ }^{1}$ Reproduced from: B. Cornelissen, M.B. de Rooij, B. Rietman, R. Akkerman, Frictional behaviour of carbon fibre tows: A contact mechanics model of tow-tow friction, Submitted to: Textile Research Journal, 2012.
} 


\subsection{Introduction}

High performance fibrous tows mainly find their application in structural composites, which consist of a thermoplastic or thermoset matrix and continuous fibrous tows for reinforcement. These continuous fibrous tows deform during the forming phase of production processes, for example when draping dry fabric prior to resin transfer moulding (RTM). The tows conform to the local shape of the tool surface on which the composite part is being manufactured. Usually several plies are used in a composite part, which leads to inter-tow contacts as well. Local cross-sectional changes occur in the tow due to the induced loads, which are mainly transferred in the form of friction. The tow orientation and the filament distribution affect the mechanical properties of the composite part to a large extent. Knowledge of the tow orientation and tow deformation behaviour is therefore essential to control the desired product quality in terms of e.g. mechanical performance, dimensional accuracy and visual appearance.

The frictional behaviour of fibrous tows during processing typically involves intra-tow (on the microscopic filament scale), inter-tow, and tow-metal interactions. This work deals with the frictional behaviour of the inter-tow system, i.e. the frictional behaviour of tow-tow contacts. The frictional behaviour for tow-metal contact was studied in Chapter 3.

Several researchers investigated the frictional behaviour of contacting fibrous tows [1-6]. These experiments were performed on different setup types for a variety of experimental parameters. Yuksekkaya provided an overview describing the majority of these experiments in 2009 [7].

Experimental work on the frictional behaviour of fibrous tows showed that interfilament friction and surface interactions determine the deformation behaviour

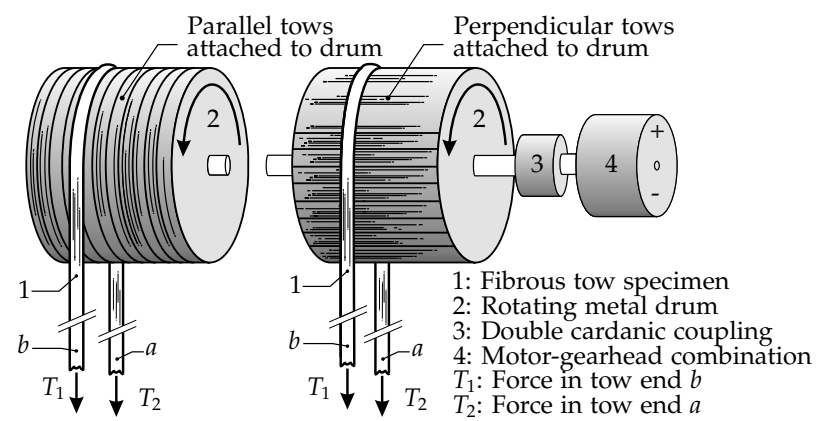

Figure 4.1 Schematic description of the capstan experiment for friction characterisation of fibrous tows. A tow specimen is wrapped around a friction drum on which tows of the same material are attached in either a parallel (left) or perpendicular (right) orientation. 
of the fibrous tows [8] (Chapter 2). Capstan experiments consisted of measuring forces in the ends of fibrous tow specimens wrapped around a rotating friction drum covered with fibrous tow material. This setup is schematically illustrated in Figure 4.1. The current work proposes a contact mechanics modelling approach of tow friction to provide a theoretical understanding of the observed behaviour.

A model for the contact mechanics of fibrous tows during forming is proposed in Section 4.2. The scope of the model and material properties are explained, followed by a derivation of typical loading conditions for tow material, based on a capstan friction experiment. Subsequently, a contact mechanics approach is proposed to determine the contact area for both perpendicular and parallel sliding tow contact. The effect of adhesion on the developed frictional force between tows in sliding contact is assessed as well. The model results are presented in Section 4.3, followed by a comparison with experimental data in Section 4.4 to validate the model.

\subsection{Contact mechanics modelling approach}

This section deals with the model assumptions and presents the contact mechanics approach of the contact area between tows in sliding contact.

\subsubsection{Scope of the modelling approach}

The contact mechanics approach of tow deformation behaviour is based on the relation between the exerted compressive load on sliding filaments in fibrous tows and the developed frictional force. The area of contact between the filament and the fibrous counterface is load dependent [9-11]. Consequently, this results in a load dependency of the frictional force between the tow and the counterface. Howell proposed the following empirical friction law [9]:

$$
F_{\mathrm{f}}=k N^{n},
$$

where $N$ is the applied normal load on the contacting body (in this case a tow that consists of many filaments). Gupta and Mogahzy gave the fitting parameters $k$ and $n$ a theoretical background [10,12]. The index $n$ is governed by the (visco)elastic properties of the junctions in the contacting asperities under compression or the shape of the pressure-area curve. The value of $k$ is determined by chemical, physical and morphological properties of the filament material and the filament-counterface contact dimensions.

Roselman and Tabor described the frictional behaviour of single carbon filaments in contact in the 70s $[13,14]$. The friction equation consists of a shear friction part 


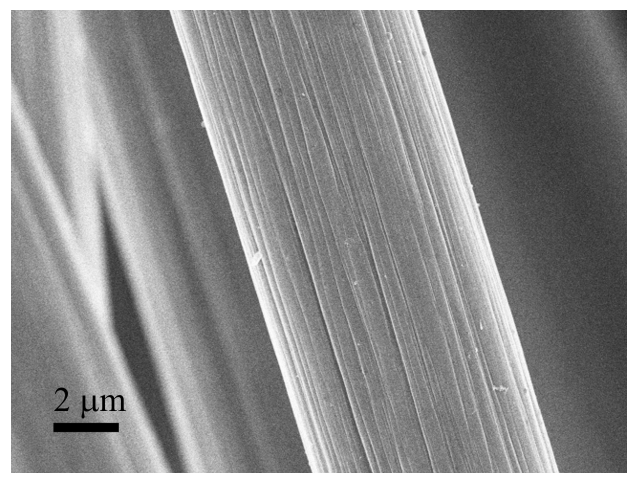

Figure 4.2 Micrograph (SEM) of a carbon filament with a typical diameter of $7.0 \mu \mathrm{m}$. The ridges in the axial filament direction are clearly visible, the radius of curvature $R_{\text {ridge }}$ is approximately $100 \mathrm{~nm}$.

involving the product of a real contact area $A_{r}$ between the contacting filaments with an interfacial shear strength $\tau$, and a ploughing part $P$ :

$$
F_{\mathrm{f}}=A_{\mathrm{r}} \tau+P \text {. }
$$

Analogously, we assume that the same friction relation describes the frictional force $F_{\mathrm{f}}$ between fibrous tows in sliding contact. However, in the current modelling approach we assume that all deformations at the asperity level take place in the elastic regime. Since the ploughing part of friction is caused by plastic deformation at the level of asperities only, this ploughing part $P$ is neglected.

\subsubsection{Material}

The tow-tow contacting behaviour was modelled for carbon fibre tow material, for which experimental data of both perpendicular and parallel contact friction was obtained [8] (Chapter 2). Table 4.1 lists the relevant properties of the carbon fibre tows. The fibrous tows received a thermal treatment to remove the applied surface finish (epoxy based).

Figure 4.2 shows a SEM micrograph of a typical carbon filament. The surface topography of the carbon filament consists of ridges in the axial filament direction. The typically observed radius of curvature $R_{\text {ridge }}$ of approximately $100 \mathrm{~nm}$ is comparable to the value of $R_{\text {ridge }} \approx 200 \mathrm{~nm}$ reported by Roselman and Tabor [13]. 
Table 4.1 Manufacturer data (M) of the Torayca T300JB carbon tow material used in the contact model. Additional data of equivalent carbon tow material from literature sources is indicated with the corresponding reference.

\begin{tabular}{lcccc}
\hline Description & Symbol & Unit & Value & Ref. \\
\hline Density & $\rho$ & $\mathrm{kg} / \mathrm{m}^{3}$ & 1780 & $\mathrm{M}$ \\
Nr. of filaments in the tow & $n_{\mathrm{fil}}$ & - & 3000 & $\mathrm{M}$ \\
Filament radius & $R_{\text {fil }}$ & $\mu \mathrm{m}$ & 3.5 & {$[15], \mathrm{M}$} \\
Axial elastic modulus & $E_{\text {axial }}$ & $\mathrm{GPa}$ & 230 & {$[15], \mathrm{M}$} \\
Transverse elastic modulus & $E_{\text {trans }}$ & $\mathrm{GPa}$ & 15 & {$[16]$} \\
Transverse Poisson coefficient & $v$ & - & 0.445 & {$[15]$} \\
Work of adhesion & $w$ & $\mathrm{~mJ} / \mathrm{m}^{2}$ & 95.1 & {$[17]$} \\
C-C interatomic spacing & $z_{0}$ & $\AA$ & 1.54 & {$[18]$} \\
\hline
\end{tabular}

\subsubsection{From tow to filament load}

The typical compressive load acting on a single filament is derived from actual measurement data, obtained in the aforementioned capstan friction experiment [8] (Chapter 2). Figure 4.1 illustrates the experiment schematically. A fibrous tow was draped on a metal friction drum, having a radius $R_{\text {drum }}=25.0 \mathrm{~mm}$, with a known wrapping angle $\theta_{\text {wrap }}=\pi$. The tensile tow end loads $T_{1}$ at $\theta_{1}=0$ and $T_{2}$ at $\theta_{2}=\theta_{\text {wrap }}$ were measured. An apparent coefficient of friction $\mu_{\text {app }}$ can be obtained from the capstan relation:

$$
\mu_{\mathrm{app}}=\ln \left(\frac{T_{2}}{T_{1}}\right) \frac{1}{\theta_{\mathrm{wrap}}} .
$$

Amontons' law is the main underlying assumption in the capstan equation, stating that the frictional force $F_{\mathrm{f}}$ between the tow and the friction drum is directly proportional to the normal load $N(\theta)$ in unit $\mathrm{N}$ exerted on the tow by the friction drum:

$$
F_{\mathrm{f}}=\mu_{\mathrm{app}} N(\theta) .
$$

The description of $F_{\mathrm{f}}$ in Equation (4.4) is also referred to as Coulomb friction. The tensile tow load $T(\theta)$ at any arbitrary angle $\theta$ follows from the known ingoing tensile load $T_{1}$ and the apparent coefficient of friction given by Equation (4.3):

$$
T(\theta)=T_{1} \exp \left(\mu_{\mathrm{app}} \theta\right) .
$$

The estimation of $T(\theta)$ in Equation (4.5) assumes Coulomb friction, although a non-Coulomb type of behaviour for tow friction was mentioned before in Equation (4.1). However, the load range in which the individual capstan measurements took place was relatively small and thus the difference between 


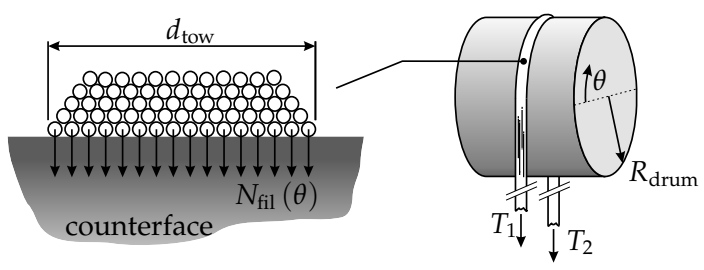

Figure 4.3 Uniform normal load distribution assumption of the bottom filaments of the stationary fibrous tow. The contacting counterface tows are oriented perpendicularly or parallel to the stationary tow. Note that the friction drum rotates in the opposite direction of $\theta$ (as illustrated in Figure 4.1).

the uniform apparent coefficient of friction $\mu_{\text {app }}$ from Equation (4.4) and the Howell behaviour of Equation (4.1) is relatively small as well. Therefore, the straightforward Coulomb friction behaviour relation of Equation (4.5) was used for the normal load derivation in this work.

The distributed normal load $N_{\text {tow }}$ (in $\mathrm{N} / \mathrm{m}$ arc length) in the contact between the stationary and moving tows follows directly from load equilibrium of an infinitesimal part of the stationary tow, Section 4.A contains the derivation:

$$
N_{\text {tow }}(\theta)=\frac{T_{\text {tow }}(\theta)}{R_{\text {drum }}} .
$$

An estimation of the number of filaments in direct contact with each other is required to calculate the distributed normal load on a filament $N_{\text {fil }}(\theta)$ along the wrapped length $l_{\text {wrap }}=\theta_{\text {wrap }} R_{\text {drum }}$. Assuming a close packing of filaments, the normal load in the stationary tow is transferred from one layer of filaments to the layer beneath. The bottom layer of filaments, i.e. the layer in direct contact with the filaments from the moving tow, transfers the normal load, as illustrated in Figure 4.3. The amount of contacting filaments $n_{\text {fil }}$ for each tow material was estimated from observations of the contacting tow shape during capstan experiments [8] (Chapter 2). The transferred normal loads from filament layer to filament layer is assumed to be uniformly distributed along the filaments of the bottom layer. The distributed normal load on the individual contacting filaments of the stationary tow in the capstan setup then becomes:

$$
N_{\text {fil }}(\theta)=\frac{N_{\text {tow }}(\theta)}{n_{\text {fil }}} .
$$

Contact area calculations based on $N_{\text {fil }}$ level are described in Section 4.2.4 for the perpendicular filament contacts and in Section 4.2 .5 for the parallel filament contacts. 


\subsubsection{Perpendicular tow contact}

The contact between filaments with radius $R_{\text {fil }}$ under a perpendicular orientation is modelled with two crossed cylinders, as illustrated in Figure 4.4. The radius of curvature of the capstan friction drum $R_{\text {drum }}=25.0 \mathrm{~mm}$ is large compared to the filament radius $R_{\text {fil }}=3.5 \mu \mathrm{m}$ and is therefore approximated by a flat surface. Using a contact mechanics analogy, the crossed cylinders can be represented by a sphere indenting a plane. The mean effective radius of curvature $R_{\mathrm{m}}$ of the equivalent contact is defined as:

$$
R_{\mathrm{m}}=\left(\frac{1}{R_{\mathrm{x} 1}}+\frac{1}{R_{\mathrm{y} 1}}+\frac{1}{R_{\mathrm{x} 2}}+\frac{1}{R_{\mathrm{y} 2}}\right)^{-1} .
$$

Where $R_{\mathrm{x} 1}=R_{\mathrm{x} 2}=R_{\mathrm{fil}}$ and $R_{\mathrm{y} 1}=R_{2 \mathrm{y}}=\infty$. This parameter $R_{\mathrm{m}}$ translates all curvatures in the two-body contact to one spherical body in contact with a flat surface [19]. The sphere indents an elastic half-plane, as illustrated in Figure 4.4. In this first approximation of the contact, the filament surface is assumed to be smooth, i.e. without any surface irregularities.

The compressive load $P_{\text {perp }}$ on the sphere in the contact analogy is a load in unit $\mathrm{N}$. This force is derived from the local normal filament load in Equation (4.7). Multiplication of $N_{\text {fil }}(\theta)$ with a projected arc length corresponding to one filament diameter leads to the load (in unit $N$ ) of the perpendicular contact at the angular coordinate $\theta$ :

$$
P_{\text {perp }}(\theta)=2 R_{\text {fil }} N_{\text {fil }}(\theta) .
$$

The radius of the contact area between a sphere under the compressive load

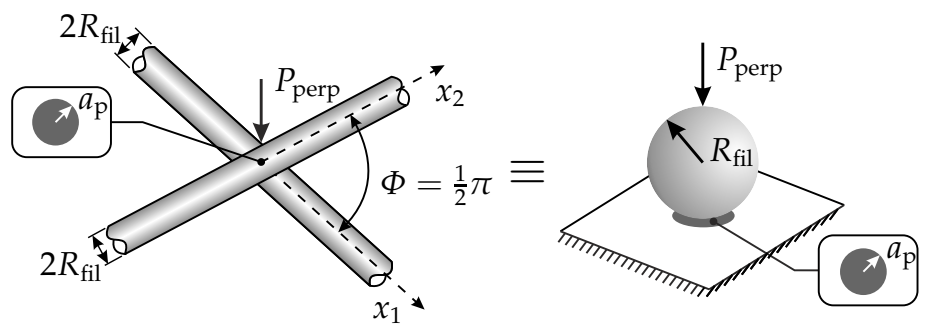

Figure 4.4 Schematic illustration of filaments in perpendicular contact. The contact between the filaments is represented by the analogy of a sphere indenting an elastic half-plane. The contact area $A_{\mathrm{p}}$ is circular with contact radius $a_{\mathrm{p}}$. 
$P_{\text {perp }}(\theta)$ on an elastic half-plane for Hertzian contact is [19]:

$$
a_{\mathrm{p}}=\left(\frac{3 P_{\text {perp }}(\theta) R_{\mathrm{m}}}{2 E^{\star}}\right)^{1 / 3}
$$

where $E^{\star}$ represents the reduced modulus of elasticity of the two filaments in contact:

$$
E^{\star}=\left(\frac{1-v_{1}^{2}}{E_{1}}+\frac{1-v_{2}^{2}}{E_{2}}\right)^{-1} .
$$

Because the contacting filaments are made of the same material, with the transverse moduli of elasticity $E_{1}=E_{2}=E_{\text {trans }}$ and the Poisson ratios $v_{1}=$ $v_{2}=v$, Equation (4.11) reduces to:

$$
E^{\star}=\left(\frac{2\left(1-v^{2}\right)}{E_{\text {trans }}}\right)^{-1} .
$$

The relevant material properties are listed in Table 4.1. The obtained circular contact area $A_{\mathrm{p}}=\pi a_{\mathrm{p}}^{2}$ is a first approximation due to the smooth filament surface assumption. This first approximation does not account for the presence of the ridges on the filament surface, illustrated in Figure 4.2. The typical radius of curvature of the ridge of approximately $100 \mathrm{~nm}$ is small compared to the filament radius. Based on the dimension of the first approximation contact radius $a_{\mathrm{p}}$, the perpendicular contact between carbon filaments can take place at one or two ridges. Calculating the contact area between these ridges should therefore provide a more realistic representation of the perpendicular tow friction experiment. For that purpose, the carbon filament-filament contact areas as a function of load are also modelled for the radius of a ridge $R_{\text {ridge }}$. Figure 4.5 illustrates the contact analogies for two situations, i.e. the contact between one ridge on each filament, denoted $1 \times 1$, and the contact between two ridges on each filament, denoted $2 \times 2$. The $1 \times 1$ contact analogy is equivalent to the aforementioned case of the contact of smooth filaments. The $2 \times 2$ contact of ridges was modelled by evenly distributing the load $P_{\text {perp }}$ over four individual contact areas. The resulting contact radii are $a_{\mathrm{p}, 1 \times 1}$ and $a_{\mathrm{p}, 2 \times 2}$. Additionally, $1 \times 1$ ridge contact calculations for $R_{\text {ridge }}=200 \mathrm{~nm}$ were performed to assess the sensitivity of the predicted contact area to the radius of a ridge. The results of the contact calculations as a function of the distributed normal filament load are discussed in Section 4.4.

Furthermore, a Maugis-Dugdale (MD) contact analysis provides insight in the contribution to the contact area of adhesion between the filaments [20-22]. The attractive forces between the filaments result in a non-zero contact area without an externally applied load. Therefore, the contact radius $a_{\mathrm{MD}}$ obtained from 


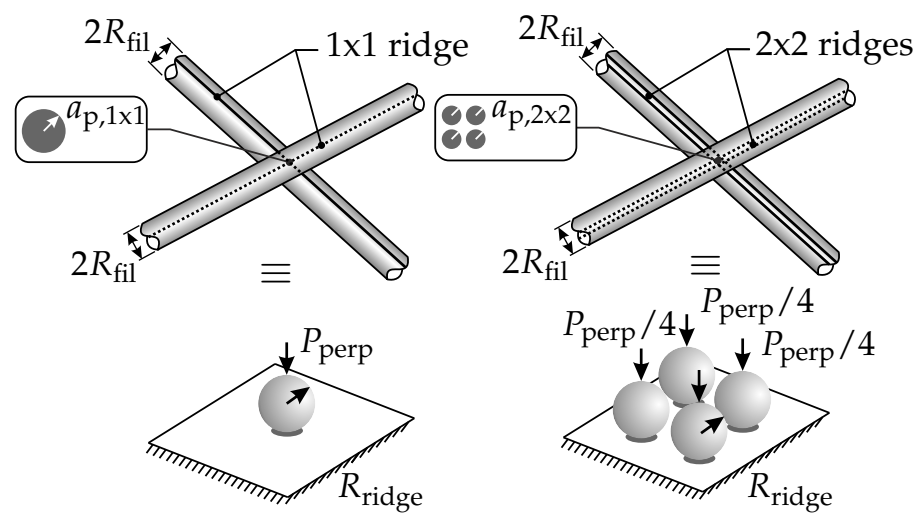

Figure 4.5 Analogies for the determination of the contact radii $a_{\mathrm{p}, 1 \times 1}$ and $a_{\mathrm{p}, 2 \times 2}$ of perpendicularly crossed filaments. The contact occurs between one or two ridges of each filament.

the Maugis-Dugdale analysis is larger than the Hertzian equivalent, which does not account for the effect of adhesion between the contacting filaments. The procedure to obtain the load-area relation for adhesive contact according to Maugis-Dugdale is presented in Section 4.B.

Summarising, the contact between perpendicularly oriented filaments is investigated for three different surface geometries represented by $R_{\mathrm{fil}}=3.5 \mu \mathrm{m}$ for a smooth filament surface assumption, and $R_{\text {ridge }}=100 \mathrm{~nm}$ as well as $R_{\text {ridge }}=200 \mathrm{~nm}$ when accounting for surface irregularities on the carbon filaments as illustrated in Figure 4.2. A variation of the amount of contacting ridges was taken into account; this is illustrated schematically in Figure 4.5. The contact calculations were performed with (MD) and without (Hertz) accounting for the contribution of adhesion between the contacting filaments. The results are presented in Section 4.3.1.

\subsubsection{Parallel tow contact}

A perfectly parallel orientation between the filaments of the stationary and sliding tows would result in a rectangular contact area in the axial direction of the filaments, as illustrated in Figure 4.6. For a Hertzian line contact, the half-width of contact $a_{\text {line }}$ is [19]:

$$
a_{\text {line }}=\left(\frac{4 N_{\mathrm{fil}} R_{\mathrm{m}}}{\pi E^{\star}}\right)^{1 / 2} .
$$

However, the filaments in the experimental setup contacted each other under a small angle, as illustrated in Figure 4.7. The estimated relative orientation of the filaments $\Phi$ was obtained from experimental observations. The filaments in 
the stationary wrapped tow crossed a number $n_{\text {oblique }}$ of moving filaments as a result of the relative orientation. Here, $n_{\text {oblique }}$ is equal to the number of filamentto-filament contacts along the wrapped length of the tow $l_{\text {wrap }}=\theta_{\text {wrap }} R_{\text {drum }}$ :

$$
n_{\text {oblique }}=\frac{1}{2} \frac{d_{\text {tow }}}{2 R_{\text {fil }}},
$$

where $d_{\text {tow }}$ is the width of the tow attached to the rotating drum. A filament in the stationary tow passes half of the width of the tow attached to the drum for $\theta_{\text {wrap }}=\pi$. Table 4.2 shows the appropriate values used in the tow-tow contact model. The relative orientation between the crossing filaments $\Phi$ then follows from this geometrical arrangement:

$$
\Phi=\arctan \left(\frac{1}{2} \frac{d_{\mathrm{tow}}}{l_{\mathrm{wrap}}}\right) .
$$

This results in $\Phi \approx 2^{\circ}$. The modelling procedure to account for the contact of the filaments under a relative orientation is described below.

The compressive load in unit $\mathrm{N}$ in each filament-to-filament contact is assumed to be equal to the distributed filament load $N_{\text {fil }}$, derived in Equation (4.7), multiplied by the projected length between two oblique filament crossings:

$$
P_{\text {par }}=N_{\text {fil }} \frac{l_{\text {wrap }}}{n_{\text {oblique }}} .
$$

Analogously to the perpendicular filament-to-filament contact, the real contact area between the filaments in almost parallel orientation depends on the assumed filament surface properties. The load-area relation was calculated for the three contact geometries described in Section 4.2.4: $R_{\text {fil }}=3.5 \mu \mathrm{m}$, $R_{\text {ridge }}=100 \mathrm{~nm}$, and $R_{\text {ridge }}=200 \mathrm{~nm}$. The general theory of oblique contact between cylindrical bodies and the contact geometry derivations are described in the literature, as for example [19,23-25]. The following equations apply when two geometrically identical cylindrical bodies contact each other under a relative

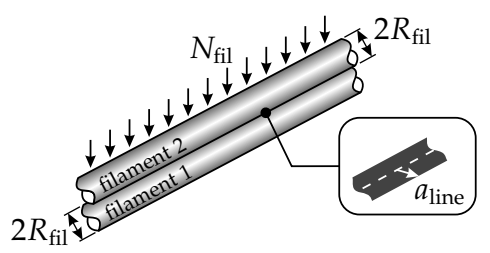

Figure 4.6 Perfectly parallel filament contact with the distributed normal filament load $N_{\text {fil }}$. The

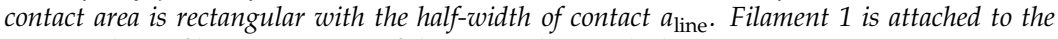
rotating drum, filament 2 is part of the wrapped tow, which is stationary. 
Table 4.2 Tow geometry input data for the oblique tow-tow contact model, representing nearly parallel contact of the filaments.

\begin{tabular}{lccc}
\hline Description & Symbol & Unit & Value \\
\hline No. of crossed filaments & $n_{\text {oblique }}$ & - & 357 \\
Wrapping angle & $\theta_{\text {wrap }}$ & rad & $\pi$ \\
Oblique contact angle & $\Phi$ & rad $/{ }^{\circ}$ & $0.032 / \approx 2$ \\
Width of moving tow & $d_{\text {tow }}$ & $\mathrm{mm}$ & 5.0 \\
\hline
\end{tabular}

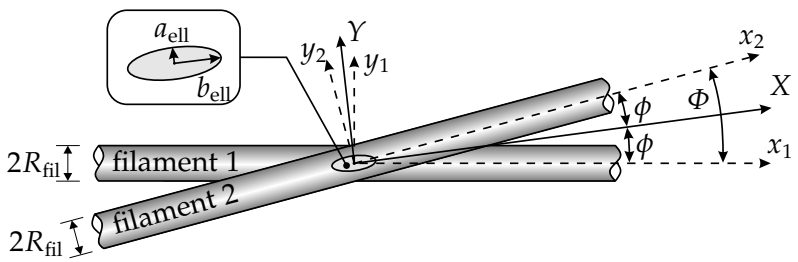

Figure 4.7 Oblique filament contact with the relative filament orientation $\Phi=2 \phi$ representing the nearly parallel orientation of filaments. The contact area is elliptic with semi-minor axis $a_{\mathrm{ell}}$ and semi-major axis $b_{\text {ell }}$. Filament 1 is attached to the rotating drum, filament 2 is part of the wrapped tow, which is stationary.

angle $\Phi \neq 0$, as illustrated in Figure 4.7. The contact analogy for the oblique contact of geometrically identical cylinders is that of an ellipsoidal punch with the principal relative radii of curvature $R_{X}$ and $R_{Y}$ which contain the translated curvatures of the contacting bodies. These radii are defined as follows $[19,25]$ :

$$
\begin{aligned}
& R_{X}=\frac{R}{1-\cos (\Phi)}, \\
& R_{Y}=\frac{R}{1+\cos (\Phi)},
\end{aligned}
$$

where $R=R_{\text {fil }}$ for a smooth filament assumption or $R=R_{\text {ridge }}$ when the surface topography of the filament is taken into account. Furthermore, the following relation exists between the principal relative radii of curvature $R_{X}, R_{Y}$ and the mean effective radius of curvature $R_{\mathrm{m}}$ of the contacting bodies [19, 25]:

$$
\begin{aligned}
\frac{1}{R_{\mathrm{X}}}+\frac{1}{R_{\mathrm{Y}}} & =\left(\frac{1}{R_{\mathrm{x} 1}}+\frac{1}{R_{\mathrm{y} 1}}+\frac{1}{R_{\mathrm{x} 2}}+\frac{1}{R_{\mathrm{y} 2}}\right) \\
& =\frac{1}{R_{\mathrm{m}}}
\end{aligned}
$$

The semi-minor axis $a_{\mathrm{ell}}$, the semi-major axis $b_{\mathrm{ell}}$ of the elliptic contact area and 
the approach distance of the deformed filament surfaces in the centre of the contact $\delta$ follow from the derived contact geometry and the applied normal load $N_{\text {par, }}$ resulting in [24]:

$$
\begin{aligned}
a_{\mathrm{ell}} & \equiv \alpha\left(\frac{3 P_{\mathrm{par}} R_{\mathrm{m}}}{2 E^{\star}}\right)^{1 / 3}, \\
b_{\mathrm{ell}} & \equiv \beta\left(\frac{3 P_{\mathrm{par}} R_{\mathrm{m}}}{2 E^{\star}}\right)^{1 / 3}, \\
\delta & \equiv \gamma\left(\frac{9 P_{\mathrm{par}}^{2}}{32 E^{\star 2} R_{\mathrm{m}}}\right)^{1 / 3},
\end{aligned}
$$

where $\alpha, \beta$ and $\gamma$ are dimensionless quantities, which yield unity for a circular contact. These quantities depend on the ratio of the principal radii of curvature of the contact:

$$
\zeta=\frac{R_{Y}}{R_{X}}
$$

where $R_{\mathrm{Y}} \leq R_{\mathrm{X}}$. The equations for the dimensionless quantities are presented in Section 4.C.

Summarising, the contact between perfectly parallel $\left(\Phi=0^{\circ}\right)$ and nearly parallel or obliquely $\left(\Phi=2^{\circ}\right.$ ) oriented filaments is investigated for three different surface geometry assumptions represented by $R_{\mathrm{fil}}=3.5 \mu \mathrm{m}$ for a smooth filament surface assumption, and $R_{\text {ridge }}=100 \mathrm{~nm}$ as well as $R_{\text {ridge }}=200 \mathrm{~nm}$ when accounting for surface irregularities on the carbon filaments as illustrated in Figure 4.2. A variation of the amount of contacting ridges was taken into account. The contact calculations were performed without taking the contribution of adhesion between the contacting filaments into account, i.e. using a Hertzian contact approach. The results are presented in Appendix 4.3.2.

\subsection{Results}

The contact model results are presented separately for the perpendicular and parallel relative tow orientations. Contact area predictions with and without accounting for surface irregularities of the filaments are presented.

\subsubsection{Perpendicular orientation}

Figure 4.8 shows the contact area per metre contacting filament for both the smooth filament surface assumption $\left(R_{\text {fil }}\right)$ and the contacting ridge situations with varying $R_{\text {ridge }}$. The predicted contact for the smooth filament assumption 
is relatively high, compared to the ridge-to-ridge contacts. The adhesion contribution to the contact area is visible in Figure 4.8 by comparing the black curves with the grey curves with the same markers. The contribution of adhesion to the contact is larger for the smooth filament situation, i.e. the curves with the circular markers, than for the ridge-to-ridge contacts, i.e. the curves with the triangular and square markers. The dimensionless normalised load range is defined as the ratio of the absolute applied load $P_{\text {perp }}$ and the adhesive pull-off force $2 \pi w R_{\mathrm{m}}$ required to separate the contacting bodies [21]:

$$
\bar{P}=\frac{P_{\text {perp }}}{2 \pi w R_{\mathrm{m}}} .
$$

Equation (4.23) shows that the effect of adhesion increases with the size of the contacting geometries, appearing in the form of $R_{\mathrm{m}}$ for a constant work of adhesion $w$, listed in Table 4.1. This explains the larger gap in Figure 4.8 between the Hertz and MD curves for the smooth filament assumption, i.e. $R_{\text {fil }}=3.5 \mu \mathrm{m}$, than for the contact between the significantly smaller geometry of the ridges. This shows the relevance of taking the surface irregularities of the filament into account.

\subsubsection{Parallel orientation}

The real contact area as a function of the distributed filament load for tows in a nearly parallel orientation is visualised in Figure 4.9. The results are shown for Hertzian contact, i.e. adhesion effects were not taken into account. The black dotted curves represent the real contact area per unit filament length for a perfectly parallel orientation of the filaments, using Equation (4.13). However, the aforementioned small relative angle of orientation $\Phi=2^{\circ}$ between the contacting filaments is expected to provide a more realistic representation of the experiment. The grey curves in Figure 4.9 were obtained by calculating the elliptic contacts along the wrapped length of a filament using the general Hertzian elliptic contact theory, explained in Appendix 4.C. The smooth filament assumption leads to a contact area of about a factor ten higher than the predictions for ridge-to-ridge contact. Furthermore, Figure 4.9 shows that the real area of contact per unit filament length for the perfectly parallel contact $\left(\Phi=0^{\circ}\right)$ is about an order of magnitude higher than the predicted contact for a small angle $\Phi=2^{\circ}$ between the stationary and moving filaments. The model results for both the perpendicular and parallel tow orientations are discussed in more detail in Section 4.4. 


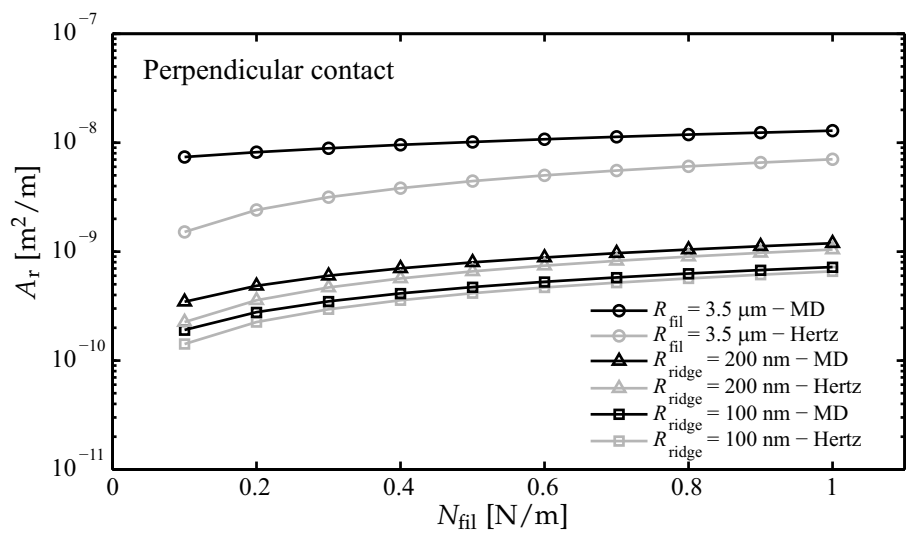

Figure 4.8 Contact area $A_{\mathrm{r}}$ as a function of the distributed normal filament load $N_{\text {fil }}$ for perpendicular contact of two filaments. The contact areas are shown for three different contact geometries: $R_{\mathrm{fil}}=3.5 \mu \mathrm{m}$ represents a smooth filament-filament contact, the contact of $1 \times 1$ small ridges is represented by $R_{\text {ridge }}=100 \mathrm{~nm}$, the contact of $1 \times 1$ large ridges by $R_{\text {ridge }}=200 \mathrm{~nm}$. The contact areas are shown with adhesion contribution $\left(M D, w=95.1 \mathrm{~mJ} / \mathrm{m}^{2}\right)$ and without adhesion contribution (Hertz).

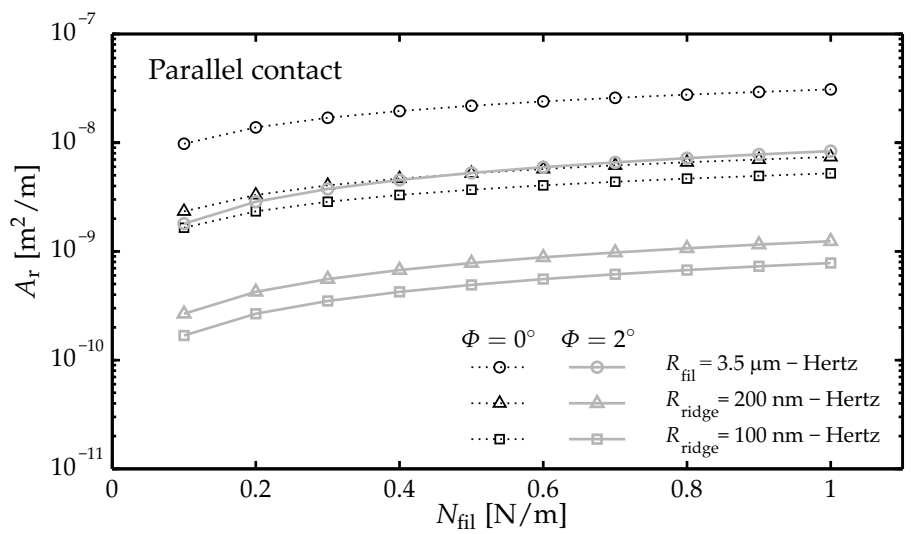

Figure 4.9 Contact area $A_{\mathrm{r}}$ as a function of the distributed filament load for perfectly parallel $\left(\Phi=0^{\circ}\right)$ and nearly parallel $\left(\Phi=2^{\circ}\right)$ contact of two filaments. The contact areas are shown for three different geometries: $R_{\mathrm{fil}}=3.5 \mu \mathrm{m}$ represents the smooth filament assumption, the contact of $1 \times 1$ small ridges is represented by $R_{\text {ridge }}=100 \mathrm{~nm}$, the contact of $1 \times 1$ large ridges by $R_{\text {ridge }}=$ $200 \mathrm{~nm}$. The areas are shown for Hertzian contact, i.e. without adhesion contribution. 


\subsection{Discussion}

The expected frictional force between the contacting filaments can be predicted from Equation (4.2). The calculated frictional force is compared with the experimental results to assess the model performance. Furthermore, several aspects of the model are discussed.

\subsubsection{Comparison with experimental results}

The model predictions are related to the experimental observations by comparing the measured frictional force $F_{\mathrm{f}}=T_{2}-T_{1}$ with a frictional force prediction based on Equation (4.2).

The normal loads on the filaments were used to predict the frictional force for a small arc length segment $\Delta s=\Delta \theta R_{\text {drum }}$ of the contacting filaments:

$$
\Delta F_{\mathrm{f}}=\Delta A_{\mathrm{r}} \tau
$$

where $\Delta A_{\mathrm{r}}$ is the real contact area of a filament segment with length $\Delta s$. The total frictional force along the wrapped length of the filament was obtained by summation of the segment frictional forces from Equation (4.24). The small arc length segments were $\Delta s=2 R_{\text {fil }}$ for the perpendicular contact and $\Delta s=$ $\pi R_{\text {drum }} / n_{\text {oblique }}$ for the nearly parallel contact situation. The frictional force for the tow is then obtained by multiplying the number of filaments in direct contact $n_{\text {fil }}$ with the summed frictional force $F_{\mathrm{f}}=\sum \Delta F_{\mathrm{f}}$ per filament. Figure 4.10 shows the results of this comparison for perpendicular contact, with (MD) and without (Hertz) the contribution of adhesion between the contacting tows. The calculations are shown for an estimated interfacial shear strength $\tau=100 \mathrm{MPa}$. The frictional force prediction for the smooth filament assumption overestimates the measured friction by more than an order of magnitude and was therefore not included in the graph.

The predicted frictional forces are in the same range as the experimental observations for perpendicular contact between the ridges on the carbon filaments. The contribution of adhesion to the friction is limited, due to the small radius of curvature of the contacting ridges. As indicated in the legend of the graph in Figure 4.10 , the solid grey $F_{\mathrm{f}}$-curve representing the Hertzian $1 \times 1$ ridge contact with $R_{\text {ridge }}=200 \mathrm{~nm}$ coincides with that of the $2 \times 2$ small ridge contact with $R_{\text {ridge }}=100 \mathrm{~nm}$. However, for the MD-curve, i.e. taking the contribution of adhesion into account, the friction is slightly higher for the $2 \times 2$ small ridge contact than for the 1x1 large ridge contact. Thus, the effect of adhesion for one large contact is smaller than the effect for several small contacts, which have the same total Hertzian contact area. It is very likely that a mixture of $1 \times 1,2 \times 2$, and $1 \times 2$ contacts occurs in an actual contact situation. Although the distribution of each of the three combinations is not known, the frictional force as a result of 


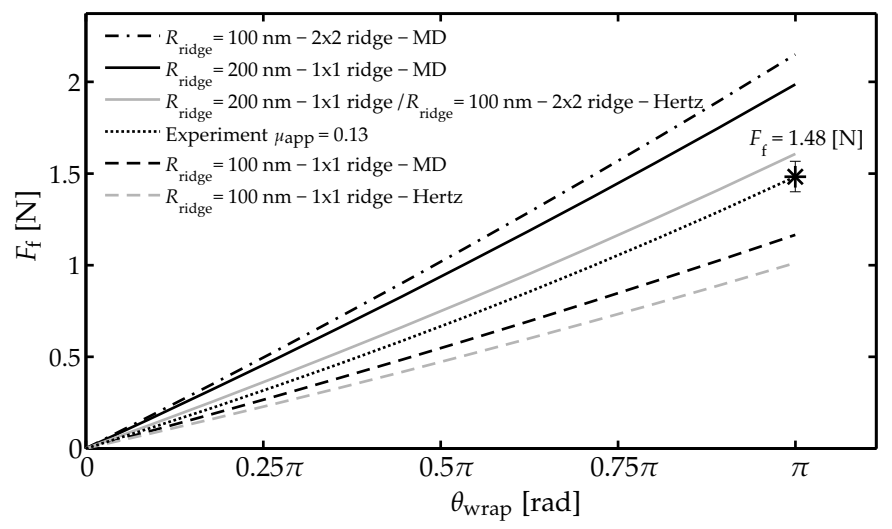

Figure 4.10 Predicted frictional force $F_{\mathrm{f}}$ as a function of the wrapping angle $\theta_{\mathrm{wrap}}$ on the capstan setup for various ridge-to-ridge contact situations in a perpendicular orientation. The star-symbol indicates the measured force in the experiment; the dotted line shows the calculated frictional force based on Equation (4.5) with $\mu_{\mathrm{app}}=0.13$. The Hertz-curves represent the friction without adhesion contribution, whereas the $M D$-curves account for the effect of adhesion. The frictional force curve for $2 x 2$ ridge contact of $R_{\text {ridge }}=100 \mathrm{~nm}$ coincides with that of $1 \times 1$ ridge contact with $R_{\text {ridge }}=200 \mathrm{~nm}$ for Hertzian contact.

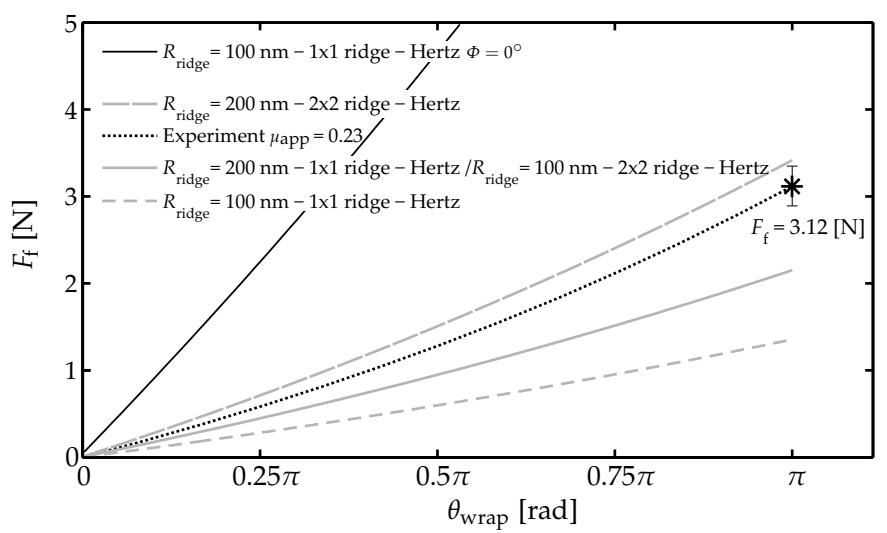

Figure 4.11 Predicted frictional force $F_{\mathrm{f}}$ as a function of the wrapping angle $\theta_{\mathrm{wrap}}$ on the capstan setup for various ridge-to-ridge contact situations in nearly parallel contact, i.e. $\Phi=2^{\circ}$. The star-symbol indicates the measured force in the experiment; the dotted line shows the calculated frictional force based on Equation (4.5) with $\mu_{\mathrm{app}}=0.23$. The frictional force curve for $2 x 2$ ridge contact of $R_{\text {ridge }}=100 \mathrm{~nm}$ coincides with that of $1 \times 1$ ridge contact with $R_{\text {ridge }}=200 \mathrm{~nm}$. The solid black line depicts the contact for a perfectly parallel orientation of filaments, i.e. $\Phi=0^{\circ}$. 
the mixture of the aforementioned contact situations can be expected to lie close to the experimentally observed value indicated by the star symbol in Figure 4.10.

Figure 4.11 shows the results for the parallel tow contact, i.e. under a small angle $\Phi=2^{\circ}$. The Hertzian contact is shown for the same interfacial shear strength as for perpendicular contact, i.e. $\tau=100 \mathrm{MPa}$. The predicted frictional force appears to be in qualitative as well as quantitative agreement with the experimentally observed value indicated by the star symbol. Thus, the modelled oblique contact at a relative angle $\Phi=2^{\circ}$ of ridges on the filaments appears to provide a good representation of the actual experiment. The thin solid black curve in Figure 4.11 depicts the frictional force prediction for $1 \times 1$ ridge-toridge $\left(R_{\text {ridge }}=100 \mathrm{~nm}\right)$ contact in perfectly parallel orientation, i.e. $\Phi=0^{\circ}$. This clearly illustrates the overestimation of the frictional force $F_{\mathrm{f}}$ when a perfectly parallel orientation of the filaments is assumed. A mixture of ridgeto-ridge contact situations is assumed to apply in reality, similar to the case of perpendicular contact.

\subsubsection{Model assumptions}

Several simplifying assumptions were made in the contact modelling procedure. Firstly, in the view of the tow cross-section, a uniform distribution of the distributed normal loads $N_{\text {fil }}$ on each filament in the bottom layer of the stationary tow was assumed, as illustrated in Figure 4.3. This approximation neglects load variations at for example the edges of the tow, where fewer filaments are present to transmit the normal load to the bottom layer. The true value of $N_{\text {fil }}$ is expected to vary slightly along the width of the tow. However, the current approach appears to give an adequate representation.

Secondly, an ideal packing of filaments in the tow was assumed, which is not the case in reality. A small amount of entangled or misaligned filaments was present in the tow material, disturbing the parallel arrangement of filaments within a tow, although the supplied tow material had no intentionally applied twist. However, these effects are very likely averaged out in the capstan experiment. Furthermore, the close packing assumption implies that there is no spacing between the filaments in the tow, thus the amount of contacting filaments in the bottom layer of the stationary tow $n_{\text {fil }}$ is an upper bound estimate of the actual situation. Variations of $n_{\text {fil }}$ along the wrapped length $l_{\text {wrap }}$ of the tow are expected to occur as well, due to a varying width of the tow on the capstan drum. The effect of the tow width variation was not taken into account in the current work. Another effect that was not taken into account is the contribution of digging in of filaments of the contacting tows. This effect, where a filament is in contact with two other filaments under a wedge-like angle, is described in detail in previous work [8] (Section 2.5.3). It leads to an observed apparent coefficient of friction $\mu_{\text {app }}$ of the tow on a capstan setup that is about $15 \%$ higher 
than the actual coefficient of friction at the filament level. However, due to the observed relative orientation of the tows, digging in is only expected to occur locally during friction experiments, i.e. at contact lengths smaller than the filament contact length on the capstan $l_{\text {wrap }}$. The values of $\mu_{\text {app }}$ on the tow and filament level were therefore assumed equal in this study. However, additional experimental work should be performed to rule out or confirm the presence of significant digging in of filaments.

Future work should focus on the assumptions regarding the amount of filaments in oblique contact $n_{\text {oblique }}$ and the corresponding contact load $P_{\text {par }}$. Furthermore, the effect of small amounts of twist in the tow were not taken into account. The filaments of twisted tows in contact have a different relative contact angle $\Phi$ than those in the currently assumed parallel arrangement of filaments within the tows. The modelling approach in this work was presented for carbon tow material; however, the frictional behaviour of any fibrous material can be modelled using this approach.

\subsection{Conclusions}

A contact mechanics model for the prediction of the friction between sliding tows has been developed. The model accounts for the difference in frictional behaviour between perpendicular and nearly parallel relative tow orientations. Qualitative and quantitative agreement was found between the contact model and observations from capstan experiments.

Because the approximation of a smooth filament surface led to an overestimation of the frictional force between sliding tows, the surface characteristics of carbon filaments were taken into account. This resulted in a good agreement between the contact model and the experimental results in the case of perpendicular and nearly parallel contact between tows. The contact area and hence the frictional force in the tow were overestimated for perfectly parallel contact of the filaments in the tow. Further investigation of the contact and load assumptions are required for an improved prediction of the frictional behaviour of sliding fibrous tows with, for example, intentionally applied twist. The current modelling approach supports the prediction of all relative tow orientations. Therefore, additional experiments at intermediate relative tow orientations can further improve the physical understanding of tow-tow friction and confirm the validity of the proposed modelling approach.

The contact model in this work provides a physical explanation for the experimentally observed orientation dependence of tow friction. The mesoscopic frictional behaviour of fibrous tows was explained by taking microscopic characteristics of the constituents into account. 


\section{References}

[1] J.D. Huffington and H.P. Stout. The friction of fibre assemblies. Wear, 3(1):26-42, 1960.

[2] E.A. Nikonova and A.B. Pakshver. The friction properties of textile yarns. Fibre Chemistry, 4(6):657-660, 1973.

[3] M.M. Robins, R.W. Rennell, and R.D. Arnell. The friction of polyester textile fibres. J Phys D, 17(7):1349-1360, 1984.

[4] B.J. Briscoe and F. Motamedi. Role of interfacial friction and lubrication in yarn and fabric mechanics. Text Res J, 60(12):697-708, 1990.

[5] C.M. Leech. The modelling of friction in polymer fibre ropes. Int J Mech Sci, 44(3):621-643, 2002.

[6] C. Rubenstein. Review on the factors influencing the friction of fibres, yarns and fabrics. Wear, 2(4):296-310, 1959.

[7] M.E. Yuksekkaya. More about fibre friction and its measurements. Text Prog, 41(3):141-193, 2009.

[8] B. Cornelissen, B. Rietman, and R. Akkerman. Frictional behaviour of high performance fibrous tows: Friction experiments. Compos Part A Appl Sci Manuf, 44:95-104, 2013.

[9] H.G. Howell and J. Mazur. Amontons' law and fibre friction. J Text Inst Trans, 44(2):T59-T69, 1953.

[10] B.S. Gupta and Y.E. El Mogahzy. Friction in fibrous materials. Part I: Structural model. Text Res J, 61(9):547-555, 1991.

[11] S.A. Grishanov. Fundamental modelling of textile fibrous structures. In: X. Chen (editor), Modelling and predicting textile behaviour. chapter 2, 41-111, Woodhead Publishing, 2010.

[12] Y.E. El Mogahzy and B.S. Gupta. Friction in fibrous materials. Part II: Experimental study of the effects of structural and morphological factors. Text Res $J$, 63(4):219-230, 1993.

[13] I.C. Roselman and D. Tabor. The friction of carbon fibres. J Phys D, 9(17):2517-2532, 1976.

[14] I.C. Roselman and D. Tabor. The friction and wear of individual carbon fibres. J Phys D, 10(8):1181-1194, 1977.

[15] M. Ueda and T. Takiguchi. Measurement of transverse Young's modulus of carbon fibres by angular characteristics of ultrasonic scattering. In: Proceedings of the IEEE 1990 Ultrasonics Symposium. volume 2, 1081-1085, Publ by IEEE, Honolulu, HI, USA, 1990.

[16] R. Maurin, P. Davies, N. Baral, and C. Baley. Transverse properties of carbon fibres by nano-indentation and micro-mechanics. Appl Compos Mater, 15(2):61-73, 2008.

[17] Y. Luo, Y. Zhao, Y. Duan, and S. Du. Surface and wettability property analysis of CCF300 carbon fibers with different sizing or without sizing. Mater Design, 32(2):941-946, 2011.

[18] J.F. Shackelford. Introduction to materials science for engineers. Prentice-Hall, 4 th edition, 1996. 
[19] K.L. Johnson. Contact Mechanics. Cambridge University Press, 9th print edition, 1985.

[20] D. Maugis. Adhesion of spheres: The JKR-DMT transition using a Dugdale model. J Colloid Interface Sci, 150(1):243-269, 1992.

[21] K.L. Johnson and J.A. Greenwood. An adhesion map for the contact of elastic spheres. J Colloid Interface Sci, 192(2):326-333, 1997.

[22] E. Barthel. Adhesive elastic contacts: JKR and more. J Phys D, 41(16):1-20, 2008.

[23] H. Hertz. Ueber die Berührung fester elastischer Körper. J Reine Angew Math, 92:156-171, 1881.

[24] H. Moes. Lubrication and beyond. University of Twente, 2000. URL http://www.utwente.nl/ctw/tr/Research/Publications/Books/, Retrieved 11 Sept. 2012.

[25] B. Sümer, C.D. Onal, B. Aksak, and M. Sitti. An experimental analysis of elliptical adhesive contact. J Appl Phys, 107(11):1-7, 2010. 


\section{A Appendix: Derivation of the normal tow load}

Figure 4A.1 depicts the loads on a small part of the tensioned wrapped tow on the counterface. The normal load in unit $\mathrm{N}$ is expressed as the product of the normal stress component $\sigma$ with the projected area formed by $t R_{\text {drum }} d \theta$, where $t$ is the local tow width and $R_{\text {drum }} d \theta$ is the arc length of the tow section. The vertical force equilibrium $\Sigma F_{\mathrm{y}}=0$ in the tow section then yields:

$$
\sigma t R_{\mathrm{drum}} d \theta-T(\theta+d \theta) \sin \left(\frac{d \theta}{2}\right)-T(\theta) \sin \left(\frac{d \theta}{2}\right)=0
$$

The term $\sin (d \theta / 2) \approx d \theta / 2$ for infinitesimally small $d \theta$. Likewise, $d T$ is small, so $T(\theta+d \theta) \approx T(\theta)$. Then, the following equilibrium exists:

$$
\sigma t R_{\mathrm{drum}} d \theta=2 T(\theta) \frac{d \theta}{2} .
$$

Bringing the arc length $R_{\text {drum }} d \theta$ to the right-hand side of Equation (4A.2) gives the distributed normal load $N_{\text {tow }}(\theta)=\sigma t$ in unit $\mathrm{N} / \mathrm{m}$ arc length:

$$
N_{\text {tow }}(\theta)=\frac{T(\theta)}{R_{\text {drum }}}
$$

Thus, the local distributed normal load on the wrapped tow was derived using the tensile load in the tow and the capstan drum geometry.

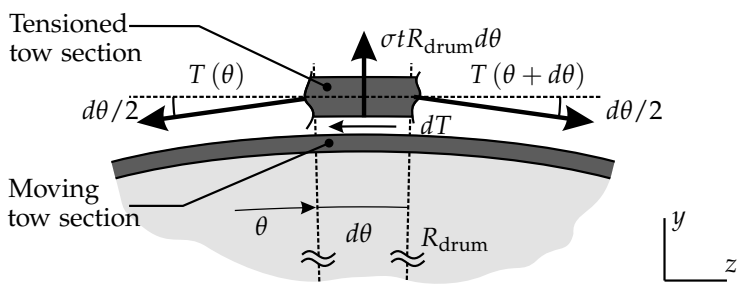

Figure 4A.1 Schematic illustration of the tow-tow contact on the capstan friction drum. The bottom or moving tow is attached to the rotating drum, the tensioned, stationary tow is wrapped around the drum, a sliding contact is formed. 


\section{B Appendix: Maugis-Dugdale adhesive contact calcu- lations}

This appendix presents the approach to obtain the contact area between filaments in a perpendicular orientation, accounting for adhesion effects. The mean effective radius of curvature $R_{\mathrm{m}}$ is determined from the cylindrical bodies with $R_{\mathrm{y} 1}=R_{\mathrm{y} 2}=\infty$ and $R_{\mathrm{x} 1}=R_{\mathrm{x} 2}$ is determined by $R_{\mathrm{fil}}$ or $R_{\text {ridge, }}$ depending on the smooth or ridge-containing filament surface description, respectively. The mean effective radius of curvature $R_{m}$ and the reduced elasticity modulus $E^{\star}$ are defined as:

$$
\begin{aligned}
R_{\mathrm{m}} & =\left(\frac{1}{R_{\mathrm{x} 1}}+\frac{1}{R_{\mathrm{y} 1}}+\frac{1}{R_{\mathrm{x} 2}}+\frac{1}{R_{\mathrm{y} 2}}\right)^{-1}, \\
E^{\star} & =\left(\frac{1-v_{1}^{2}}{E_{1}}+\frac{1-v_{2}^{2}}{E_{2}}\right)^{-1} .
\end{aligned}
$$

The following non-dimensional parameters are introduced to facilitate the contact calculations [21]:

$$
\begin{aligned}
\bar{a} & \equiv a_{\mathrm{MD}}\left(\frac{E^{\star}}{3 \pi w R_{\mathrm{m}}^{2}}\right)^{1 / 3}, \\
\bar{c} & \equiv c_{\mathrm{MD}}\left(\frac{E^{\star}}{3 \pi w R_{\mathrm{m}}^{2}}\right)^{1 / 3}, \\
\bar{\delta} & \equiv \delta_{\mathrm{MD}}\left(\frac{8 E^{\star 2}}{9 \pi^{2} w^{2} R_{\mathrm{m}}}\right)^{1 / 3}, \\
\bar{P} & \equiv \frac{P_{\text {perp }}}{2 \pi w R_{\mathrm{m}}},
\end{aligned}
$$

where $w$ is the work of adhesion listed in Table 4.1 and $P_{\text {perp }}$ represents the contact load in unit $\mathrm{N}$. The dimensionless parameter $\bar{P}$ is the ratio between $P_{\text {perp }}$ and the adhesive pull-off force $2 \pi w R_{\mathrm{m}}$ required to separate the contacting bodies. The intimate contact radius is represented by $a_{\mathrm{MD}}$, the radius $c_{\mathrm{MD}}$ represents the extent to which the maximum attractive force due to surface interactions $\sigma_{0}=w /\left(0.97 z_{0}\right)$ acts. Here, $z_{0}$ is the interatomic or intermolecular equilibrium spacing [21]. The transition parameter $\lambda$ is a measure of the ratio of elastic deformation to the range of surface forces and is defined as [21]:

$$
\lambda \equiv\left(\frac{w}{0.97 z_{0}}\right)\left(\frac{9 R_{\mathrm{m}}}{\pi w E^{\star 2}}\right)^{1 / 3}
$$


The following non-linear system of equations is solved numerically to obtain the contact parameters being the dimensionless intimate contact radius $\bar{a}$ and the dimensionless radius of adhesion $\bar{c}$, respectively, with $m=c_{\mathrm{MD}} / a_{\mathrm{MD}}[20,21]$ :

$$
\begin{aligned}
& \frac{\lambda \bar{a}^{2}}{2}\left[\left(m^{2}-2\right) \arccos \left(\frac{1}{m}\right)+\sqrt{m^{2}-1}\right] \\
& +\frac{4 \lambda^{2} \bar{a}}{3}\left[\sqrt{m^{2}-1} \arccos \left(\frac{1}{m}\right)-m+1\right]=1, \\
& \bar{\delta}=\bar{a}^{2}-\frac{4 \lambda \bar{a}}{3} \sqrt{m^{2}-1} \\
& \bar{P}=\bar{a}^{3}-\lambda \bar{a}^{2}\left[\sqrt{m^{2}-1}+m^{2} \arccos \left(\frac{1}{m}\right)\right] .
\end{aligned}
$$

The absolute dimension of the circular contact area $A_{\mathrm{MD}}$ is then obtained from the radius of the contact area $a_{\mathrm{MD}}$ in Equation (4B.2):

$$
A_{\mathrm{MD}}=\pi a_{\mathrm{MD}}^{2}
$$

\section{C Appendix: General Hertzian elliptic contact}

The dimensionless parameters $\alpha, \beta$ and $\gamma$ account for the ellipticity of the contact between bodies in an oblique orientation $(\Phi \neq 0)$ :

$$
\begin{aligned}
& \alpha=\kappa^{1 / 3}\left[\frac{2}{\pi} \mathbf{E}(m)\right]^{1 / 3}, \\
& \beta=\kappa^{-2 / 3}\left[\frac{2}{\pi} \mathbf{E}(m)\right]^{1 / 3}, \\
& \gamma=\kappa^{2 / 3}\left[\frac{2}{\pi} \mathbf{E}(m)\right]^{-1 / 3} \frac{2}{\pi} \mathbf{K}(m) .
\end{aligned}
$$

The ellipticity ratio $\kappa=a_{\mathrm{ell}} / b_{\mathrm{ell}}$ for $a_{\mathrm{ell}}<b_{\mathrm{ell}}$ is approximated by:

$$
\begin{aligned}
& \kappa \approx\left[1+\sqrt{\frac{\ln 16 / \zeta}{2 \zeta}}-\sqrt{\ln 4}+0.16 \ln \zeta\right]^{-1}, \\
& \zeta=\frac{R_{Y}}{R_{X}} \text { with } 0<\zeta \leq 1 .
\end{aligned}
$$


The complete elliptic integrals of the first and second kind $\mathbf{K}(m)$ and $\mathbf{E}(m)$, respectively, are approximated by [24]:

$$
\begin{aligned}
\mathbf{K}(m) \approx & \frac{\pi}{2}(m-1)\left[1+\frac{2 m}{\pi(1-m)} \ln \left(\frac{4}{\sqrt{1-m}}\right)\right. \\
& \left.-\frac{3}{8} \ln (1-m)\right], \\
\mathbf{E}(m) \approx & \frac{\pi}{2}(m-1)\left[1+\frac{2 m}{\pi(1-m)}-\frac{1}{8} \ln (1-m)\right],
\end{aligned}
$$

with $m=1-\kappa^{2}$. $\mathbf{K}(m)$ and $\mathbf{E}(m)$ were solved numerically using Matlab, the variations with respect to the approximations in Eqs. (4C.4) and (4C.5) were within $0.25 \%$. 


\title{
Chapter 5
}

\section{Dry friction characterisation of carbon fibre tow and satin weave fabric for composite applications $^{1}$}

\begin{abstract}
Composites forming processes such as resin transfer moulding (RTM) typically involve a preforming step in which dry fabric material is deformed. Frictional forces in tool-fabric and fabric-fabric contacts determine the fabric deformation behaviour to a large extent. The frictional behaviour of the reinforcements is anisotropic and pressure dependent, due to the geometrical and material properties of the fibrous constituents. Previous investigations of the frictional behaviour of fibrous materials were mostly performed on a particular scale, i.e. the microscopic filament scale, the mesoscopic tow scale, or the macroscopic fabric scale. This study aims to provide a coupling between these scales by means of friction experiments on both carbon tows and carbon fabric made of the same tow material in contact with two metal counterfaces with a different roughness. The friction of a carbon 5 harness satin (5HS) weave on metal was measured on a capstan and a flat platefriction setup. The frictional behaviour of fabric was comparable to that of single tows for matching pressures based on the mesoscopic contact area with the metal counterface. This outcome provides a sound and practical basis for modelling of the frictional behaviour of sliding fabric on metal, based on the frictional behaviour of single tows. Furthermore, the agreement of the results forms a validation of both friction characterisation methods.
\end{abstract}

\footnotetext{
${ }^{1}$ Reproduced from: B. Cornelissen, U. Sachs, B. Rietman, R. Akkerman, Dry friction characterisation of carbon fibre tow and satin weave fabric for composite applications, Submitted to: Composites: Part A, 2012.
} 


\subsection{Introduction}

Preforming processes like resin transfer moulding (RTM) are often performed with dry reinforcement material. Friction plays an important role in these preforming processes. In the past several studies related to frictional behaviour of fibrous materials were performed on different geometrical scales, from the microscopic single filament level studied by Roselman and Tabor [1] to the macroscopic level in which the deformation behaviour of entire multiaxial, multiply stitched preforms was investigated by Lomov et al [2]. Hivet et al. focused on the mesoscopic effect of fabric interlocking on the frictional behaviour of fabric-fabric contact and presented tow-tow friction experiments as well [3].

This work aims to provide a coupling between the micro-mesoscopic frictional behaviour of tows and the behaviour of fabric material on the meso-macroscopic level. With this purpose in mind and the micro-mesoscopic frictional behaviour of tows covered in Chapter 2, the focus lies on the frictional behaviour of tow and fabric material in contact with a metal counterface. Tow-tow and fabricfabric contact measurements are possible as well, although these measurements are not addressed in this work. Figure 5.1 illustrates the multi-scale nature of composite materials in a three-level decomposition with the associated length scale for each level. Additionally, the associated contact areas and pressures addressed in subsequent sections are included.

Carbon fibre tow and fabric specimens made from the same tow material were used in friction experiments. The friction between 5 Harness Satin (5Hs) carbon fabric and mild steel was determined on two different experimental setups in order to validate the employed capstan setup. In the capstan setup approach, a ribbon of dry carbon fabric was wrapped around a rotating metal drum, measurements on tows extracted from the fabric were performed in the same manner. In the second setup a fabric specimen was pulled through two metal clamping blocks with plane surfaces. Both experimental setups have different

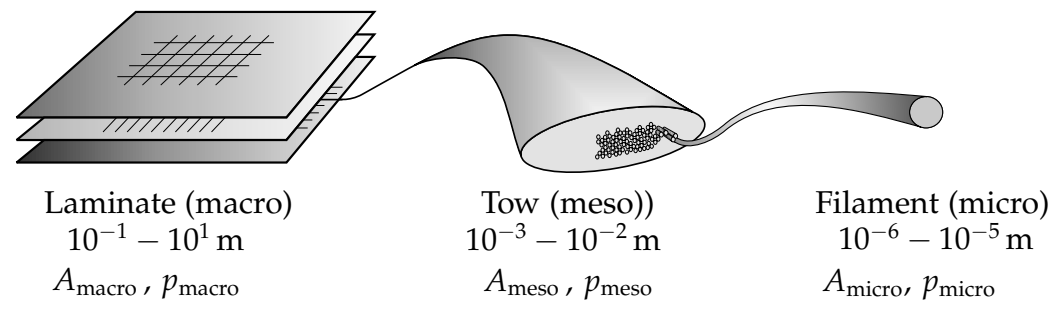

Figure 5.1 Hierarchical structure of a typical composite product and its constituents with their characteristic length scales. The associated contact areas $A$ and pressures $p$ are addressed in the following sections. 
sliding velocity and loading capabilities with some overlap. Measurements in this overlap region were compared and were used as a validation for both friction measurement setups. A straightforward relation between the friction of fibrous tows and $5 \mathrm{Hs}$ fabric on the capstan setup is proposed, based on contact area measurements.

Section 5.2 provides detailed information on the specimen materials and the experimental setups. The two different experimental setups are described and the relevant material properties are listed in this section. In Section 5.3 a relation is proposed between the frictional forces and the contact area, for both tow and fabric materials in contact with a metal counterface. The presented approach is based on experimental observations and modelling work of the frictional behaviour of fibrous tows [4] (Chapters $2-4$ ). The results of the performed friction measurements on tow and fabric material for the current work, including a summary of the observations, are presented in Section 5.4. Subsequently, the relation between tow and fabric friction and the relevant mechanisms is discussed in Section 5.5, together with a comparison of both experimental methods. Finally, Section 5.6 presents the general conclusions from this study.

\subsection{Materials and methods}

Tow and fabric friction measurements were performed on a capstan setup for two different metal counterfaces. Additionally, fabric friction measurements were performed on a plate-friction setup on one of the metal counterfaces. This section describes the properties of the fibrous tow and fabric material, as well as the properties of the metal counterface materials. The measurement methods that were applied in the capstan and plate-friction setup are explained.

\subsubsection{Tow and fabric material}

The fabric material for the experiments was provided by Ten Cate Advanced Composites. The fabric was woven in a weight balanced 5 Hs pattern, as shown in Figure 5.2. However, this weave is not balanced geometrically, due to a difference in crimp ratio between the warp and weft direction, originated by the nature of the weaving process. A surface finish to protect and facilitate handling was applied on the carbon fibre tows by the tow manufacturer, Torayca. This finish was removed after weaving by Ten Cate by means of a thermal treatment.

The tow specimens were extracted from the fabric material to ensure identical material and surface properties. Friction experiments on the capstan setup, which is described in Section 5.2.3, were performed on tow as well as fabric specimens on two different counterfaces. Validation measurements were performed with fabric specimens on a plate-friction setup, which is described 
Table 5.1 Properties of the 5Hs carbon fibre fabric used in the friction experiments (manufactured by Ten Cate Advanced Composites, type: CD 0286). The fabric was woven with Torayca T300JB tow material.

\begin{tabular}{lccc}
\hline Description & Symbol & Unit & Value \\
\hline Areal weight & $W_{\text {area }}$ & $\mathrm{g} / \mathrm{m}^{2}$ & 285 \\
Warp count (fabric) & $C_{\text {warp }}$ & tows $/ \mathrm{m}$ & 700 \\
Weft count (fabric) & $C_{\text {weft }}$ & tows $/ \mathrm{m}$ & 700 \\
Filaments count (tow) & $n_{\text {fil }}$ & & 3000 \\
Filament diameter & $d_{\text {fil }}$ & $\mu \mathrm{m}$ & 7.0 \\
Linear density (tow) & $D$ & tex & 198 \\
Axial E-modulus (tow) & $E_{\text {axial }}$ & $\mathrm{GPa}$ & 230 \\
Transverse E-modulus (tow) & $E_{\text {trans }}$ & $\mathrm{GPa}$ & 15 \\
\hline
\end{tabular}

in Section 5.2.4. The properties of the tow and fabric material are summarised in Table 5.1.

\subsubsection{Friction in textile materials}

This work deals with the friction of dry tow and fabric material. The term $d r y$ in this context refers to the absence of a lubricating film between the two interacting materials, such as the surface finish applied by the tow manufacturer.

The well-known Coulomb friction law is the most straightforward approach to characterise the dry friction between two sliding materials. The frictional force $F_{\mathrm{f}}$ is considered to be directly proportional to the applied normal load $N$ through

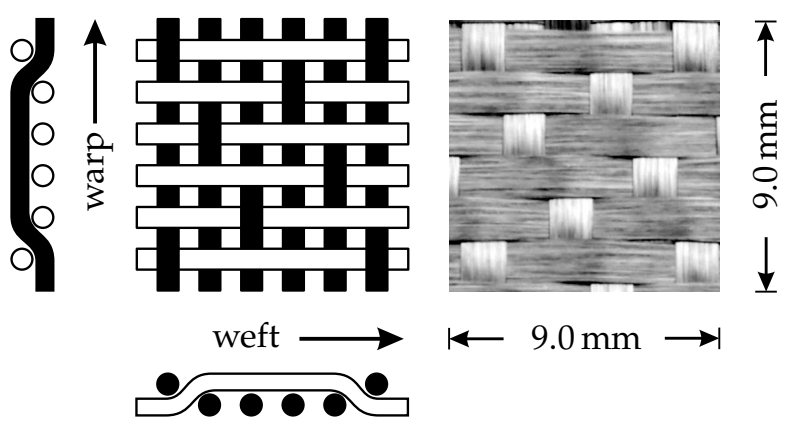

Figure 5.2 Schematic overview and photographic detail of the 5Hs weave used for the fabric friction measurements. 
the coefficient of friction $\mu$ :

$$
F_{\mathrm{f}}=\mu N \text {. }
$$

However, the coefficient of friction has been observed to vary with the applied normal load on the tow, whereas the Coulomb friction implies a constant value $[5,6]$. This load dependency is included in Howell's equation, a widely accepted relation between the normal load and the resulting frictional force, given as [7]:

$$
F_{\mathrm{f}}=k N^{n},
$$

where $k$ is an experimentally determined proportionality constant, which relates the normal load $N$ to the frictional force $F_{\mathrm{f}}$. The load index $n$ is a fitting parameter that relates to the deformation mechanism in the real contact between asperities of the contacting surfaces. The value of $n$ ranges from $n=\frac{2}{3}$ for fully elastic deformation to $n=1$ for fully plastic deformation of the contacting asperities. The Howell approach of friction can be expressed in terms of Coulomb friction by substitution of $F_{f}$ in Equation (5.1) with Equation (5.2):

$$
\mu_{\mathrm{equ}}=k N^{n-1},
$$

where $\mu$ is in this case the Coulomb-type coefficient of friction that would be measured at the given normal load $N$. It is now clear that the calculated $\mu$ in Equation (5.1) would not remain constant with a variation of the normal load in the case of load-dependent material behaviour.

\subsubsection{Capstan friction setup}

The capstan measuring method has been widely applied since the beginning of the twentieth century. The first experiments were performed on cotton, wool, viscose, and nylon tow material [8-10]. Other synthetic materials like polyester were studied later as well [11-13]. The frictional behaviour of high modulus and strength materials like carbon and aramid has been studied on capstan setups by several authors starting from the seventies of the last century and is ongoing [14-18].

Figure 5.3 illustrates the capstan setup schematically. The tow specimens can be easily replaced by fabric specimens, since the width of the friction drum is $60 \mathrm{~mm}$.

The capstan relation gives the apparent coefficient of friction as a function of the tensile forces $T_{1}$ (ingoing) and $T_{2}$ (outgoing) in both specimen ends and the 


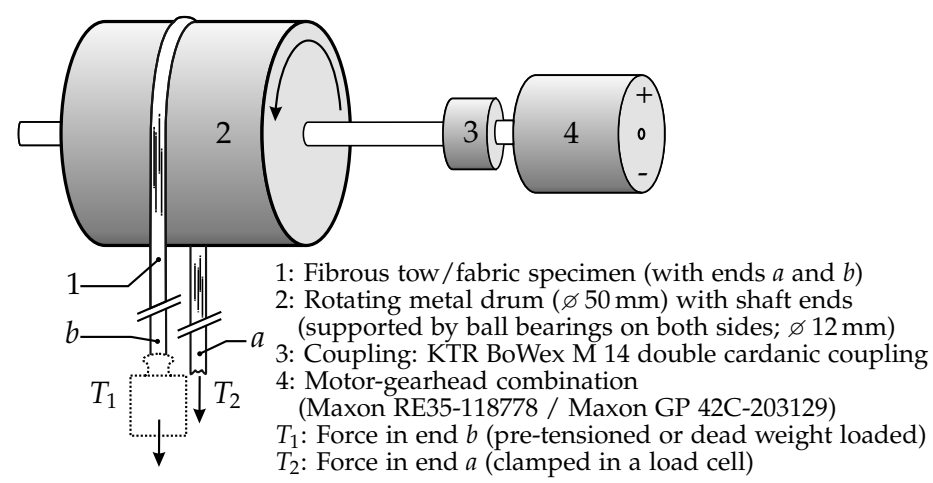

Figure 5.3 Schematic description of the capstan experiment for friction characterisation of fibrous tows.

wrapping angle $\theta$ of the specimen on the drum:

$$
\mu_{\mathrm{app}}=\ln \left(\frac{T_{2}}{T_{1}}\right) \frac{1}{\theta_{\mathrm{wrap}}}
$$

where $\theta_{\text {wrap }}=\pi$ in the experiments described in this work. The loads $T_{1}$ and $T_{2}$ were measured by means of load cells at both clamped ends of the fabric specimens, which had a total length of approximately $90 \mathrm{~cm}$. The tow specimens were loaded by attaching a dead weight to tow end $b$ in Figure 5.3; tow end $a$ was clamped in a load cell.

The apparent coefficient of friction $\mu_{\text {app }}$ is derived from the measured capstan frictional force and is an integral quantity. The capstan measuring approach provides a comparison of the frictional behaviour of tow and fabric material on different counterfaces and loading conditions. The pressure dependency of the frictional force that follows from Equation (5.2) is inherently part of the apparent coefficient of friction, because the pressure on the specimen varies along the capstan friction drum. Thus, $\mu_{\mathrm{app}}$, which is a tow-counterface system parameter, reflects the average of a varying local coefficient of friction along the wrapped length of the specimen. The two counterfaces used in this work consist of a metal friction drum with a rough counterface and a drum with mild steel foil; both are further described in Section 5.2.5.

\subsubsection{Plate-friction setup}

To date, a variety of plate-type devices has been used on dry fabric material. Several researchers used a setup consisting of a horizontal surface on which a weight-loaded sled was pulled over a certain distance, a fabric specimen was 


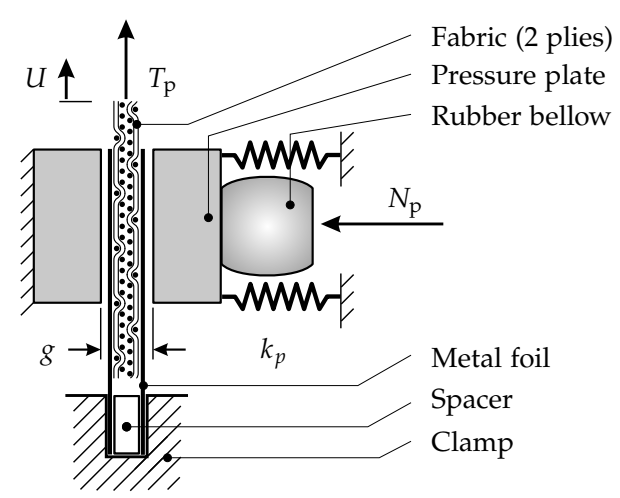

Figure 5.4 Schematic overview of the plate-friction setup.

attached to either one or both surfaces. For example, this device variant was used by Zurek et al. for fabric-fabric friction measurements of polymeric material [19], Virto and Naik in fabric friction experiments on steel, nylon, and rubber counterfaces [20]. Hivet et al. performed measurements in a similar fashion on carbon and glass fabrics, except that a sliding table and a stationary upper friction plate were used [3]. Vidal-Sallé and Massi performed carbon fabric-tow and tow-tow measurements on a comparable experimental setup [21].

Another setup variant consists of pulling a fabric specimen between two compressed plates. This option is favoured in the study of friction of fabric reinforcements in the presence of a thermoplastic matrix for stamp forming purposes [22-24]. In the present study a custom-built setup of this type [25, 26] was used to perform sliding friction tests with fabric sliding between two planar metal counterfaces under compression. The fabric specimen, with a total length of $180 \mathrm{~mm}$, was embedded between pressure blocks, which were covered with cold-rolled mild steel foil (the same type as on the capstan friction drum), as illustrated in Fig. 5.4. After closing the pressure plates by pressurising a pneumatic rubber bellow, the fabric was pulled upwards with a defined velocity $U$ utilising a universal testing machine. The apparent coefficient of friction $\mu_{\mathrm{app}}$ for the planar surface friction is readily calculated by:

$$
\mu_{\mathrm{app}}=\frac{T_{\mathrm{p}}}{2 N_{\mathrm{p}}},
$$

where $T_{p}$ is the required pulling force (measured with a $1 \mathrm{kN}$ load cell) in the longitudinal direction of the fabric at the applied normal load $N_{\mathrm{p}}$. The factor 2 in the denominator of Equation (5.5) is required, since two friction interfaces contribute to the required pulling force $T_{P}$.

An additional force caused by internal friction of the apparatus has to be 
overcome to close the pressure blocks. This force can be modelled as a spring with stiffness $k_{\mathrm{p}}$ and pretension $F_{0}$. The actual gap width $g$ between the blocks was measured by linear variable differential transformers (LVDTs). Then, $N_{\mathrm{p}}$ is calculated from the load F, measured by three $200 \mathrm{~N}$ load cells in the following manner:

$$
N_{\mathrm{p}}=F-F_{0}+k_{\mathrm{p}} g .
$$

The parameters for the spring stiffness $k_{\mathrm{p}}$ and the pretension $F_{0}$ were determined by a calibration procedure. Furthermore, the closing system is not perfectly elastic but exhibits some hysteresis. This limits the precision of the normal force measurement to $\pm 1.5 \mathrm{~N}$.

\subsubsection{Metal counterfaces}

The frictional interfaces used in this research were chosen from a production perspective. The topography of the metal foil represents metal tooling like RTM moulds or vacuum forming tools. The material was used in the form of foil to provide identical surface topographies on both experimental setups. A self-adhesive variant of the foil was used on the capstan setup. The rough counterface of the metal capstan friction drum is used as a reference surface to assess the effect of a smaller real contact area between the specimen and the counterface. An extensive friction experiment was performed on the rough surface for carbon, aramid and E-glass fibre tows, reported in [4] (Chapter 2).

Table 5.2 lists the relevant properties of the two counterfaces and Figure 5.5 shows plots of the metal counterfaces made with laser confocal microscopy. The difference in surface structure between the two topographies is clearly visible (note the different scales of both $z$-axes). Table 5.3 gives an overview of which experiments were performed on which setups in terms of specimen type, topography type, and in the case of fabric, the orientation of the dominant tow contact with respect to the sliding direction of the friction drum. The fabric specimens were loaded along the weft tows (see Figure 5.2) in all cases, but by changing the side of the fabric on the counterface, the dominant contact was made by either the undulations in longitudinal (long.) or in transverse (trans.) direction.

\subsection{Friction and contact area}

In Chapter 3, it was shown that the friction for sliding tow-metal contact can be well predicted by assuming that the frictional force $F_{\mathrm{f}}$ is the product of the real contact area $A_{\mathrm{r}}$ on the filament level (microscale) and the interfacial shear 

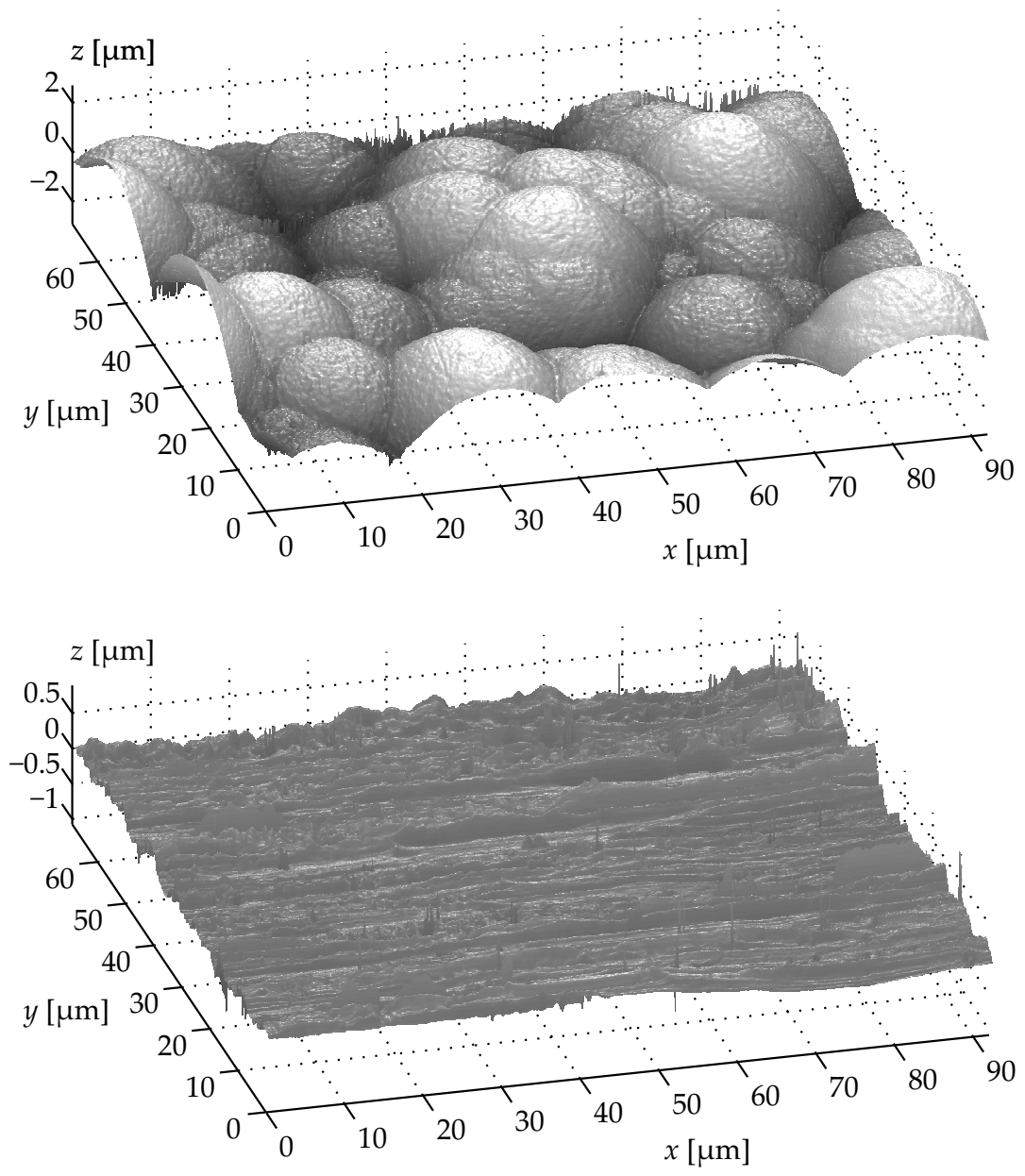

Figure 5.5 Laser confocal microscopy images $(92 \times 69 \mu \mathrm{m})$ of the metal friction drum and foil topographies (magnification $150 \times ; 1$ pixel represents $0.045 \times 0.045 \mu \mathrm{m}$ ). Top: Rough topography. Bottom: Foil topography. The z-scale is magnified with respect to the $x$-and $y$-scale. Note the vertical scales of the surface plots, illustrating the difference in roughness scales between the two topographies. 
Table 5.2 Properties of the counterface materials used in the friction experiments in the form of a custom-made metal capstan friction drum with the 'rough' topography and cold-rolled mild steel foil, manufactured by Georg Martin (type: M-Tech F), denoted 'foil'. The latter was used for plate-friction measurements as well.

\begin{tabular}{clccc}
\hline Topography & Description & Symbol & Unit & Value \\
\hline \multirow{2}{*}{ Rough } & Drum radius & $R_{\text {drum }}$ & $\mathrm{mm}$ & $25 \pm 0.01$ \\
& Roughness (RMS) & $\mathrm{Sq}$ & $\mu \mathrm{m}$ & 1.1 \\
\cline { 2 - 5 } Foil & Thickness & $t$ & $\mathrm{~mm}$ & $0.050 \pm 0.005$ \\
& Roughness (RMS) & $\mathrm{Sq}$ & $\mu \mathrm{m}$ & 0.11 \\
\hline
\end{tabular}

Table 5.3 Summary of the setup/topography/fabric/orientation combinations for tow and fabric friction experiments. Abbreviations: long. denotes a longitudinal orientation of the dominant undulations in the fabric with respect to the sliding direction, whereas trans. denotes a transverse orientation.

\begin{tabular}{ccc}
\hline Topography & Capstan & Plate-friction \\
\hline Rough & Tow, Fabric long./trans. & \\
Foil & Tow, Fabric long. & Fabric long. \\
\hline
\end{tabular}

strength $\tau$ of the friction interface (based on the adhesion theory of friction [14]):

$$
F_{\mathrm{f}}=A_{\mathrm{r}} \tau \text {. }
$$

The microscopic contact area of a carbon filament on a counterface with a topography consisting of many asperities is about $10 \%$ of the nominal contact area $A_{\mathrm{n}}$, i.e. a Hertzian line contact assuming perfectly smooth surfaces, see Section 3.3. The microscopic contact area $A_{\text {micro }}$ of a filament on a relatively smooth surface, represented by the foil material, is larger than that on a surface with a higher roughness (i.e. the rough topography) at equal load. The frictional behaviour of fibrous tows was predicted based on filament level contact calculations taking the amount of filaments in direct contact with a metal counterface into account [4]. In turn, the fabric consists of fibrous tows. Consequently, the friction of fabric instead of tow material on metal should depend on $A_{\mathrm{r}}$ in the same way. The interfacial shear strength $\tau$ of the fabric-metal system is assumed to be identical to that of the tow-metal system, i.e. $100 \mathrm{MPa}$, discussed in Chapter 3. The fabric specimens were loaded at comparable macroscopic pressure values $p_{\text {macro }}$. Here, the pressure is determined from the macroscopic or projected area of the specimen on the counterface $A_{\text {macro }}$ :

$$
p_{\text {macro }}=\frac{N_{\mathrm{p}}}{A_{\text {macro }}} \text {. }
$$


Table 5.4 Experimental settings for the capstan and plate-friction setups.

\begin{tabular}{lcccc}
\hline Description & Symbol & Unit & Plate-friction & Capstan \\
\hline Sliding velocity & $U$ & $\mathrm{~mm} / \mathrm{min}$ & $0.03-1000$ & $1000-2000$ \\
Macroscopic contact area & $A_{\text {macro }}$ & $\mathrm{mm}^{2}$ & $50 \times 50$ & $78.5 \times 25 / 50^{(*)}$ \\
Applied normal load & $N_{\mathrm{p}}$ & $\mathrm{N}$ & $25-250$ & $31-66^{(* *)}$ \\
Macroscopic pressure & $p_{\text {macro }}$ & $\mathrm{kPa}$ & $10.0-100$ & $8.0-16.8 / 16.0-33.6$ \\
\hline${ }^{(*)}$ Two widths of the specimens were used to vary the macroscopic pressure. \\
${ }^{(* *)}$ Calculated from the tensile load in the specimen: $N_{\mathrm{p}}=\pi R_{\text {drum }} T / R_{\text {drum }}[4]$ (Chapter 2).
\end{tabular}

Table 5.4 summarises the normal forces and the corresponding macroscopic pressures during testing.

The comparison between tow and fabric friction is based on the assumption that approximately the same amount of tow material is in contact with the counterface. Here, $A_{\text {macro }}$ of a fabric specimen on the capstan drum would overestimate the amount of contact due to the undulations in the fabric. We thus seek for a measure to account for the fabric architecture without having to determine the microscopic contact area $A_{\text {micro }}$ filament by filament, while simultaneously taking the contribution of undulations into account.

For that purpose, we introduce the mesoscopic contact area $A_{\text {meso. }}$ For an individual tow $A_{\text {meso }}$ equals its macroscopic (or projected) area of contact $A_{\text {macro }}$, i.e. its width multiplied by its contact length on the capstan drum. For the fabric specimens, it is a contact area that was determined by static loading of fabric specimens on both experimental setups.

A practical method was used to characterise $A_{\text {meso }}$. In this procedure pieces of (mildly) adhesive tape were gently attached to the 5Hs carbon specimens with their adhesive side facing the carbon material. Subsequently, the specimens were mounted in each setup and load was applied as if a regular sliding measurement was performed, except that no displacement was imposed. Consequently, the tape was brought into intimate contact with a part of the fabric, starting at the most protruding parts of the undulations of the dominant weaving direction. This led to small elliptic areas $A_{\text {meso }}^{(i)}$ (indicated in Figure 5.6) where the undulated tows came in direct contact with the tape. The mesoscopic contact area is the sum of the individual elliptic areas:

$$
A_{\text {meso }}=\sum_{i} A_{\text {meso }}^{(i)}
$$

Thus, the mesoscopic pressure $p_{\text {meso }}$ follows from the applied normal load and $A_{\text {meso: }}$ :

$$
p_{\text {meso }}=\frac{N_{\mathrm{p}}}{A_{\text {meso }}},
$$



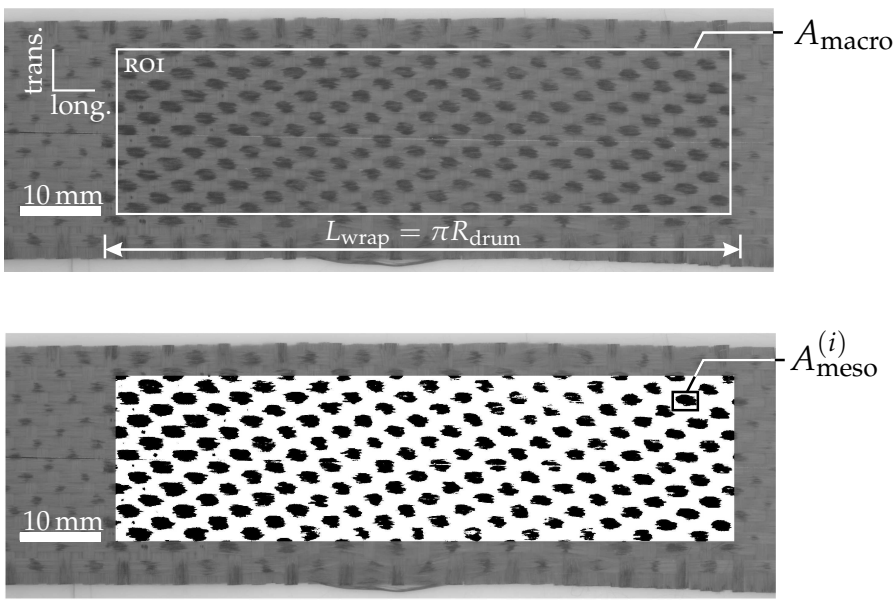

Figure 5.6 Mesoscopic contact determination of a 5Hs fabric specimen on the capstan friction drum by static loading of a specimen with adhesive tape between the specimen and the counterface. Top: Part of the fabric ribbon that was in contact with the friction drum with the white rectangle marking the Region Of Interest (ROI). Bottom: Thresholded RoI where the mesoscopic contact is approximately $30 \%$ of the total RoI area.

where $A_{\text {meso }} \leq A_{\text {macro }}$ by definition and thus $p_{\text {meso }} \geq p_{\text {macro }}$.

Photographs were taken after removing the fabric specimens from the setup. The difference in contrast between intimate contact locations and the rest of the fabric was large enough to separate the areas by thresholding. Figure 5.6 shows this area for the capstan setup, whereas Figures 5.7 to 5.9 show the results for the plate-friction setup at three different values of $p_{\text {macro }}$.

\subsection{Results}

Some typical force measurements and the resulting apparent coefficient of friction $\mu_{\text {app }}$ on the capstan setup are illustrated in Figure 5.10. The graph shows the typically periodic signal of the load cells, which was recorded at a sampling frequency of $10 \mathrm{~Hz}$. The period of the signal coincides with the rotational velocity of the friction drum, which is clearly illustrated by the signals of fabric on the foil at 1000 and $2000 \mathrm{~mm} / \mathrm{min}$. The shape of the curve originates from geometrical and alignment imperfections of the friction drum. The signal for measurements with the foil counterface shows a distinct block-like shape, caused by a small overlap region $(\approx 10 \mathrm{~mm})$ of the foil. When the locally double foil thickness passed the tow contact region, it caused an almost instantaneous increase of the tensile force in both specimen ends. Therefore there was no significant phase difference between the $T_{1}$ and $T_{2}$ signals. 

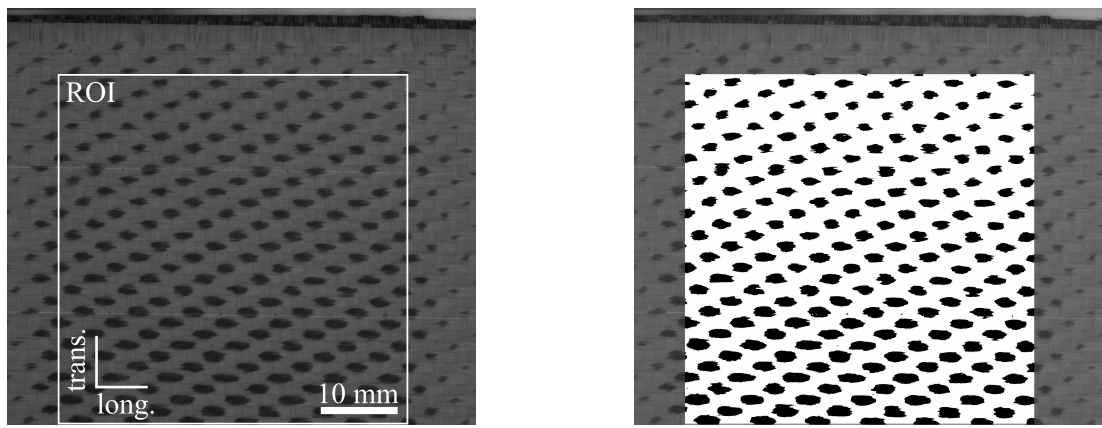

Figure 5.7 Mesoscopic contact area of a 5Hs fabric specimen in the plate-friction setup. Left: Contacting part in the pressure plates at $p_{\text {macro }}=20 \mathrm{kPa}$. The white rectangle marks the Region Of Interest (ROI). Right: Thresholded ROI, the mesoscopic contact area is approximately $24 \%$ of the total RoI $(2000 \times 2000$ pixel $\approx 45.7 \times 45.7 \mathrm{~mm})$.
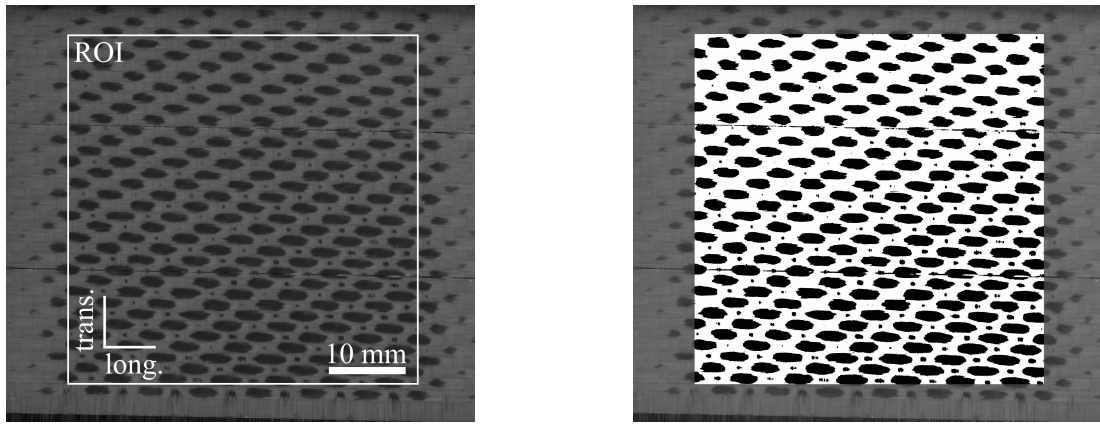

Figure 5.8 Mesoscopic contact area of a 5Hs fabric specimen in the plate-friction setup. Left: Contacting part in the pressure plates at $p_{\text {macro }}=60 \mathrm{kPa}$. The white rectangle marks the region of interest (ROI). Right: Thresholded ROI, the mesoscopic contact area is approximately $39 \%$ of the total ROI $(2000 \times 2000$ pixel $\approx 45.7 \times 45.7 \mathrm{~mm})$.
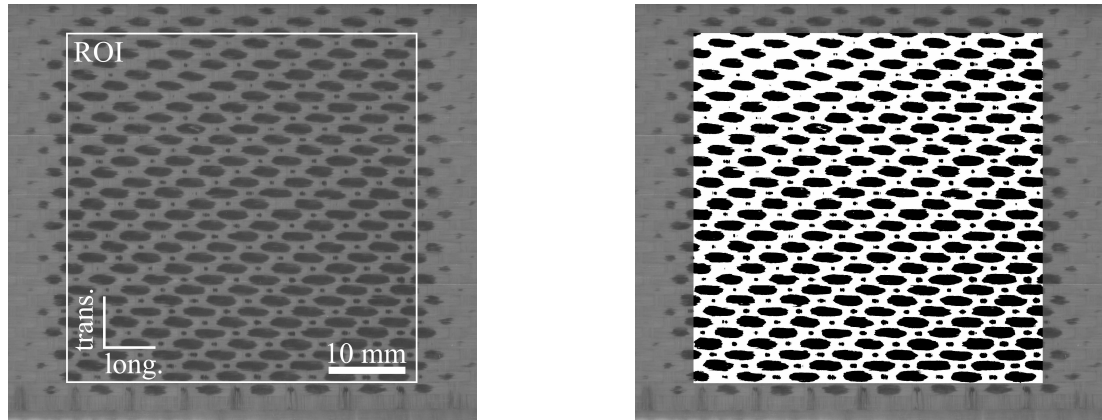

Figure 5.9 Mesoscopic contact area of a 5Hs fabric specimen in the plate-friction setup. Left: Contacting part in the pressure plates at $p_{\text {macro }}=100 \mathrm{kPa}$. The white rectangle marks the region of interest (ROI). Right: Thresholded ROI, the mesoscopic contact area is approximately $45 \%$ of the total ROI $(2000 \times 2000$ pixel $\approx 45.7 \times 45.7 \mathrm{~mm})$. 

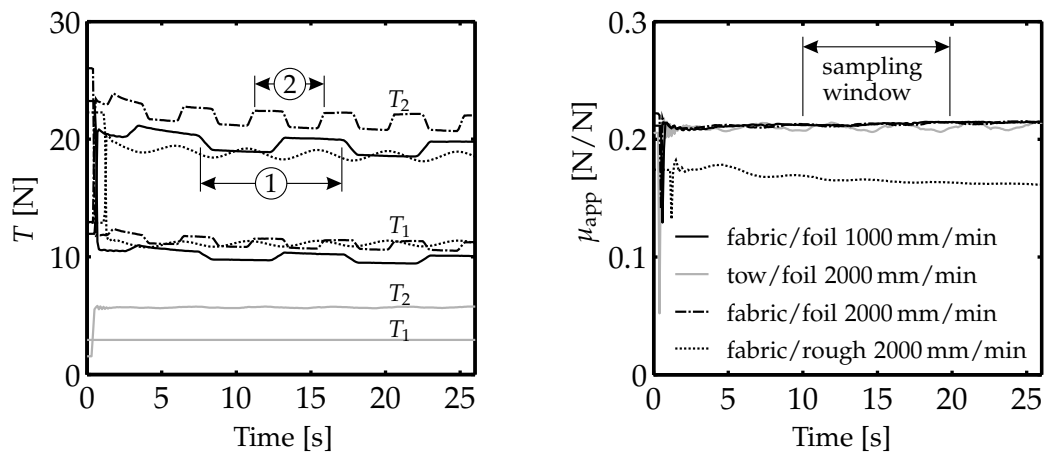

Figure 5.10 Left: Typical measurements on the capstan setup of the ingoing tensile loads $T_{1}$ and outgoing tensile loads $T_{2}$. The symbol (1) shows the period of one drum revolution at a sliding velocity of $1000 \mathrm{~mm} / \mathrm{min}$ and (2) at a sliding velocity of $2000 \mathrm{~mm} / \mathrm{min}$. Right: Corresponding $\mu_{\mathrm{app}}$ as a function of time. The abrupt changes of $T_{1}, T_{2}$ and $\mu_{\mathrm{app}}$ in the first seconds of each measurement were caused by the motor start-up. The value of $\mu_{\mathrm{app}}$ was sampled in the time interval $10.0 s-19.6 s$.
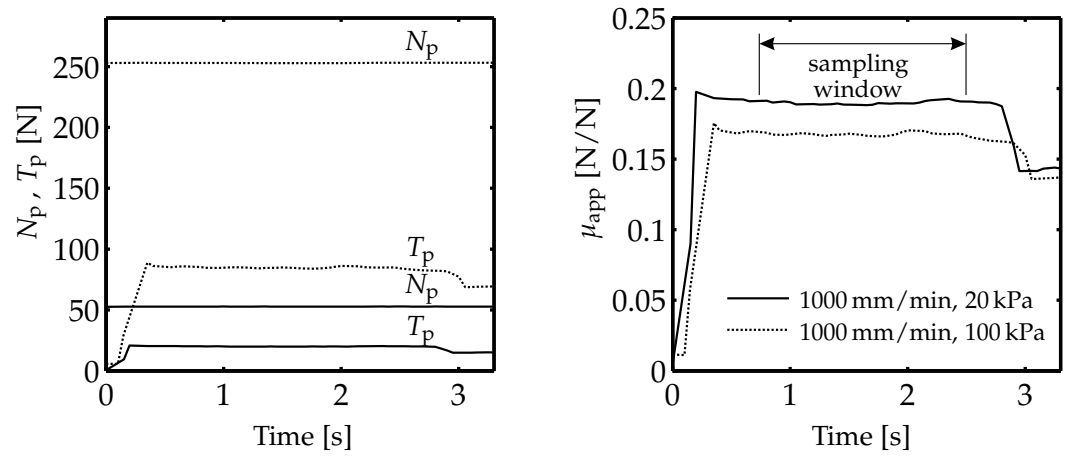

Figure 5.11 Typical measurements on the plate-friction setup at a constant pulling velocity. Left: Graph with the typical normal load $N_{\mathrm{p}}$ and pulling force $T_{\mathrm{p}}$ for two measurements on $5 \mathrm{HS}$ fabric specimens. The associated pressures are $p_{\text {macro }}=100 \mathrm{kPa}$ for $N_{\mathrm{p}} \approx 250 \mathrm{~N}$ and $p_{\text {macro }}=20 \mathrm{kPa}$ for $N_{\mathrm{p}} \approx 50 \mathrm{~N}$. Right: Corresponding $\mu_{\mathrm{app}}$ values of the typical fabric friction measurements. The value of $\mu_{\mathrm{app}}$ was sampled in the flat part of the graph, typically in the range $0.7-2.5 \mathrm{~s}$ for $U=1000 \mathrm{~mm} / \mathrm{s}$. 


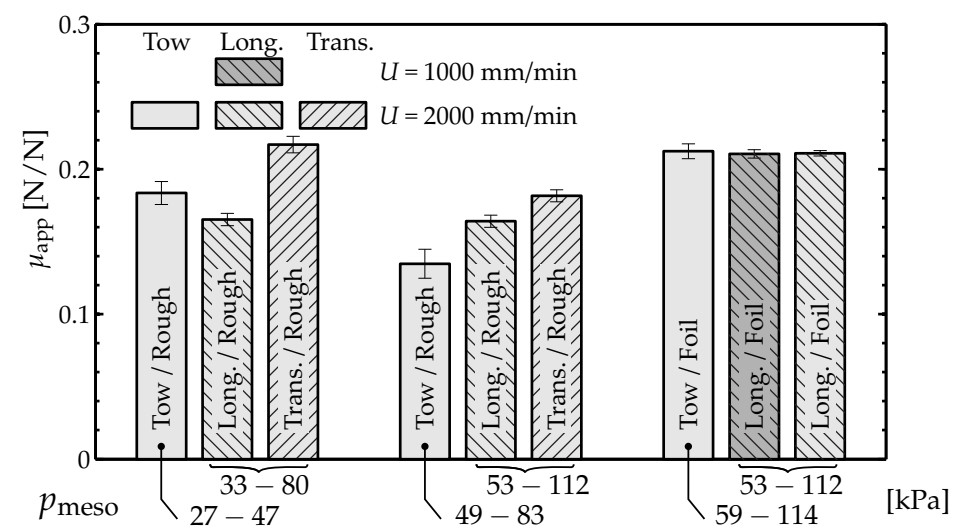

Figure 5.12 Results of the capstan friction experiments with tow and fabric material on two different counterfaces, 'Rough' and 'Foil'. The ranges of the mesoscopic pressure $p_{\text {meso }}$ are shown separately for the tow and fabric specimens. These pressure ranges were estimated from the mesoscopic contact area $A_{\text {meso }}$ and the applied loads at the specimen ends.

Figure 5.12 summarises the capstan friction measurements on both tow and fabric specimens on the rough and foil counterface. The measurements on the rough counterface were performed at two macroscopic pressure ranges by varying the fabric specimen width $(25$ and $50 \mathrm{~mm})$.

The tow friction measurements were performed by attaching a dead weight to one of the tow ends. The weight was $300 \mathrm{~g}$ to represent the high mesoscopic pressure range $49 \leq p_{\text {meso }} \leq 83 \mathrm{kPa}$ (rough), $59 \leq p_{\text {meso }} \leq 114 \mathrm{kPa}$ (foil) and $162 \mathrm{~g}$ to represent the low mesoscopic pressure range $27 \leq p_{\text {meso }} \leq 47 \mathrm{kPa}$. The mesoscopic contact area $A_{\text {meso }}=30 \%$ of $A_{\text {macro }}$ for the fabric on the capstan was taken into account in the determination of the required dead weights. The variation of the $p_{\text {meso }}$ ranges between the rough and foil measurements on tow was caused by the different amount of spreading of the tow during the measurements, this is further discussed in Section 5.5.1.

The bar plot in Figure 5.12 is divided into three groups, based on the macroscopic pressure and the counterface type. The first two groups show the results for tow and fabric friction on the rough counterface. The fabric specimens were measured with both the longitudinal and transverse dominant side facing the metal friction drum.

The sliding friction of the tows is comparable to that of the fabric in longitudinally dominant contact, but an exception is formed by the low apparent coefficient of friction for the tow on the rough counterface at $49 \leq p_{\text {meso }} \leq$ $83 \mathrm{kPa}$. This observation is further discussed in Section 5.5.1.

The third set of bars in the plot shows the results for friction of tow and fabric material on the metal foil. The fabric friction was measured for longitudinally 

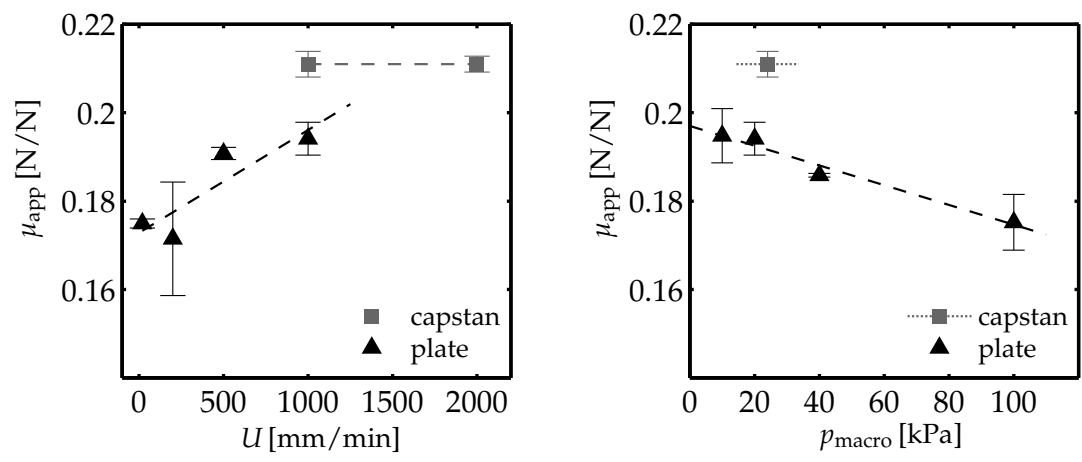

Figure 5.13 Results of capstan and plate-friction measurements on fabric for the 'Foil' counterface. Left: $\mu_{\text {app }}$ with varying sliding velocity $U\left(p_{\text {macro }}=20 \mathrm{kPa}\right)$. Right: $\mu_{\text {app }}$ with varying pressure $p_{\text {macro }}(U=1000 \mathrm{~mm} / \mathrm{min})$. In the capstan experiment $p_{\text {macro }}$ varied along the wrapped length of the specimen, the dotted line indicates the pressure range.

dominant contact only, since the transversely dominant direction measurements could not be performed on the plate-friction setup (the tows were simply pulled out of the fabric). The fabric friction was measured at two velocities, no significant effect of the velocity was observed. Therefore we conclude that the frictional behaviour of the fabric is well represented by the single tow, as long as the applied load leads to comparable mesoscopic pressure values.

Figure 5.11 shows two typical measurements for the plate-friction setup. The left graph shows the applied normal load and the measured pulling force on the universal testing machine. The right graph shows the obtained $\mu_{\text {app }}$ as a function of time. The sampling rate was not constant in this setup, which explains, for example, the difference in slope of the curves in the first tens of seconds. Figure 5.13 shows $\mu_{\text {app }}$ for the plate-friction measurements of fabric against foil. The aforementioned capstan measurements of fabric on foil are plotted for comparison in grey. The left graph in Figure 5.13 shows the apparent coefficient of friction as a function of the sliding velocity $U$ at a fixed value of $p_{\text {macro }}=20 \mathrm{kPa}$. The results suggest a velocity-dependent frictional behaviour, which was not observed on the capstan setup. This observation is discussed in Section 5.5.2.

The right graph in Figure 5.13 shows the pressure dependency of $\mu_{\text {app }}$ at a fixed pulling velocity $U=1000 \mathrm{~mm} / \mathrm{min}$. The black dashed line represents a linear fit through the plate-friction results. An interpretation of this decreasing trend with pressure is provided in Section 5.5.2. The photographs and subsequent image analysis in Figures 5.7 to 5.9 suggest a non-uniform pressure distribution on the fabric specimens. This observation is discussed separately in Section 5.5.2. 


\subsection{Discussion}

The results in Section 5.4 showed that the obtained apparent coefficients of friction for fabric on the metal foil are in approximately a $10 \%$ range of each other when the values from the setups are compared. However, several observations need further investigation to better understand the presented results. The details of these observations are first discussed for the capstan experiment in Section 5.5.1. Next, an investigation of the results for fabric friction on both setups is discussed in Section 5.5.2. Section 5.5.3 discusses the practical advantages and disadvantages of both setups.

\subsubsection{Capstan setup: Tow versus fabric friction}

The frictional behaviour of both tow and fabric specimens was investigated on the capstan friction setup. Here the observations presented in Section 5.4 are further discussed. The observed trends of $\mu_{\text {app }}$ for tow and fabric specimens are discussed. Next, the effect of a variation in dominant tow orientation in the fabric on the observed frictional behaviour is addressed.

\section{Trends in frictional behaviour}

A closer look at Figure 5.12 shows a different behaviour of the tow and fabric specimens on the rough counterface, whereas the results for the foil counterface resulted in nearly identical apparent coefficients of friction. The filaments in the individual tows have more freedom to reorganise than those in the fabric, because the weave pattern limits the freedom of movement of the filaments. Consequently, a different frictional behaviour could be observed between tow and fabric measurements on the same counterface for similar mesoscopic pressures $p_{\text {meso }}$.

The average tow width after the capstan measurements was $2.3 \mathrm{~mm}$ on both measurement sets on the rough and $2.0 \mathrm{~mm}$ on the foil counterface. These average tow widths were based on five measurements in each sample and were measured with callipers. A larger tow width results in a lower mesoscopic pressure on a larger contact area, in turn leading to a higher apparent coefficient of friction. Since the amount of spreading of the individual tows on the rough counterface was larger than that on the foil counterface, the difference of the $\mu_{\text {app }}$ between tow and fabric should be larger for the rough than for the foil counterface, i.e. $\mu_{\text {app }}$ should indeed be higher for the tow measurements than for the longitudinal fabric measurements.

The results of tow and fabric friction on the rough counterface in Figure 5.12 appear to confirm this reasoning for the low meso pressure range $27 \leq p_{\text {meso }} \leq 47 \mathrm{kPa}$ for the tow and $33 \leq p_{\text {meso }} \leq 80 \mathrm{kPa}$ for the fabric 
specimens. However, the value of $\mu_{\mathrm{app}}=0.13$ for the higher mesoscopic pressure range $49 \leq p_{\text {meso }} \leq 83 \mathrm{kPa}$ for the tow measurements is rather unexpected. Currently, we do not have an explanation for this result. The environmental humidity ranged between $52.8 \% \mathrm{RH}$ and $54.0 \% \mathrm{RH}( \pm 0.1 \% \mathrm{RH})$ for the $162 \mathrm{~g} \hat{=} p_{\text {meso }}=27-47 \mathrm{kPa}$ measurement and between $62.3 \% \mathrm{RH}$ and $63.3 \% \mathrm{RH}( \pm 0.1 \% \mathrm{RH})$ for the $300 \mathrm{~g}$ measurements. The recorded temperature values varied from $23.2^{\circ} \mathrm{C}$ to $23.4^{\circ} \mathrm{C}$ for $162 \mathrm{~g}$ and $23.4^{\circ} \mathrm{C}$ to $23.5^{\circ} \mathrm{C}\left( \pm 0.1^{\circ} \mathrm{C}\right)$ for the $300 \mathrm{~g}$ measurements. These variations are not likely to cause the observed difference in $\mu_{\mathrm{app}}$ between the measurements of tow friction on the rough topography.

Tow friction measurements on the rough friction topography in Chapter 2 on identical tow material, which received the same thermal treatment, yielded a significantly higher value of $\mu_{\mathrm{app}}=0.17$. The tow used in the latter situation was heat treated on the bobbin directly and not extracted from the fabric. The tows from the bobbin showed slightly less cohesion than the tows extracted from the fabric when pulling the tows apart in transverse direction. This could indicate that a larger remainder of sizing was still present on the tows extracted from the fabric than the tow specimens from the bobbin. Additionally, the relative humidity range during this set of measurements was lower, $32.5-33.6 \% \mathrm{RH}( \pm 0.1 \% \mathrm{RH})$. Therefore, it is difficult to compare these measurement results directly.

\section{Fabric orientation}

The apparent coefficient of friction for the transversely dominant contact was higher than that for the longitudinally dominant side. This is probably caused by the tendency of the filaments to start rolling. Since the filaments are kept in place by the crossing weft tows, there is no freedom to roll and a sliding motion takes place. This is a different behaviour than that of the longitudinally dominant sliding, where the majority of the contacting filaments experiences sliding in the axial filament direction. This stick-slip-like inhibited rolling mechanism is not further elaborated upon in this work. A comparable discussion of the effect of transversely dominant fabric friction can be found in [27].

\subsubsection{Comparison of fabric friction on both setups}

The following subsections elaborate on the observed variations in fabric friction on the foil topography. The setup-specific load application as well as the observed velocity and pressure dependencies are addressed. 


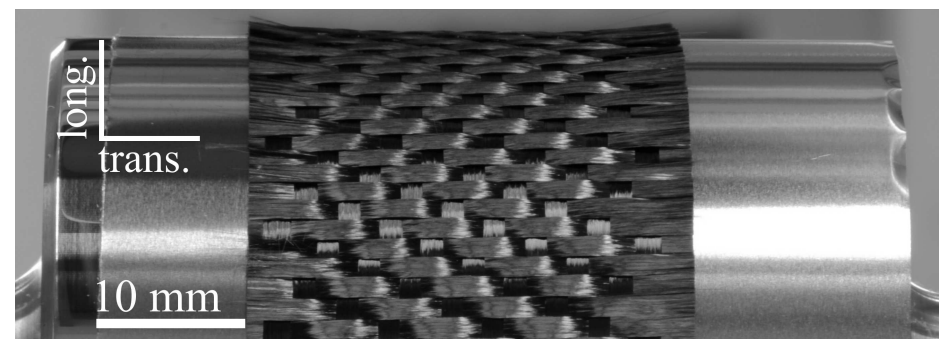

Figure 5.14 Detail of a 5Hs fabric specimen on the capstan setup. The undulations in the fabric are visible; the longitudinally dominant side of the fabric is in direct contact with the foil counterface.

\section{Load application}

The contact load on the capstan fabric specimen is induced by applying tensile forces at the specimen ends. The tows have some freedom to reorganise in a direction normal to the friction drum surface, corresponding to the through-thethickness direction of the fabric specimen. In other words, the tows in direct contact with the metal counterface can push other, non-directly contacting tows to the outside. This results in a change in undulation of the tows in the fabric specimen; Figure 5.14 shows a typical example of a $5 \mathrm{Hs}$ fabric specimen on the foil counterface for longitudinally dominant contact. The tows in the 2-ply fabric specimen in the plate-friction setup are constrained at both sides by the pressure plates and do not have the aforementioned freedom to reorganise. This difference in freedom of tows to reorganise will inherently affect the mesoscopic contact area $A_{\text {meso }}$ with the metal counterface. Consequently this will affect the measured apparent coefficient of friction $\mu_{\mathrm{app}}$. This phenomenon could be the cause of the absolute difference in apparent friction depicted by the graphs in Figure 5.13.

\section{Velocity dependency}

The left graph in Figure 5.13 shows a velocity-dependent frictional behaviour for the measurements on the plate-friction setup; the black dashed line shows a linear fit through the plate-friction data. The two velocities from the capstan setup measurements show no dependency of $\mu_{\mathrm{app}}$ on the sliding velocity, despite the relatively large difference of the applied velocities. Therefore, the observed velocity behaviour appears to be setup-dependent.

A closer look at the kinematics of both experiments shows that the fabric specimen in the capstan setup is stationary, whereas in the plate-friction setup it is pulled through the friction section. The latter system involves a constant input of 'fresh', uncompressed fabric material. The fabric is compacted when entering 
the friction section of the setup, which requires a certain amount of energy. The required compaction energy is supplied by the universal testing machine. A higher tensile force $T_{\mathrm{p}}$ is required if the fabric material is pulled through the friction section at a higher velocity, since the compaction energy is related to the volume of fabric passing the friction section per unit time. One could therefore speak of the required compaction power. At the same time the normal force $N_{\mathrm{p}}$ does not vary with the pulling velocity, which leads to a change of $\mu_{\mathrm{app}}$, in accordance with Equation (5.5). Of course this compaction phenomenon does not occur in the capstan test for stationary fabric specimens, which explains why no significant velocity dependency was observed for this setup type.

\section{Pressure dependency}

The expected pressure-dependent frictional behaviour of textile and tow material, mentioned in Section 5.2.2, could not be confirmed in the current work. The results of plate-friction measurements in the right graph of Figure 5.13 show a decreasing trend of $\mu_{\text {app }}$ with increasing $p_{\text {macro }}$. However, the pressure range is not sufficiently large to determine the coefficients $k$ and $n$ of the Howell relation of Equation (5.2) with acceptable confidence. We can conclude that the expected trend of a decreasing apparent coefficient of friction with pressure was observed qualitatively.

\section{Pressure distribution in the plate-friction setup}

The mesoscopic contact area measurements illustrated in Figures 5.7 to 5.9 showed a gradient of the size of the small elliptic contact areas $\left(A_{\text {meso }}^{(i)}\right)$ in the transverse direction of the RoI. This gradient appears as a result of a misalignment between the friction plates. Aligning two planar surfaces is known to be a difficult procedure and care was taken to avoid alignment problems when designing the device [25]. However, misalignment of the plates, in particular in the lower region of the macroscopic pressure range, could not be avoided.

The misalignment could be caused by the fabric specimen itself, since it consists of two stacked plies (with the weft-dominant side facing outward). Fabric interlocking should not cause a thickness variation, provided the tow spacing in the fabric is evenly distributed in both fabrics. To eliminate this as a possible source of misalignment, additional measurements were performed with load cells instead of fabric between the plates. An uneven load distribution over the three load cells was observed up to $p_{\text {macro }} \approx 60 \mathrm{kPa}$.

A scatter plot was made of the relative surface area of the elliptic contact shapes identified in the thresholding procedure of Section 5.3 for comparison. This plot is presented in Figure 5.15. The horizontal axis represents the position of elliptic areas in the transverse direction of the ROI, with the origin in the left top corner 


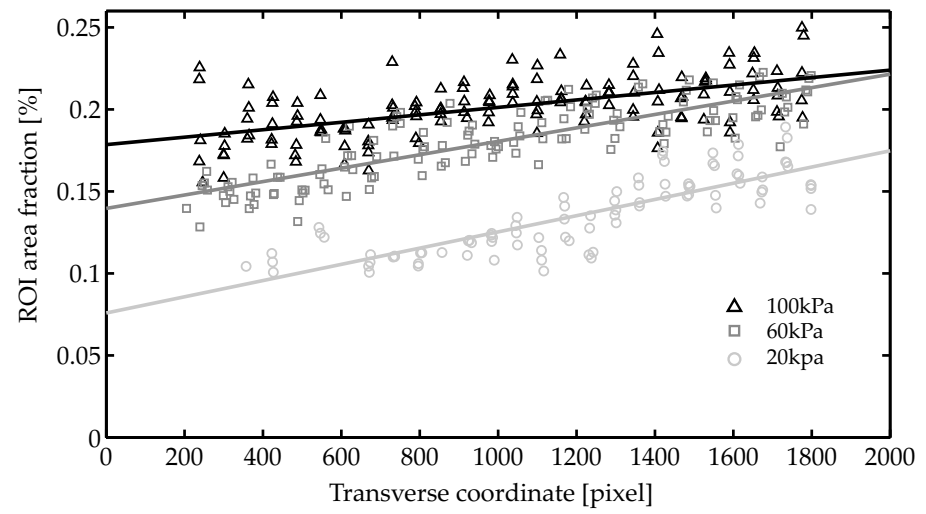

Figure 5.15 Fraction of the total RoI area of individual elliptic contact areas as a function of the transverse coordinate. The ROIs are shown in Figures 5.7 to 5.9.

(see Figures 5.7 to 5.9). A linear fit was made for each setting of $p_{\text {macro }}$ through the relative area of the elliptic contacts with respect to the total ROI area as a function of the position in transverse direction of the specimen. The slope of the fitted line is a measure for the misalignment. This graph shows a decreasing slope and thus a decreasing misalignment with increasing pressure, showing the same trend as the load cell verification results.

However, the misalignment error and the resulting pressure variation in the transverse direction do not make the friction measurement invalid. The apparent friction coefficient is influenced by the pressure variation, since the frictional behaviour of textile materials is pressure dependent. As mentioned before in Section 5.2.3, the apparent coefficient of friction is an integral quantity. The conclusion from this investigation is therefore that we can still speak of the apparent coefficient of friction, although the pressure distribution between the plates is not uniform. It would be appropriate to indicate a pressure range in the right graph of Figure 5.13 for the plate-friction measurements in the same manner as was done for the capstan measurement. However, the required absolute local pressure measurements are beyond the scope of this study.

The pressure variation across the friction tester plates can be estimated on the basis of the bulk compressibility $C_{\mathrm{b}}$ (unit $\mathrm{Pa}^{-1}$ ) of the fabric specimen between the plates. This bulk compressibility was estimated from the LVDT-data during the plate-friction measurements. The value of $C_{b}$ varies with $p_{\text {macro }}$ and the packing density of the filaments in the fabric specimens [28]. The resulting pressure difference $\Delta p_{\text {macro }}$ as a result of a misalignment distance $\Delta t$ is estimated as follows [28], neglecting the setup compliance:

$$
\Delta p_{\text {macro }}=-\frac{1}{C_{\mathrm{b}}} \frac{\Delta t}{t_{0}}
$$


where the typical thickness of the two-ply arrangement at $p_{\text {macro }}=100 \mathrm{kPa}$ is $t_{0}=0.60 \mathrm{~mm}$ in the plate-friction experiment and $C_{\mathrm{b}}=1.31 \mathrm{MPa}^{-1}$. Using Equation (5.11), a misalignment $\Delta t$ of for example $10.0 \mu \mathrm{m}$ would thus result in a pressure difference in the specimen of $\approx 13 \mathrm{kPa}$. This coarse calculation clearly shows the effect of even small misalignments. Note that the actual compaction behaviour of woven fabrics is more complex, as described (amongst others) in references [29-32].

\subsubsection{Practical use: Capstan versus plate-friction setup}

Both experimental setups have their practical advantages and drawbacks, which are summarised in Table 5.5. Generally, the capstan method is suited for both fabric and tow specimens, whereas the plate-friction setup is only suitable for fabric testing. The capstan setup is readily accessible — prior to as well as during the measurements - due to the single friction interface between specimen and friction drum. Further experimental work to characterise fabric-fabric and towfabric frictional behaviour can be performed on the capstan setup as well.

Table 5.5 Comparison of the capstan and plate-friction setups.

\begin{tabular}{|c|c|c|}
\hline & Setup & Description \\
\hline \multirow{2}{*}{ Pros } & Capstan & $\begin{array}{l}\text { Easy force application and alignment } \\
\text { Unlimited sliding distance } \\
\text { Suitable for tow and fabric specimens }\end{array}$ \\
\hline & Plate & $\begin{array}{l}\text { Uniform heating of plates (up to } 420^{\circ} \mathrm{C} \text { ) } \\
\text { Small amount of specimen material required } \\
\text { Displacement control by universal testing machine }\end{array}$ \\
\hline \multirow{2}{*}{ Cons } & Capstan & $\begin{array}{l}\text { No direct control of normal force (tension dependent) } \\
\text { Varying normal force along the drum circumference } \\
\text { No heating capability }\end{array}$ \\
\hline & Plate & $\begin{array}{l}\text { Short sliding distance }(\leq 50 \mathrm{~mm}) \\
\text { Hysteresis in the closing mechanism } \\
\text { Pressure variation due to non-parallel contact of the plates }\end{array}$ \\
\hline
\end{tabular}

\subsection{Conclusions}

The sliding frictional behaviour of 5Hs weave consisting of carbon fibre tows can be predicted on the basis of the frictional behaviour of single tows. The loads on the fabric and tow specimens should be applied such that the mesoscopic pressures $p_{\text {meso }}$ are equal. A coupling between the micro-mesoscopic tow friction and the meso-macroscopic fabric friction is hereby established. The 
experimentally observed frictional behaviour supports the assumed mechanism of the adhesion theory of friction.

Friction experiments were performed on a capstan and a plate-friction type setup. The measurement results were quantitatively comparable, although the setups relied on two different load application methods. The agreement of the results forms a validation of both friction characterisation methods.

\section{References}

[1] I.C. Roselman and D. Tabor. The friction and wear of individual carbon fibres. $J$ Phys D, 10(8):1181-1194, 1977.

[2] S.V. Lomov, I. Verpoest, M. Barburski, and J. Laperre. Carbon composites based on multiaxial multiply stitched preforms. Part 2. KES-F characterisation of the deformability of the preforms at low loads. Compos Part A Appl Sci Manuf, 34(4):359-370, 2003.

[3] G. Hivet, S. Allaoui, B.T. Cam, P. Ouagne, and D. Soulat. Design and potentiality of an apparatus for measuring yarn/yarn and fabric/fabric friction. Exp Mech, 52(8):1123-1136, 2012.

[4] B. Cornelissen, B. Rietman, and R. Akkerman. Frictional behaviour of high performance fibrous tows: Friction experiments. Compos Part A Appl Sci Manuf, 44:95-104, 2013.

[5] C. Rubenstein. Review on the factors influencing the friction of fibres, yarns and fabrics. Wear, 2(4):296-310, 1959.

[6] M.E. Yuksekkaya. More about fibre friction and its measurements. Text Prog, 41(3):141-193, 2009.

[7] H.G. Howell and J. Mazur. Amontons' law and fibre friction. J Text Inst Trans, 44(2):T59-T69, 1953

[8] H. Buckle and J. Pollitt. 16-An instrument for measuring the coefficient of friction of yarns against other materials. J Text Inst Trans, 39(6):T199-T210, 1948.

[9] H. L. Röder. 16-Measurements of the influence of finishing agents on the friction of fibres. J Text Inst Trans, 44(6):T247-T265, 1953.

[10] C. Mack and C. Rubenstein. The effective coefficient of friction for strings traversing cylinders transversely and slantwise. Br J Appl Phys, 9(6):247-249, 1958.

[11] M.J. Schick. Friction and lubrication of synthetic fibers. Part I: Effect of guide surface roughness and speed on fiber friction. Text Res J, 43(2):103-109, 1973.

[12] M.M. Robins, R.W. Rennell, and R.D. Arnell. The friction of polyester textile fibres. J Phys D, 17(7):1349-1360, 1984.

[13] A.D. Vickers, D.G. Beale, Y.T. Wang, and S. Adanur. Analyzing yarn-to-surface friction with data acquisition and digital imaging techniques. Text Res $\mathrm{J}$, 70(1):36-43, 2000.

[14] I.C. Roselman and D. Tabor. The friction of carbon fibres. J Phys D, 9(17):2517-2532, 1976. 
[15] B.J. Briscoe and F. Motamedi. Role of interfacial friction and lubrication in yarn and fabric mechanics. Text Res J, 60(12):697-708, 1990.

[16] S. Rebouillat. Tribological properties of woven para-aramid fabrics and their constituent yarns. J Mater Sci, 33(13):3293-3301, 1998.

[17] I.F. Brown and C.J. Burgoyne. The friction and wear of kevlar 49 sliding against aluminium at low velocity under high contact pressures. Wear, 236(1-2):315-327, 1999.

[18] L. Liu, J. Chen, B. Zhu, T.X. Yu, X.M. Tao, and J. Cao. The yarn-to-yarn friction of woven fabrics. ESAFORM 2006 Proceedings, 1:807-810, 2006.

[19] W. Zurek, D. Jankowiak, and I. Frydrych. Surface frictional resistance of fabrics woven from filament yarns. Text Res J, 55(2):113-121, 1985.

[20] L. Virto and A. Naik. Frictional behavior of textile fabrics - Part I: Sliding phenomena of fabrics on metallic and polymeric solid surfaces. Text Res J, 67(11):793-802, 1997.

[21] E. Vidal-Sallé and F. Massi. Friction measurement on dry fabric for forming simulation of composite reinforcement. Key Eng Mat, 504-506:319-324, 2012.

[22] J.L. Gorczyca-Cole, J.A. Sherwood, and J. Chen. A friction model for thermostamping commingled glass-polypropylene woven fabrics. Compos Part A Appl Sci Manuf, 38(2):393-406, 2007.

[23] K.A. Fetfatsidis, L.M. Gamache, J.L. Gorczyca, J.A. Sherwood, D. Jauffrès, and J. Chen. Design of an apparatus for measuring tool/fabric and fabric/fabric friction of woven-fabric composites during the thermostamping process. Int J Mater Form, 1-11, 2011.

[24] U. Sachs, K. Fetfatsidis, J. Schumacher, G. Ziegmann, S. Allaoui, G. Hivet, E. Vidal-Sallé, and R. Akkerman. A friction-test benchmark with Twintex PP. Key Eng Mat, 504-506:307-312, 2012.

[25] R. Akkerman, R.H.W. Ten Thije, U. Sachs, and M.B. De Rooij. Friction in textile thermoplastic composites forming. In: 10th International Conference on Textile Composites: Recent Advances in Textile Composites, TEXCOMP 10. 271-279, Lille, 2010.

[26] U. Sachs, R. Akkerman, S.P. Haanappel, ten Thije R.H.W., and de Rooij M.B. Friction in forming of UD composites. In: The 14th International Conference on Material Forming: ESAFORM 2011 Proceedings. volume 1353, 984-989, AIP-Press, 2011.

[27] J.L. Gorczyca, J.A. Sherwood, L. Liu, and J. Chen. Modeling of friction and shear in thermostamping of composites - Part I. J Compos Mater, 38(21):1911-1929, 2004.

[28] B. Chen, A.H.-D. Cheng, and T.-W. Chou. Nonlinear compaction model for fibrous preforms. Compos Part A Appl Sci Manuf, 32(5):701-707, 2001.

[29] S.V. Lomov and I. Verpoest. Compression of woven reinforcements: A mathematical model. J Reinf Plast Comp, 19(16):1329-1350, 2000.

[30] Z.-R. Chen, L. Ye, and T. Kruckenberg. A micromechanical compaction model for woven fabric preforms. Part I: Single layer. Compos Sci Technol, 66(16):3254-3262, 2006.

[31] Z.-R. Chen and L. Ye. A micromechanical compaction model for woven fabric preforms. Part II: Multilayer. Compos Sci Technol, 66(16):3263-3272, 2006. 
[32] P. Potluri and T.V. Sagar. Compaction modelling of textile preforms for composite structures. Compos Struct, 86(1-3):177-185, 2008. 



\section{Chapter 6}

\section{Closing the multi-scale loop}

The multi-scale nature of fibrous reinforcements plays a large role throughout this thesis. Figure 6.1 shows how the chapters in the thesis relate to the various scales ranging from the macroscopic fabric scale to the sub-microscopic level of ridges and asperities. The discussion section provides a general reflection on the study of the role of friction in tow mechanics and the practical relevance of the findings. The general conclusions from the previous chapters are presented next. The recommendations section presents several suggestions for further modelling and experimental work. The final section of this chapter provides an outlook on friction modelling and its applications.

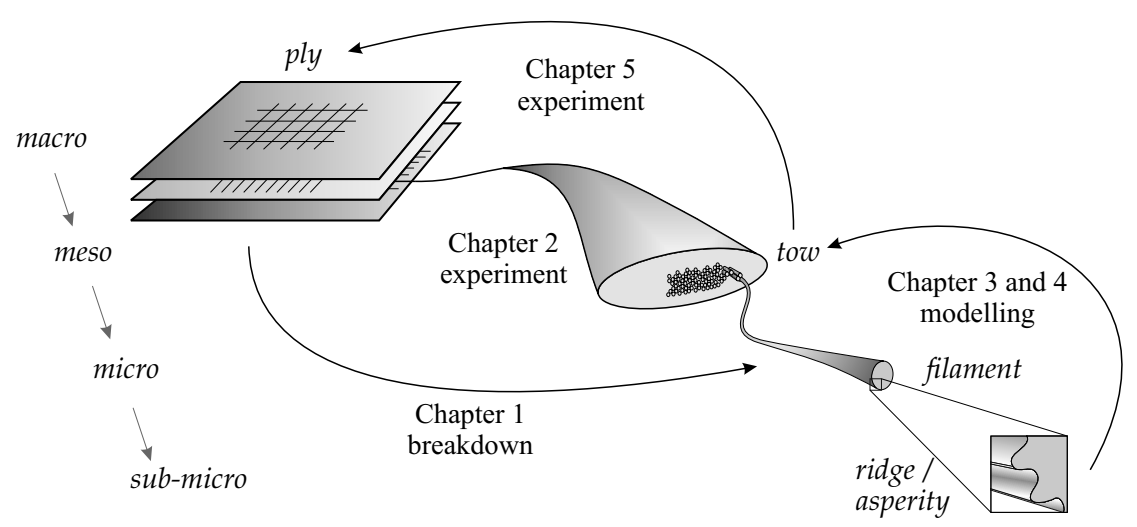

Figure 6.1 Closing the multi-scale loop. Chapter 1 presents a translation of macroscopic deformations of plies to the filament interactions on the microscopic level. Chapters 2 to 5 describe the inverse path followed to close the loop by means of modelling and experimental work. 


\subsection{Discussion}

The previous chapters addressed the dynamic frictional behaviour of fibrous tows from a multi-scale perspective. Experimental findings on the micromesoscopic scale were a starting point for theoretical contact mechanics based models. The characterisation of the frictional behaviour of tows on the mesoscopic level required modelling of filament-counterface interactions on the microscopic level. Likewise, understanding the friction of filaments required knowledge of the behaviour on the sub-microscopic scale, i.e. the surface topography had to be characterised on the asperity level. This bottom-up procedure yielded a thorough understanding of the physical background of the observed frictional behaviour, starting from the basic deformation behaviour of filaments. The last step in the multi-scale framework consisted of friction experiments on fabric and tow material in contact with metal counterfaces. The area of tow mechanics provided the coupling between the microscopic origin of friction and its effects on the macroscopic scale, thus closing the multi-scale loop, depicted in Figure 6.1.

\section{Modelling frictional behaviour across the scales}

The multi-scale nature of friction was investigated down to the scale where constant interfacial properties could be assumed, i.e. the sub-microscopic asperity (metal) and ridge (filament) level. Although room for quantitative improvement is certainly present, a good qualitative agreement of the model predictions in Chapters 3 and 4 was found with the experimental findings in Chapter 2.

Simplifying assumptions were made in the modelling part of this thesis. The theory of adhesive friction was applied to the fibrous tow materials, with the additional assumption that the developed frictional forces at the asperity level consist entirely of shearing of the asperities, i.e. wear effects due to ploughing are not taken into account. This implies that in the relation between the real contact area $A_{\mathrm{r}}$ of the system and the interfacial shear strength $\tau$ to describe the dynamic frictional force $F_{\mathrm{f}}$, first mentioned in Section 2.5.3 [1]:

$$
F_{\mathrm{f}}=A_{\mathrm{r}} \tau+P,
$$

the ploughing contribution $P$ is assumed to be zero. The values of the interfacial shear strength and adhesional properties in the form of the work of adhesion $w$ of the filaments were estimated, based on the literature. Given the typical values of $\tau$ and $w$, good agreement was found between models and experiments. An investigation into the sensitivity to these properties was performed, confirming the qualitative performance of the model. Equation (6.1) assumes a linear dependency of the frictional force $F_{\mathrm{f}}$ on $\tau$. 
The contribution of adhesion to the real contact area depends on both the mechanical properties of the filaments in the tow and their geometrical properties, such as the filament diameter and the surface topography. For the studied materials this contribution was most apparent for aramid filaments, followed by carbon and finally E-glass filaments. The filament diameters and values of the work of adhesion are comparable for the three studied materials. The adhesion contribution decreases with an increase of the transverse elastic moduli of the filaments. The lowest value of the elastic modulus was found for aramid filaments with $E_{\text {trans }}=1.5 \mathrm{GPa}$, then the intermediate value of $15 \mathrm{GPa}$ for carbon, and the largest value of $72 \mathrm{GPa}$ for E-glass, which is the only isotropic fibre in this study. Thus, depending on the material, it is worthwhile to include the contribution of adhesion between the contacting bodies in the friction modelling approaches (see Sections 3.3 and 4.3).

The Maugis-Dugdale approach is suitable to account for the adhesion effects in the contact modelling of fibrous materials, since it covers the transition between relatively soft materials like aramid and relatively hard materials like E-glass [2, 3]. Apart from the filament geometry in terms of diameter, the adhesion effect is influenced by the sub-microscopic characteristics of the filaments. Chapter 4 showed that apparently only the ridges on the surface of the carbon filaments are in contact when considering tow-tow sliding friction. Thus the contacting bodies have a smaller geometry than the initially assumed filament diameter. The adhesion contribution to the real contact area in the case of perpendicularly contacting ridges (with $R_{\text {ridge }}=100 \mathrm{~nm}$ ) was only $8-25 \%$ of the total contact compared to $45-79 \%$ for the smooth filament surface assumption, as illustrated in Figure 4.8. Therefore, the sub-microscopic characteristics of the filaments should be addressed as well when modelling bodies with a similar stiffness in contact.

\section{Topography descriptions}

\section{Metal counterfaces}

In Chapter 3, Section 3.2.3, the topography of the metal friction drum surfaces was characterised by a statistical approach, based on the work of Greenwood and Williamson [4]. This approach, to represent the surface topographies of the metal counterfaces on the sub-microscopic asperity level, leaves room for improvement. The assumption made in Section 3.2.3 that the asperities do not interact with each other should be verified, as this has an influence on the relation between the real contact area $A_{\mathrm{r}}$ and the distributed normal load on the filament $N_{\text {fil }}$. The contact modelling approach of Chapter 3 was based on the assumption that, upon further approach of the filament to the friction drum, the individual contacts grow in size. At the same time the number of contacts increases, depending on the height distribution of the asperities. 
However, with a further decreasing separation of the surfaces, the asperities can coalesce and form so-called contact patches. The density of asperities $\eta_{\text {small }}$ thus decreases as the surfaces are brought closer together. Nayak proposed a method to account for the formation of contact patches in the plastic deformation of rough surfaces in contact [5]. Greenwood later showed [6] that the concept of asperity coalescence applies to any deformation model in the range of separation distances $d \leq 3 \sigma_{\text {small }}$, where $\sigma_{\text {small }}$ represents the standard deviation of the surface topography asperity height distribution. This range of separation distances also applies to the study in the case of elastic deformation of asperities described in Chapter 3.

A simplification in the statistical representation of the metal counterfaces comprises the assumption of a constant radius of curvature $\beta_{\text {small }}$ of the contacting asperities, see Chapter 3. Taking into account the variation of the asperity radii as well as their non-circular but rather elliptical shape should improve the representation of the friction drum surface topographies, as was argued by Bush et al. [7]. It is then also useful to reconsider the assumption of purely elastic deformation of contacting asperities, i.e. to try to determine whether the fibrous materials have a distinct yield point and thus deform plastically above the yield stress $\sigma_{\mathrm{y}}$. This discussion can be concluded by noting that the debate about the best representation of rough surfaces in contact and their deformation behaviour is still as lively as it was several decades ago [8-11].

\section{Filament surface}

In Chapter 3, addressing tow-metal friction, it was assumed that the filaments conform to the metal counterface due to their relatively high compliance compared to the metal counterfaces. Therefore a smooth filament surface assumption was made. The frictional force predictions based on this assumption agreed with the experimental observations. The model results for tow-tow friction in Chapter 4 suggested that the contact between carbon filaments takes place on the level of the small ridges that define the surface topography of the filaments. Thus, when modelling the contact between two bodies with a similar stiffness, in this case the carbon filaments, it is important to account for the surface topography of the individual filaments.

As mentioned in Section 1.2, the sizing or surface finish on filaments can act as a lubricant between the solid bodies in contact. Similarly, the presence of a thermoset or thermoplastic matrix material can act as a lubricant. This study focused on modelling the frictional behaviour of fibrous materials without sizing or matrix to first identify the solid constituent behaviour as such. Therefore, the presence of a surface finish or sizing on the filaments was not taken into account in the contact modelling approaches presented in Chapters 3 and 4 . A part of the carbon fibre tows used in the tow friction experiments, referred to as desized in Chapter 2, received a thermal treatment to remove as much of the sizing on 
the filament surface as possible to enable measurements on dry fibrous materials. The 5Hs carbon fabric specimens used in the experiments described in Chapter 5 received the same treatment. In further modelling work an additional viscoelastic medium can be added to the contact system to represent the lubricating sizing or matrix material. Including this additional medium, i.e. a thermoset or thermoplastic polymer, requires a description of non-Newtonian viscous friction, which is not included in the current modelling approaches.

\section{Validation of the capstan experiment}

In Chapter 2 several experiments were performed to validate the capstan friction setup. The effect of interchanging the moving and stationary part of the setup, i.e. measuring the friction of a sliding tow on a stationary metal friction drum, was verified for tow-metal contact to assess the effect of wear and temperature on the measured frictional force. The similarity of these results with those of a stationary tow on a rotating drum proved wear and temperature effects to be negligible in the time frame of the experiment.

The validation of the parallel tow measurements was provided by the twisted strand method, an alternative friction testing method, which is well suited for testing fibrous materials. These measurements confirmed the observed behaviour on the capstan friction setup for all materials except E-glass. At the same time, the effect of digging in of filaments was assessed. Its contribution to the observed apparent coefficient of friction $\mu_{\text {tow-tow,app }}$ is probably significant: a contribution of up to $15 \%$ of the coefficient of friction $\mu_{\text {fil-fil,app }}$ between two isolated filaments in contact can be expected from theory, as discussed in Section 2.5.3.

A third validation was performed by comparing the capstan results to those obtained with parallel plate results on a woven fabric. Based on the modelling results of Chapters 3 and 4, the frictional behaviour of carbon fibre tows was linked to that of carbon fibre fabric in Chapter 5. The frictional behaviour of tow and fabric material is comparable as long as the mesoscopic pressure $p_{\text {meso }}$ is equivalent, i.e. the normal load per unit contacting mesoscopic area must be the same for the tow and fabric specimens. An adequate estimation of this mesoscopic contact area, discussed in Section 5.5, could be made with a simple technique using adhesive tape. The main conclusion from the experiments in Chapter 5 implies that one has to account for the undulations in a fabric specimen that result in discontinuous contacts with the metal counterface (on a macro-mesoscopic level), in contrast to the continuous contact of a tow specimen on the capstan friction drum. The agreement of the frictional behaviour of fabric on the capstan setup with the fabric friction measurements at comparable mesoscopic pressure on a plate-friction setup provided an additional means of validation. The capstan setup is also suitable 
for fabric-fabric friction measurements, with minor modifications of the setup. Characterisation of the transverse frictional behaviour of tows, i.e. involving sliding of parallelly oriented arrangements of filaments in a direction transverse to the filament axis (illustrated in Figure 1.3), is difficult to achieve with the capstan setup. Nevertheless, the friction mechanisms involved in transverse sliding are important when considering inter-ply sliding, as demonstrated in Chapter 1, Section 1.2.

\subsection{Conclusions}

The general aim of this thesis is to provide a thorough insight in the physical background of the frictional behaviour of fibrous tows. The major results of this work can be summarised as follows:

1. The presented multi-scale approach enables the translation of macroscopic deformations of textile reinforcements to the microscopic frictiondominated interactions between filaments, using the intermediate mesoscopic tow scale.

2. A physical understanding of the frictional behaviour of tows down to the sub-microscopic level is provided, explaining the macroscopically observed response from a single elementary phenomenon, i.e. the contact mechanics friction model.

3. The multi-scale aspects of textile reinforcements are addressed in the presented modelling approaches, in which also quantitative agreement with experiments is demonstrated.

4. A validated experimental setup suitable for multi-scale friction experiments is obtained.

5. The experimental as well as the modelling procedures are suitable to account for the pressure dependency of the frictional behaviour of fibrous tows by means of the Howell relation: $F_{\mathrm{f}}=k N^{n}$.

The frictional behaviour of fibrous tows was studied in a multi-scale context. Both experimental and theoretical work were performed to gain insight into the mechanism of fibrous tow friction. The experiments described in Chapter 2 provided the relevant parameters that formed the basis for the contact mechanics modelling approaches of tow friction presented in Chapters 3 and 4 . The multi-scale nature of friction clearly manifested itself in the analytical-statistical modelling approaches. Surface characteristics down to the sub-microscopic level of asperities on the metal counterfaces and small ridges on carbon filaments were taken into consideration for the determination of the real contact areas. 
The bottom-up approach of the tow-metal and tow-tow modelling procedures provided the means to predict the experimentally observed frictional behaviour of tows in Chapter 2. Finally, a coupling with the ply or laminate scale in this study was provided in Chapter 5, where the frictional behaviour of carbon fabric was linked to tow friction measurements. The 'macroscopic' conclusion of this study is that the sub-microscopic friction at the level of contacting asperities and filament ridges determines the final macroscopic behaviour of dry arrangements of fibrous tows to a large extent. This study provided a coupling between the multiple length scales. As such, it forms a basis for further modelling and experimental work.

\subsection{Recommendations}

The breakdown of macroscopic deformations to the microscopic filament level presented in Chapter 1 shows that the frictional forces on the filament level play an important role in all deformation mechanisms. The proposed approach provides a physical background for the macroscopic deformation mechanisms in textile reinforcements during forming. The frictional behaviour of tows and filaments can be related to the macroscopic deformations by assessing the associated tow and filament level load cases. In a broader sense, any arbitrary deformation mechanism of tows or textiles, for example the spreading of tows on guide pins, can be analysed using this approach. This reduces the amount of arbitrary assumptions to account for scale-dependent material behaviour. In the following paragraphs several recommendations are presented for further experimental work and model improvements.

\section{Transverse sliding of filaments}

The filament level friction mechanisms identified in Figure 1.3 consist of longitudinal and transverse sliding with respect to the filament axis. The longitudinal sliding of filaments was addressed for several contact situations. However, the transverse sliding of filaments with respect to each other was not investigated as such. This friction mechanism mainly occurs in sliding fabric-fabric contact. It is an important mode of frictional behaviour for this contact type and it should be addressed when modelling inter-ply deformation $[12,13]$. The transverse sliding mechanism can be considered from the multiscale perspective and related to the ploughing term $P$ in Equation (6.1). The sub-microscopic interlocking of ridges can cause damage of filaments during transverse sliding of parallel oriented filaments. This phenomenon was not addressed in this thesis. Similarly, this mechanism can take place on the microscopic scale, i.e. interlocking of filaments [12]. Transverse friction occurs on the mesoscopic level when, for example, interlocking of undulations in woven 
fabric takes place during inter-ply friction [13]; this can lead to disruption of the fabric architecture. Representing these mechanisms by using a non-zero ploughing term $P$ provides a possible means to account for the contribution of transverse sliding to the observed frictional force $F_{\mathrm{f}}$.

\section{Model accuracy improvement}

The friction modelling approaches presented in Chapters 3 and 4 contain a simplification of the distributed normal load on the stationary tow. The load on each filament throughout the tow cross-section was assumed to be uniform. Several mechanisms in particular determine the accuracy of this assumption: the tow width-to-height ratio, the filament packing density, the distribution of filament diameters, the actual filament load distribution, the actual crosssectional shape of the tow and the presence or absence of sizing on the filaments. The filament loads in a relatively wide tow with a rectangular cross-sectional shape and closest packing of filaments agree well with the assumption made in this study. However, the contact between tows in, for example, a plain weave fabric subject to large shear deformations is expected to deviate from the aforementioned tow shape. More accurate model predictions thus require taking non-uniform filament loads, varying filament diameters and variations in filament packing densities into account.

Further model improvements can be expected from a more accurate determination of material and interfacial properties such as the interfacial shear strength $\tau$ and the work of adhesion $w$ between filaments and other counterface materials, as mentioned in Section 3.4.1. Furthermore, the assumption of elastic deformation behaviour of the filament materials deserves a closer experimental investigation.

\section{Variation of materials and fabric architectures}

In the current study, the friction experiments on fabric specimens were limited to a $5 \mathrm{Hs}$ architecture of carbon fibre material. Although the measurement results were in qualitative agreement with the model predictions, experiments with different fabric architectures and tow materials should be performed to provide a more complete validation of the proposed modelling approaches. Furthermore, the aforementioned transverse sliding of filaments should be investigated by means of fabric-fabric contact experiments. An alternative method to characterise the transverse frictional behaviour was used by Gupta and Chang [12]. This method consisted of two planar surfaces covered with filaments placed in parallel and sliding with respect to each other in a direction transverse to the filament axis. Variations in orientation showed that the frictional forces increased steeply when the filaments were in parallel contact, 
i.e. the relative orientation $\Phi$ was zero, similar to the model prediction for longitudinal sliding of parallel oriented tows in Chapter 4.

\subsection{Future trends in friction modelling}

This research on the frictional behaviour of fibrous tows provides a first step towards inclusion of the effect of microscopic material properties in macroscopic models as used in, for example, macro- and mesoscopic finite element (FE) approaches. Friction models need to be included on the microscopic level to correctly account for its physical origin. The contact area and load-dependent behaviour of friction is one aspect that should be taken into account to correctly predict the frictional forces in the forming of dry arrangements of fibrous tows. The current tow-metal and tow-tow contact modelling approaches need further work to obtain multi-scale material models based on established mechanical properties of filaments. Only then can the inaccuracies be overcome that often accompany modelling strategies involving averaging of properties across length scales.

This thesis provides the basic ingredients to develop tools to predict the filament distributions in textile reinforcements during forming processes. These filament distributions and process-induced stresses determine to a large extent the mechanical performance of the reinforcement across the length scales. Implementation of the multi-scale loop in deformation modelling, and thus taking the process-related deformation history into account in the performance prediction of CFRPS, results in, for example, more accurate failure criteria for textile composites and optimised structures. The ever-increasing computational power together with decreasing costs of exploiting this power will further facilitate the implementation of the multi-scale loop. These efforts can lead to simulation of component performance taking into account the microscopic material behaviour and thus enabling more accurate predictions. The improved modelling accuracy will reduce expensive trial-and-error based optimisation. This will eventually support the virtual modelling and testing of entire structures like those mentioned in Chapter 1.

\section{References}

[1] I.C. Roselman and D. Tabor. The friction of carbon fibres. J Phys D, 9(17):2517-2532, 1976.

[2] D. Maugis. Adhesion of spheres: The JKR-DMT transition using a Dugdale model. J Colloid Interface Sci, 150(1):243-269, 1992.

[3] K.L. Johnson and J.A. Greenwood. An adhesion map for the contact of elastic spheres. J Colloid Interface Sci, 192(2):326-333, 1997. 
[4] J.A. Greenwood and J. B. P. Williamson. The contact of nominally flat surfaces. Proc R Soc Lon Ser A, 295(1442):300-319, 1966.

[5] P.R. Nayak. Random process model of rough surfaces in plastic contact. Wear, 26(3):305-333, 1973.

[6] J.A. Greenwood. A note on Nayak's third paper. Wear, 262(1-2):225-227, 2007.

[7] A.W. Bush, R.D. Gibson, and G.P. Keogh. The limit of elastic deformation in the contact of rough surfaces. Mech Res Commun, 3(3):169-174, 1976.

[8] J.A. Greenwood. A simplified elliptic model of rough surface contact. Wear, 261(2):191-200, 2006.

[9] B.N.J. Persson. Contact mechanics for randomly rough surfaces. Surf Sci Rep, 61(4):201-227, 2006.

[10] G. Carbone and F. Bottiglione. Asperity contact theories: Do they predict linearity between contact area and load? J Mech Phys Solids, 56(8):2555-2572, 2008.

[11] G. Carbone and F. Bottiglione. Contact mechanics of rough surfaces: A comparison between theories. Meccanica, 46(3):557-565, 2011.

[12] B.S. Gupta and P.-T. Chang. Structural studies in continuous-filament yarns. Part III: Studies with fiber friction as a variable. Text Res J, 46(2):90-99, 1976.

[13] S. Allaoui, G. Hivet, A. Wendling, P. Ouagne, and D. Soulat. Influence of the dry woven fabrics meso-structure on fabric/fabric contact behavior. J Compos Mater, 46(6):627-639, 2012. 


\section{Dankwoord}

Dit is het dan, het ei is gelegd! Er rest mij nog in dit deel van het proefschrift het woord te richten aan iedereen die op de meest uiteenlopende manieren heeft bijgedragen aan het tot stand komen van dit boekje.

Laat ik beginnen mijn goedlachse promotor Remko Akkerman te bedanken. Onze inspirerende overlegmomenten ervaar ik als zeer waardevol. Ondanks een bomvolle agenda wist je me op de cruciale momenten met goede raad bij te staan. Jouw aanpak waarin je promovendi de ruimte krijgen om op eigen manier inzicht te krijgen in de materie werkt bijzonder prettig. Daarnaast slaag je erin om met ogenschijnlijk gemak de essentie van elk probleem snel en helder in te kaderen, wat zeker goed van pas kwam de afgelopen jaren.

Bert Rietman, je nuttige werk als begeleider en reviewer van talrijke 1.0-versies en je vrolijke noot heb ik erg gewaardeerd. Ook wil ik Matthijn de Rooij bedanken, je kwam halverwege het onderzoek aan boord om enthousiast mee te denken over de tribologische aspecten van het onderzoek, bedankt voor je deskundige bijdrage! Naast bovengenoemde begeleiders nam Johan van Ravenhorst deel aan de leescommissie. Jouw drive om alles wat je leest tot in de details te begrijpen is bewonderenswaardig. Mooi dat je nu in je eigen promotiewerk je nieuwsgierigheid de vrije loop kan laten.

Now some words in English to Amir Bakhtiary Davijani: thanks for your hard work on modelling the spreading behaviour of fibrous tows in your master's assignment. Although the results of your research are not part of this thesis, it was very useful to better understand the deformation behaviour of tows. I learned a lot from our cooperation, both from a work-related as well as a cultural perspective.

Debbie en Belinda, jullie zijn de stille krachten die zo'n beetje de hele Horst Noord-gang organisatorisch soepel laten draaien. Superbedankt voor al jullie mailtjes, belletjes en acties om soepele vergaderingen, zorgeloze conferentietrips en minimale formulierellende mogelijk te maken. Conditioneren is een vak dat vooral Debbie verstaat, met verse koffie om 9 uur weet je mij en vele anderen altijd weer te verwennen, top!

Mijn dank gaat ook uit naar de leden van de 'User Group', bestaande uit Jan Jager en Jan Veurink van API, Marijn Warmoeskerken van de EFSM vakgroep, 
Piet Leegstra van PPG Fiber Glass, Douwe Dros en Hans Meerman van Teijin Aramid en Sebastiaan Wijskamp van Ten Cate Advanced Composites. De afgelopen twee en een half jaar hebben we elkaar over en weer van inzichten kunnen voorzien, ik heb veel gehad aan jullie ervaringen uit de praktijk. Uiteraard wil ik jullie ook bedanken voor het leveren van de nodige materialen, het beschikbaar stellen van tijd en apparatuur voor validatie-experimenten en jullie enthousiasme bij het verzorgen van de meetings op locatie.

De kaapstaanderopstelling in het PT-lab heeft een groter potentieel dan ik aan het begin van mijn onderzoek vermoedde. Het uitbuiten van de mogelijkheden had flink meer tijd gekost zonder de bijdragen van (in willekeurige volgorde) Gert-Jan Nevenzel, Laura Vargas Llona, Bert Vos, Laurent Warnet, Erik de Vries, Walter Lette, Bert Wolbert, Norbert Spikker en Martin Sprenkeler. Laatstgenoemde is tevens hofleverancier van (weekend)koffie en de nodige hilarische momenten geweest, Martin, je bent me er eentje!

Speciale aandacht verdient Ton Bor met z'n meesterwerk: de TX sidecar zijspanmountainbike. Elke rit was weer een feest, Ton! Er zijn maar weinig mensen die vertrouwen weten te winnen door me bij één van de eerste sessies head-first de Rijssense bosgrond van dichtbij te laten inspecteren.

Ondanks de telkens wisselende samenstelling was kantoor N-128 immer de plek waar je naast inzichtverhogende inhoudelijke discussies en praktische oplossingen ook terecht kon voor de meest smakeloze filmpjes, (slechte) grappen of plakbandhumor. Bedankt iedereen die deze sfeercombinatie mede mogelijk maakte, de kantoorbewoners door de jaren heen: Roy Visser, Wouter Grouve, Sebastiaan Haanappel, Uli Sachs, Sybren Jansma, Iqbal Abdul Rasheed, Luca Mainini en natuurlijk alle 'vaste klanten'.

Ook wil ik mijn paranimfen Arjen Beijk en Guus van Dalum bedanken. Fijn dat jullie me bijstaan bij veel meer dan alleen de verdediging.

Steun en motivatie kreeg ik van de kant van mijn familie, schoonfamilie en vrienden. Wellicht onbewust hebben jullie meer dan eens bijgedragen aan het ontstaan van dit proefschrift.

Lieve Marleen, dit verhaaltje eindigt bij jou. Ik hou van je!

Bo, december 2012 


\section{Publications}

\section{Journal articles}

1. B. Cornelissen, B. Rietman, and R. Akkerman. Frictional behaviour of high performance fibrous tows: Friction experiments. Compos Part A Appl Sci Manuf, 44(1):95-104, 2013. (Chapter 2 of this thesis).

2. B. Cornelissen, M.B. de Rooij, B. Rietman, and R. Akkerman. Frictional behaviour of high performance fibrous tows: A contact mechanics model of tow-metal friction. Submitted to: Wear, December 2012. (Chapter 3 of this thesis).

3. B. Cornelissen, M.B. de Rooij, B. Rietman, and R. Akkerman. Frictional behaviour of carbon fibre tows: A contact mechanics model of tow-tow friction. Submitted to: Textile Research Journal, December 2012. (Chapter 4 of this thesis).

4. B Cornelissen, U. Sachs, B. Rietman, and R. Akkerman. Dry friction characterisation of carbon fibre tow and satin weave fabric for composite applications. Submitted to: Compos Part A Appl Sci Manuf, December 2012. (Chapter 5 of this thesis).

\section{Conference proceedings}

1. B. Cornelissen and R. Akkerman. Analysis of yarn bending behaviour. In: 17th International Conference on Composite Materials (ICCM-17), Edinburgh, United Kingdom, 2009.

2. B. Cornelissen, L. Warnet, and R. Akkerman. Friction measurements on carbon fibre tows. 14th International Conference on Experimental Mechanics (ICEM-14), Poitiers, France. In: F. Brémand (editor) EPJ Web of Conferences, vol 6, 2010. 
3. B. Cornelissen and R. Akkerman. Towards modelling of the frictional behaviour of deforming fibrous tows: A geometrical approach. 10th International Conference on Textile Composites (TEXCOMP 10), Lille, France. In: Proceedings of the 10th International Conference on Textile CompositesTEXCOMP 10: Recent Advances in Textile Composites. 405-413, 2010.

4. B. Cornelissen, B. Rietman, M.B. De Rooij, and R. Akkerman, Tow mechanics: A contact mechanics approach of friction in fibrous tows during forming. 15th ESAFORM conference on material forming, Erlangen, Germany. In: Key Engineering Materials: Material Forming ESAFORM 2012, 504-506:325-330, 2012. 